\title{
Micobacteriose de ovinos (Ovis aries) do Estado de São Paulo, Brasil. Correlação entre teste imunoalérgico, cultivo e histopatológico.
}

Tese apresentada ao Programa de Pós-Graduação em Epidemiologia Experimental e Aplicada às Zoonoses da Faculdade de Medicina Veterinária e Zootecnia da Universidade de São Paulo para obtenção do título de Doutor em Medicina Veterinária.

Departamento:

Medicina Veterinária Preventiva e Saúde Animal

Área de concentração:

Epidemiologia Experimental e Aplicada às Zoonoses

Orientador:

Profa. Dra. Sônia Regina Pinheiro

São Paulo 
Autorizo a reprodução parcial ou total desta obra, para fins acadêmicos, desde que citada a fonte.

\section{DADOS INTERNACIONAIS DE CATALOGAÇÃO-NA-PUBLICAÇÃO}

(Biblioteca Virginie Buff D’Ápice da Faculdade de Medicina Veterinária e Zootecnia da Universidade de São Paulo)

Micobacteriose de ovinos (Ovis aries) do Estado de São Paulo, Brasil. Correlação entre teste imunoalérgico, cultivo e histopatológico / André Guaragna Marcondes. - São Paulo : A. G. Marcondes, 2007.

$$
93 \mathrm{f} \text {. : il. }
$$

Tese (doutorado) - Universidade de São Paulo. Faculdade de Medicina Veterinária e Zootecnia. Departamento de Medicina Veterinária Preventiva e Saúde Animal, 2007.

Programa de Pós-Graduação: Epidemiologia Experimental e Aplicada às Zoonoses.

Área de concentração: Epidemiologia Experimental e Aplicada às Zoonoses.

Orientador: Profa. Dra. Sônia Regina Pinheiro.

1. Micobacteriose. 2. Corynebacterium pseudotuberculosis. 3. Ovinos. I. Título. 


\section{UNIVERSIDADE DE SÃO PAULO \\ Faculdade de Medicina Veterinária e Zootecnia}

\section{Comissão de Bioética}

\section{CERTIFICADO}

Certificamos que o Projeto intitulado "Avaliação da prova de tuberculina intradérmica dupla comparativa (IDC) em ovinos (Ovis aries)", protocolo n619/2005, utilizando 90 (noventa) ovinos, sob a responsabilidade da Profa Dra Sônia Regina Pinheiro, está de acordo com os princípios éticos de experimentação animal da Comissão de Bioética da Faculdade de Medicina Veterinária e Zootecnia da Universidade de São Paulo e foi aprovado na reunião do dia 12/12/06.

(We certify that the Research "Evaluation of comparative intradermical skin test (CID) in sheep (Ovis aries)", protocol number 619/2005, utilizing 90 sheep's, under the responsibility of Profa Dr $^{a}$ Sônia Regina Pinheiro, agree with Ethical Principles in Animal Research adopted by Bioethic Commission of the Faculty of Veterinary Medicine and Zootechny of University of São Paulo and was approved in the meeting of the day 12/12/2006).

São Paulo, 13 de dezembro de 2006

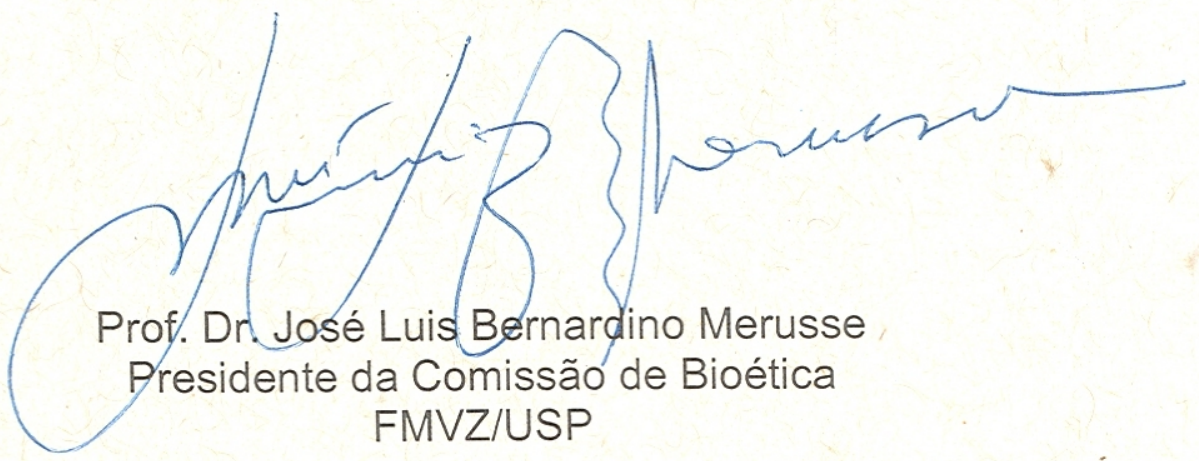




\section{FOLHA DE AVALIAÇÃO}

Nome: MARCONDES, André Guaragna

Título: Micobacteriose de ovinos (Ovis aries) do Estado de São Paulo, Brasil. Correlação entre teste imunoalérgico, cultivo e histopatológico

Tese apresentada ao programa de Pós-Graduação em Epidemiologia Experimental e Aplicada às Zoonoses da Faculdade de Medicina Veterinária e Zootecnia da Universidade de São Paulo para obtenção do título de Doutor em Medicina Veterinária

Data:

\section{Banca Examinadora}

Prof. Dr.:

Instituição:

Assinatura:

Julgamento:

Prof. Dr.:

Instituição:

Assinatura:

Julgamento:

Prof. Dr.:

Instituição:

Assinatura:

Julgamento:

Prof. Dr.:

Instituição:

Assinatura:

Julgamento:

Prof. Dr.:

Instituição:

Assinatura:

Julgamento: 
DEDICATÓRIA 
À minha mulher Margarete e aos meus filhos André,Carolina e Giovana dedico este trabalho... a gente nunca sabe o que a maré vai trazer amanhã... 
Aos meus pais José Geraldo e Gilda, pelo apoio e incentivo. 
Aos meus avôs Raul e Geraldo, cujos exemplos de probidade, dedicação, firmeza e caráter ainda permanecem muito tempo depois que partiram. 


\section{AGRADECIMENTOS}




\section{AGRADECIMENTOS}

À Profa. Dra. Sônia Regina Pinheiro, que tanto acreditou em mim, pela orientação, amizade e sobretudo paciência (Sônia: porque sem emoção... não tem graça!!).

Aos colegas do Serviço de Vigilância Agropecuária do Aeroporto Internacional de Viracopos por ajudarem a tornar este trabalho possível.

Ao prof. Dr. Paulo César Maiorka, pela presteza e qualidade do trabalho hitopatológico.

Ao Prof. Dr. Nilson Roberto Benites, pelo importante apoio técnico e sugestões que muito contribuíram para este trabalho.

Ao Prof. Dr. Sílvio Arruda Vasconcellos, pelas sugestões na fase final deste projeto.

À Dra. Érica Chimara do Instituto Adolfo Lutz, pela identificação das micobactérias.

À Dra. Eliana Roxo, pelas muitas sugestões e incentivo.

À Zenaide Maria de Morais, pelo imprescindível apoio "técnico-logístico" na parte laboratorial deste trabalho e também pelo exemplo de dedicação e eficiência, minha sincera gratidão e admiração.

Ao colega de pós-graduação Carlos, pela grande ajuda na parte prática deste trabalho.

À equipe de bilbiotecárias da FMVZ/USP, pelo auxílio na pesquisa e revisão da tese.

E a todos os pós-graduandos, funcionários do laboratório e do departamento que direta ou indiretamente colaboraram com este trabalho: Flávia, Gisele, dona Odete, Deise, Tânia, Cristina, Virgínia, Danival... muito obrigado! 
RESUMO 


\section{RESUMO}

MARCONDES, A. G. Micobacteriose de ovinos (Ovis aries) do Estado de São Paulo, Brasil. Correlação entre teste imunoalérgico, cultivo e histopatológico. [Mycobacteriosis of ovine (Ovis aries) from Sao Paulo State, Brazil. Correlation between immuno allergic, culture and histopathologic tests]. 2007. $93 \mathrm{f}$. Tese (Doutorado em Medicina Veterinária) - Faculdade de Medicina Veterinária e Zootecnia, Universidade de São Paulo, São Paulo, 2007.

A escassez de dados sobre tuberculose e micobacterioses em ovinos (Ovis aries) motivou o presente trabalho de isolamento e tipificação de microorganismos presentes em linfonodos e lesões macroscópicas sugestivas de tuberculose. Foram avaliados pelo teste tuberculinico, 353 ovinos das raças Santa Inês e Texel de duas propriedades da região de Pindamonhangaba - São Paulo. Dos 57 animais selecionados para abate, 31 apresentavam reação ao PPD bovino maior que ao PPD aviário e 26 com reação ao PPD bovino menor que ao PPD aviário. Onze animais $(19,3 \%)$ apresentaram na necrópsia lesões sugestivas de tuberculose. Os órgãos afetados foram o fígado, linfonodo submandibular, intestino, pulmão, linfonodo mediastino e glândula mamária. Foram isoladas micobactérias de sete $(12,3 \%)$ animais e a tipificação genética pelo método de PRA demonstrou cinco $(71,42 \%)$ infectados pelo Mycobacterium flavescens 1, um (14,28\%) pelo M. kansasi, e um $(14,28 \%)$ por micobactéria pertencente ao Complexo M. tuberculosis. Exames bacteriológicos para outras bactérias e/ou fungos isolaram Corynebacterium pseudotuberculosis em quatro $(7,01 \%)$ dos 57 animais abatidos. Houve isolamento simultâneo de micobactérias e de Corynebacterium pseudotuberculosis em dois (3,5\%) dos 57 animais abatidos. Os exames histopatológicos apontaram em nove $(15,78 \%)$ animais a presença de granuloma e coloração de Ziehl-Neelsen positivo. A análise dos resultados obtidos permitiram concluir que, neste trabalho, os testes imunoalérgicos (Teste Cervical Simples e Teste Cervical Comparativo) não foram capazes de diferenciar infecção provocada pelo $M$. flavescens 1, M. kansasi, complexo M. tuberculosis e C. pseudotuberculosis. Nos exames macroscópico e histopatológico lesões provocadas por $M$. flavescens $1, M$. kansasi, e C. pseudotuberculosis não foram diferenciáveis das provocadas pelo complexo $M$. tuberculosis.

Palavras-chave: Micobacteriose. Corynebacterium pseudotuberculosis. Ovinos. 


\section{SUMMARY}

MARCONDES, A. G. Mycobacteriosis of ovine (Ovis aries) from Sao Paulo State, Brazil. Correlation between immuno allergic, culture and histopathologic tests. [Micobacteriose de bovinos (Ovis aries) do Estado de São Paulo, Brasil. Correlação entre teste imunoalérgico, cultivo e histopatológico]. 2007. 93 f. Tese (Doutorado) - Faculdade de Medicina Veterinária e Zootecnia, Universidade de São Paulo, São Paulo, 2007.

The occurrence of few data on ovine (Ovis aries) tuberculosis and mycobacteriosis has motivated this work of isolation and typing microorganism found in lymph nodes and tuberculosis-like gross lesions. Tuberculin skin test was performed in 353 Santa Ines and Texel ovine breeds of two properties located at Pindamonhangaba Municipality - Sao Paulo State. Fifty seven animals were selected to be slaughtered and 31 of them had the bovine PPD skin test higher than avian PPD and other 26 presented bovine PPD reaction lower than avian PPD. Eleven animals (19.3\%) showed tuberculosis-like gross lesions at necropsy. Most affected organs were liver, submandibular lymph nodes, intestines, lungs, mediastinic lymph nodes and mammary gland. It was possible to isolate mycobacteria from seven $(12.3 \%)$ animals and genetic typing by the PRA method showed that five animals $(71.42 \%)$ were infected with Mycobacterium flavescens 1, one (14.28\%) with M. kansasi, and one (14.28\%) with M. tuberculosis complex mycobacteria. Bacteriological culture isolation for other bacteria and/or fungi were positive for Corynebacterium pseudotuberculosis in four $(7.01 \%)$ of 57 slaughtered animals. There was a concomitant isolation of mycobacteria and Corynebacterium pseudotuberculosis in two (3.5\%) of 57 slaughtered animals. Histopathologic examination demonstrated the presence of granuloma and positive Ziehl-Neelsen staining in nine (15.78\%) animals. Results analysis allowed concluding that in this work, immuno-allergic tests (Simple Cervical Test and Comparative Cervical Test) were not capable to differentiate infection caused by $M$. flavescens $1, M$. kansasi, $M$. tuberculosis complex and $C$. pseudotuberculosis. During gross examination and histopathology, lesions caused by M. flavescens 1, M. kansasi, and C. pseudotuberculosis were not distinguishable from those caused by M. tuberculosis complex.

Key words: Mycobacteriosis. Corynebacterium pseudotuberculosiS. Ovines. 
LISTA DE FIGURAS, QUADROS E TABELAS 


\section{LISTA DE FIGURAS}

Figura 1 - Tricotomia para a realização da prova intradérmica dupla comparativa

Pág.

40

Figura 2 - Mensuração da espessura da pele com cutímetro

Figura 3 - Aplicação intradérmica de tuberculina. Notar a formação do "botão" no momento da aplicação

Figura 4 - Fotografia de lesão no fígado do animal 33 .....

50

Figura 5 - Fotografia de lesão no intestino do animal 33

50

Figura 6 - Fotografia de lesão no linfonodo submandibular do animal 129

Figura 7 - Fotomicrografia de granuloma com necrose de caseificação presente na parede do intestino do animal 33

Figura 8 - Fotomicrografia de lesão na parede do intestino do animal 33 com presença de bacilo álcool-ácido resistente

Figura 9 - Fotomicrografia de granuloma com necrose de caseificação do linfonodo submandibular do animal 129 


\section{LISTA DE QUADROS}

Quadro 1 - Interpretação do Teste Cervical Simples em ovinos

Pág. segundo os parâmetros estabelecidos por Cyrillo (2006)

Quadro 2 - Interpretação do Teste Cervical Comparativo em ovinos segundo os parâmetros estabelecidos por Cyrillo (2006). 


\section{LISTA DE TABELAS}

Tabela 1 - Ovinos de duas propriedades da região de Pág. Pindamonhangaba - SP, Brasil submetidos ao diagnóstico intradérmico de tuberculina pelo Teste Cervical Simples (TCS) segundo a propriedade e a natureza do resultado obtido

Tabela 2 - Ovinos de duas propriedades da região de Pindamonhangaba - SP, Brasil submetidos ao diagnóstico intradérmico de tuberculina pelo Teste Cervical Comparativo (TCC) segundo a propriedade e a natureza do resultado obtido

Tabela 3 - Ovinos de duas propriedades da região de Pindamonhangaba - SP, Brasil submetidos ao diagnóstico de tuberculose pelo Teste Cervical Comparativo (TCC) segundo a propriedade e avaliação do resultado obtido.

Tabela 4 - Ovinos de duas propriedades da região de Pindamonhangaba - SP, Brasil segundo identificação do animal, a propriedade, natureza do resultado dos testes imunoalérgicos, lesões macroscópicas encontradas e órgãos colhidos na necrópsia.

Tabela 5 - Ovinos de duas propriedades da região de Pindamonhangaba - SP, Brasil abatidos e necropsiados com órgãos e tecidos submetidos a cultivos para isolamento de micobactérias ou outros microorganismos segundo: identificação do animal e propriedade, tipo de cultivo efetuado, órgão ou tecido examinado e a natureza do resultado obtido.

Tabela 6 - Ovinos de duas propriedades da região de Pindamonhangaba - SP, Brasil submetidos a testes imunoalérgicos aplicados ao diagnóstico da tuberculose, abatidos e necropsiados, com lesões macroscópicas sugestivas,submetidas a cultivos para micobactérias e outros microorganismos e exame histopatológico segundo a natureza dos resultados obtidos. 
Tabela 7 - Ovinos de duas propriedades da região de Pindamonhangaba - SP, Brasil submetidos a testes imunoalérgicos aplicados ao diagnóstico da tuberculose, abatidos, necropsiados, com lesões macroscópicas sugestivas de micobactérias, submetidas a cultivo para micobactérias e outros microorganismos, exame histopatológico e tipificação genética dos microorganismos isolados, segundo a natureza dos resultados obtidos....................................

Tabela 8 - Ovinos de duas propriedades da região de Pindamonhangaba - SP, Brasil submetidos a testes imunoalérgicos aplicados ao diagnóstico da tuberculose, abatidos e necropsiados, com lesões macroscópicas sugestivas,submetidas a cultivos para micobactérias e outros microorganismos e exame histopatológico segundo a natureza dos resultados obtidos. 
LISTA DE ABREVIATURAS E SÍMBOLOS 


\section{LISTA DE ABREVIATURAS E SÍMBOLOS}

\begin{tabular}{|c|c|}
\hline$\%:$ & Por cento \\
\hline$\pm:$ & Mais ou menos \\
\hline$\Delta:$ & Diferença (entre medidas) \\
\hline${ }^{\circ} \mathrm{C}:$ & Graus Celsius \\
\hline${ }^{\circ} \mathrm{GL}:$ & Graus Gay-Lussac \\
\hline$\mu \mathrm{L}:$ & Microlitro \\
\hline ABIEC: & Associação Brasileira das Indústrias Exportadoras de Carne \\
\hline AIDS: & Síndrome da Imunodeficiência adquirida \\
\hline BAAR: & Bacilo álcool ácido resistente \\
\hline BCG: & Bacilo Calmette-Guérin \\
\hline $\begin{array}{l}\mathrm{BHI}: \\
\text { C. }\end{array}$ & Brain Heart Infusion \\
\hline pseudotuberculosis: & Corynebacterium pseudotuberculosis \\
\hline DNA: & Ácido desoxiribonucléico \\
\hline EDTA: & Ácido etileno-diamino-tetracético \\
\hline FAO: & Food and Agriculture Organization \\
\hline FMVZ: & Faculdade de Medicina Veterinária e Zootecnia \\
\hline HIV: & Vírus da imunodeficiência humana \\
\hline HOVET: & Hospital Veterinário \\
\hline IBGE: & Instituto Brasileiro de Geografia e Estatística \\
\hline IMA: & Instituto Mineiro de Agricultura \\
\hline LC: & Linfadenite Caseosa \\
\hline M. africanum: & Mycobacterium africanum \\
\hline M. avium: & Mycobacterium avium \\
\hline M. bovis: & Mycobacterium bovis \\
\hline M. flavescens 1: & Mycobacterium flavescens 1 \\
\hline $\begin{array}{l}\text { M. kansasi: } \\
\text { M. }\end{array}$ & Mycobacterium kansasi \\
\hline nonchromogenicum: & Mycobacterium nonchromogenicum \\
\hline M. scrofulaceum: & Mycobacterium scrofulaceum \\
\hline
\end{tabular}


M. terrae:

M. triviale:

M. tuberculosis:

MAIS:

MAPA:

mg:

$\mathrm{mL}$ :

$\mathrm{mm}$ :

MOTT:

P.C.R.:

P.R.A.:

$\mathrm{Pb}$ :

PLD:

PNCEBT:

PNSCO:

PPD Av:

PPD Bv:

PPD:

PZA:

SIF:

Taq:

TCC:

TCS:

TRIS:

USP:

VPS:

VPT:

WHO:
Mycobacterium terrae

Mycobacterium triviale

Mycobacterium tuberculosis

Complexo Mycobacterium avium, $M$. intracellulare e $M$. scrofulaceum

Ministério da Agricultura, Pecuária e Abastecimento

miligrama

mililitro

milímetro

Mycobacteria other than tuberculosis

Polymerase Chain Reaction

PCR-Restriction enzyme Analysis

Pares de base

Fosfolipase D

Programa Nacional Combate e Erradicação de Brucelose e Tuberculose

Programa Nacional de Sanidade dos Caprinos e Ovinos

Derivado proteico purificado de Mycobacterium avium

Derivado proteico purificado de Mycobacterium bovis

Derivado proteico purificado

Pirazinamida

Serviço de Inspeção Federal

Thermus aquaticus

Teste Cervical Comparativo

Teste Cervical Simples

Tris(hidroximetil)amino metano

Universidade de São Paulo

Departamento de Medicina Veterinária Preventiva

Departamento de Patologia Animal

World Health Organization 


\section{SUMÁRIO}




\section{SUMÁRIO}

1 INTRODUÇÃO E REVISÃO DA LITERATURA …........................... 24

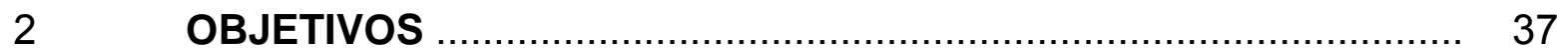

$3 \quad$ MATERIAL E MÉTODOS …............................................... 38

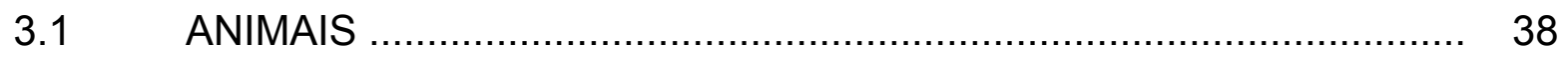

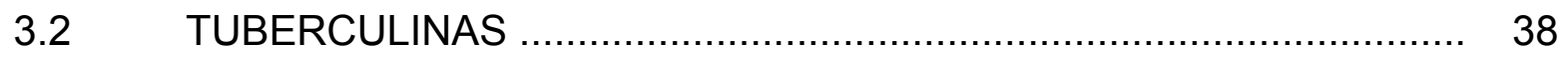

3.3 MEIOS DE CULTURA ……................................................... 38

3.4 TÉCNICAS E PROCEDIMENTOS ……........................................ 39

3.4.1 Tuberculinização .................................................................... 39

3.4.2 Exame clínico dos animais .................................................... 42

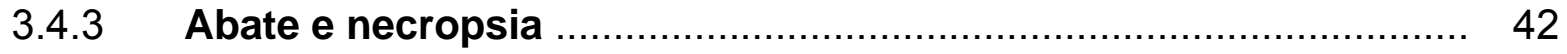

3.4.4 Exames laboratoriais ............................................................ 43

3.4.5 Histopatológico ................................................................... 44

3.4.6 Identificação de Micobactérias .................................................... 44

3.4.6.1 Obtenção do DNA …………………..................................... 44

3.4.6.2 PCR Restriction Enzyme Pattern Analysis (PRA) ..................... 45

3.4.7 Análise Estatística ................................................................. 45

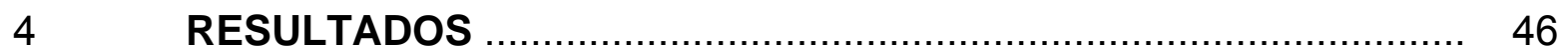

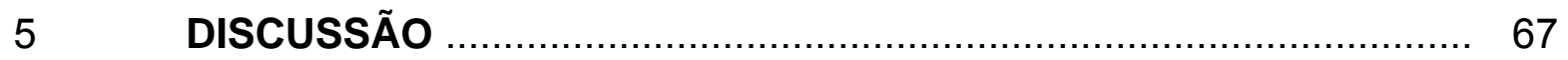

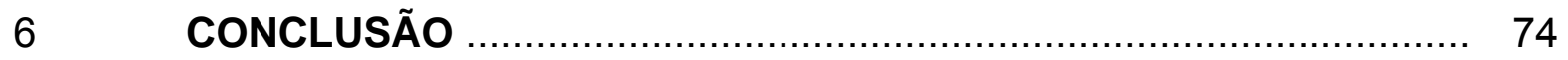

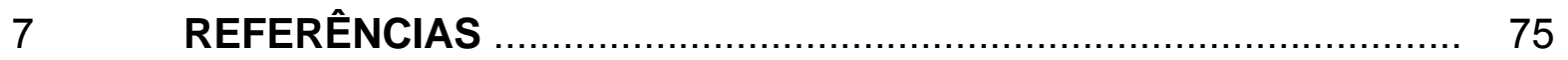

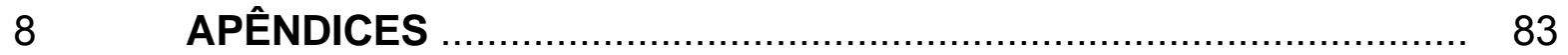




\section{INTRODUÇÃO E REVISÃO DA LITERATURA}

Em todo o mundo a tuberculose é tida como a principal causa de morte provocada por um único agente. A cada segundo uma nova pessoa é infectada. Estima-se que 1/3 da população mundial albergue o bacilo de Koch e que de 5 a 10\% desses indivíduos irão desenvolver a doença ou se tornar infectantes em algum momento de suas vidas. Em 2004 a estimativa de mortes por tuberculose foi de 1,7 milhão de pessoas (WORLD HEALTH ORGANIZATION - WHO, 2006).

A tuberculose é uma doença que acompanha o homem e os animais desde os tempos primitivos. No início do século XIX foi levantada a suspeita de que a tuberculose pudesse ser transmitida pelo leite de vacas contaminadas e, em 1846, Klenke reproduziu a doença em coelhos inoculados com leite de vacas infectadas (ANERIK, 1974; CHALMERS et al., 1996).

Em 1866, Villemin demonstrou definitivamente o caráter zoonótico da tuberculose caracterizando-a como uma doença específica produzida por agente inoculável transmissível do homem ou do bovino para outras espécies de animais susceptíveis (ANERIK, 1974).

Em março de 1882, Robert Koch isolou o agente etiológico da tuberculose e ressaltou o papel dos seres humanos e animais domésticos como as principais fontes de infecção (COLLINS et al., 1985; LONDON SCHOOL OF HYGIENE, 1994) indicando medidas preventivas para evitar a transmissão do agente pelo consumo do leite e da carne de animais infectados (ANERIK, 1974; PACKER, 1990).

O Mycobacterium tuberculosis é o principal agente etiológico da tuberculose humana e o Mycobacterium bovis dos animais de produção. É uma bactéria fracamente Gram-positiva, álcool-ácido resistente (BAAR), imóvel, baciliforme e não esporulada. Pertence à ordem Actinomycetales, família Mycobacteriaceae, gênero Mycobacterium que engloba cerca de 127 espécies e 11 subespécies (KRIEG; HOLT, 1994; EUZÉBY, 2007).

As principais espécies de micobactérias com importância epidemiológica estão incluídas no complexo Mycobacterium tuberculosis, que inclui o Mycobacterium tuberculosis, Mycobacterium bovis, Mycobacterium africanum, Mycobacterium microti, e o Mycobacterium canetti, os dois últimos introduzidos no 
grupo devido à similaridade genética (BIER, 1978; CORNER, 1994; GRANGE, 1996; ABRAHÃO, 1998; BROSCH et al., 2002; ZINK, NERLICH, 2004).

Nos anos 50 do século XX, com a descoberta de novas drogas aplicadas no combate ao bacilo de Koch e a evolução econômico-social mundial houve o consenso da comunidade científica e autoridades sanitárias, de que a derrota da tuberculose era uma questão de tempo. Contudo, no início dos anos 80 esta posição foi drasticamente revertida pois, o advento da AIDS (Síndrome da Imunodeficiência Adquirida) provocada pelo HIV ( Vírus da Imunodeficiência Humana) e o surgimento de estirpes de bacilos resistente a múltiplas drogas fizeram com que a tuberculose passasse a ser considerada como uma doença re-emergente (LONDON SCHOOL OF HYGIENE,1994; LIMA,1995; SANTOS,1995).

Cosivi et al. (1998) projetaram um aumento de 36\% da incidência anual global da tuberculose para o ano 2000, em relação a 1996. A co-infecção HIV versus tuberculose deveria subir de 315.000 (4\% dos casos de tuberculose) em 1990 para 1,4 milhões (14\%) no ano 2000. Atualmente estima-se que a tuberculose seja responsável por 13\% das mortes de pacientes com AIDS (WHO, 2006).

As micobactérias não pertencentes ao complexo Mycobacterium tuberculosis também podem provocar doença em animais e seres humanos, que nesse caso é referida como micobacteriose. Tais micobactérias são denominadas "atípicas", "mycobacteria other than tuberculosis - MOTT", "micobatérias não tuberculosas", "saprófitas", "oportunistas", "não patogênicas", "ambientais" e ainda "micobactérias patogênicas ambientais". Estão incluídas em complexos diversos como: M. avium (M. intracellulare, $M$. avium subespécie avium, $M$. avium subespécie paratuberculosis e $M$. avium subespécie sylvaticum), MAIS (M. scrofulaceum, $M$. avium e M. intracellulare), M. bovis (M. bovis, Bacilo de Calmette-Guerin - BCG e $M$. africanum) e M. terrae (M. terrae, M. nonchromogenicum e M. triviale), saliente-se contudo que essas denominações e agrupamentos ainda não apresentam unanimidade científica (KANTOR, 1979; VASCONCELLOS, 1979; PRITCHARD, 1988; KRIEG; HOLT, 1994; HAAGSMA, 1995; FALKINHAM III, 1996; PEDLEY et al., 2004).

O interesse pelos agentes etiológicos das micobacterioses aumentou em decorrência do surgimento da AIDS pois, até aquela ocasião, elas raramente provocavam doença no homem e quando o faziam, havia maior freqüência da forma 
pulmonar com raros registros de casos disseminados. Contudo, depois da AIDS as infecções disseminadas com isolamento de bacilos álcool-ácido-resistentes do sangue e das fezes passaram a ser bastante freqüentes (FALKINHAN III, 1996).

Desde os primeiros relatos de AIDS em 1982, a incidência de micobacterioses tem aumentado vertiginosamente chegando a se estimar que, nos EUA e na Europa, 25 a 50\% dos aidéticos estivessem infectados com algum tipo de micobatéria do grupo MOTT. A infecção por dois tipos de micobactérias também passou a ser mais freqüente, tornando imperativa a identificação do(s) agente(s) envolvido(s) (FALKINHAN III, 1996).

Enquanto o $M$. tuberculosis e o $M$. bovis são transmitidos de hospedeiro a hospedeiro, as outras micobactérias são ubiqüitárias tendo como habitat os componentes ambientais como solo, água, poeira e aerossóis e raramente são transmitidas por contágio direto (WOLINSKY, 1979; FALKINHAN III, 1996).

A principal característica morfológica das micobactérias é a sua complexa parede celular com $60 \%$ de sua estrutura composta por lipídios e polipeptídios diretamente relacionados com a sobrevivência do bacilo dentro das células do hospedeiro, pois impedem a formação do fago-lisossomo (QUINN et al., 2005).

As infecções por micobactérias ocorrem, na maioria das vezes, pela via respiratória com a inalação de aerossóis contaminados pelos bacilos. Uma vez inalados, os bacilos são fagocitados pelos macrófagos dos alvéolos pulmonares onde se multiplicam até causarem a destruição da célula hospedeira. Os bacilos liberados são fagocitados novamente e novo ciclo se inicia até que ocorra a resposta imune mediada por células e instale-se o estado imune caracterizado por reação de hipersensibilidade tardia. Nesta fase mediada por linfócitos $T$ inicia-se a necrose de caseificação, tentativa do organismo hospedeiro conter o crescimento intracelular das micobactérias. Há o recrutamento de novas células de defesa (macrófagos, histiócitos, células gigantes, células epitelióides, linfócitos e fibroblastos) que culmina com a formação do granuloma. O granuloma é constituído por uma parte central (freqüentemente com necrose de caseificação) circundada pelas células epitelióides, células gigantes, linfócitos, macrófagos e uma camada periférica de fibroblastos. Da lesão inicial no parênquima pulmonar os bacilos chegam ao linfonodo satélite onde formam outro granuloma denominado "complexo primário" (COLLINS, 2002; MINISTÉRIO DA AGRICULTURA, PECUÁRIA E ABASTECIMENTO - MAPA, 2006) 
Quando as micobactérias são ingeridas, a lesão inicial se forma nos órgãos digestivos e o complexo primário nos linfonodos regionais, principalmente os mesentéricos. Uma vez estabelecida, a lesão pode regredir, se estabilizar ou progredir. A generalização da doença pode se dar de duas formas: a miliar que ocorre de maneira abrupta com a entrada maciça de micobactérias na circulação e a protraída, mais comum, em que há a disseminação de bacilos pela via linfática ou sanguínea acometendo todos os tecidos, embora as lesões sejam encontradas com maior freqüência nos linfonodos (mediastínicos, mesentéricos, retrofarígeos, parotídeos, cervicais e inguinais superficiais), pulmões e fígado (ABRAHÃO, 1998; COLLINS, 2002; MAPA, 2006; OHARA, 2006).

Embora no passado a tuberculose em humanos pelo Mycobacterium bovis tenha sido epidemiologicamente importante, a aplicação de medidas de inspeção sanitárianos produtos de origem animal principalmente leite e carne fez com que a incidência da tuberculose zoonótica diminuísse significativamente. O maior rigor na inspeção das carcaças em abatedouros, a pasteurização do leite e a identificação e eliminação dos animais doentes e/ou positivos pelos exames intradérmicos foram os principais responsáveis por esse declínio observado principalmente nos países desenvolvidos (COSIVI et al., 1998).

A tuberculose bovina vem sendo alvo de intensas campanhas de erradicação e controle em vários países do mundo desde os anos de 1950 e 60. No entanto, se alguns países apresentam uma situação bastante confortável em relação à doença outros enfrentam situações alarmantes (LILENBAUM, 2000).

A tuberculose e as micobacterioses nos rebanhos de animais de produção são doenças de evolução lenta, assim muitas vezes não são exteriorizados sinais clínicos (principalmente entre os animais de criação de ciclo mais rápido) ou há apenas sinais inespecíficos como dispnéia, tosse, mastite, infertilidade, caquexia e depauperação; freqüentemente a sua presença só é percebida no momento do abate, aonde é praticamente impossível a caracterização do tipo de microorganismo envolvido (FERREIRA NETO et al., 1989; BALIAN et al., 1997; ABRAHÃO, 1998; MAPA, 2006).

Estima-se que um animal tuberculoso perde de 10 a $25 \%$ de sua capacidade produtiva, o que traz prejuízos à atividade pecuária e ainda passa a ser um foco da doença para outros animais e o homem (COSIVI et al., 1998). 
A tuberculose humana causada pelo $M$. bovis é clinicamente indistinguível da doença causada por $M$. tuberculosis. Como o $M$. bovis é naturalmente resistente à pirazinamida (PZA), droga comumente utilizada no tratamento da tuberculose, esse fato destaca a importância da identificação do agente envolvido, nem sempre efetuada ou devido à falta de recursos ou simplesmente por desconhecimento dos profissionais de saúde (ABRAHÃO, 1998; ZINK, NERLICH, 2004)

Nos países em desenvolvimento - principalmente aqueles em que a AIDS se configura como epidemia - a tuberculose zoonótica representa um sério problema de saúde pública (COSIVI et al., 1998).

O principal método de diagnóstico da tuberculose em bovinos é o teste imunoalérgico (CENTRO PANAMERICANO DE ZOONOSIS, 1988), já no postmortem os exames bacteriológicos e histopatológicos das lesões macroscópicas assumem papel de destaque servindo também para o controle com o diagnóstico realizado no campo com a avaliação da eficácia das provas tuberculínicas (CENTRO PANAMERICANO DE ZOONOSIS, 1988; ORGANIZACIÓN PANAMERICANA DE LA SALUD, 1995).

A reação alérgica à tuberculina é uma reação de hipersensibilidade retardada tipo IV mediada por resposta celular e com baixa produção de anticorpos. Após a inoculação em animal previamente sensibilizado, a tuberculina é fagocitada e seus peptídeos são apresentados na superfície celular dos macrófagos. A resposta específica tem início quando os linfócitos T sensibilizados reconhecem os antígenos tuberculínicos e secretam as citocinas, que ativam células endoteliais venulares e que por sua vez recrutam monócitos e leucócitos do sangue, enquanto outras citocinas convertem os monócitos em macrófagos ativados capazes de eliminar o antígeno. Macroscopicamente a resposta se manifesta na forma de edema e endurecimento progressivo no local da aplicação que atinge seu máximo por volta das 48 - 72 horas (mais ou menos 6 horas) pós- inoculação, diminuindo em seguida (CORRÊA; CORRÊA, 1992; MAPA, 2006)

Nos países em desenvolvimento ainda faltam estudos sistematizados sobre a relação entre animais identificados como positivos pelos testes de tuberculinização, achados post-mortem e isolamento do bacilo das lesões (FOOD AND AGRICULTURE ORGANIZATION - FAO,1993; WHO, 1993, 1994).

No Brasil, os dados oficiais sobre a prevalência da tuberculose bovina são muito escassos. Entre 1989 e 1998 as notificações ao Ministério da Agricultura 
indicavam a prevalência média de 1,3\% de animais tuberculosos pelos testes tuberculínicos (MAPA, 2006). Em 1999 o Instituto Mineiro de Agricultura (IMA), em levantamento que envolveu 23.000 bovinos de 1600 propriedades apurou a prevalência de 0,85\%. O número de propriedades envolvidas foi de $5 \%$ subindo para $15 \%$ no universo das propriedades leiteiras com algum grau de mecanização da ordenha (BELCHIOR, 2000).

Em se tratando do controle da tuberculose bovina, o Ministério da Agricultura, Pecuária e do Abastecimento lançou em 2001 o Programa Nacional de Controle e Erradicação da Brucelose e Tuberculose (PNCEBT). O PNCEBT surgiu com o objetivo de diminuir a prevalência e a incidência de novos casos de brucelose e tuberculose, assim como criar propriedades certificadas que ofereçam ao consumidor produtos de baixo risco sanitário, visando promover a qualidade dos produtos de origem animal oferecidos ao consumidor e contribuir para modernizar as cadeias produtivas do leite e da carne (MAPA, 2006). Entretanto, tal programa não contemplou a tuberculose ovina e caprina alegando a inexistência de dados que justifiquem a implantação de medidas específicas visando o controle sistemático de tal doença nos pequenos ruminantes.

A ovinocultura e a caprinocultura fazem parte dos primórdios da história da humanidade. As ovelhas (Ovis aries) foram domesticadas a partir do Muflão (Ovis orientalis) na idade do bronze por volta de 4.000 a. C., quando o homem deixou de ser nômade para se dedicar a agricultura e a criação de animais (WIKIPEDIA, 2007).

$A$ atividade de pastoreio proporcionou às comunidades antigas fonte constante de lã e pele para vestuário e carne e leite para alimentação. Os ovinos e caprinos logo passaram a fazer parte de sua economia e cultura devido às características de porte, docilidade, prolificidade e rusticidade (ROCHA, 2003).

$\mathrm{Na}$ mitologia grega, Zeus enfrentou seu pai Cronos pelo trono do monte Olimpo recoberto com a pele da cabra Amaltéia que o teria alimentado durante a infância; na astrologia, a constelação de Áries (que se assemelha a uma cabeça de carneiro com chifre em espiral) recebeu esse nome em referência ao carneiro alado Crisómalo, cuja lã era de ouro e teria sido mandado pelo espírito de Nefele para proteger seus filhos Frixo e Hele, ameaçados de morte pela madrasta Ino (KURY, 2003). 
A ovinocultura está associada mundialmente a populações pobres sendo, conjuntamente com a caprinocultura, uma das principais fontes de alimento e subsistência na maioria dos países subdesenvolvidos (ROCHA, 2003).

Em 2004, a FAO estimou o rebanho mundial de ovinos em 1,037 bilhão de cabeças, tendo a China (15,16\%), Austrália (9,10\%), Índia (6,02\%), Irã (5,20\%), Sudão $(4,53 \%)$ e Nova Zelândia $(3,86 \%)$ os maiores rebanhos. O Brasil ocupa a $16^{a}$ posição $(1,37 \%)$. Apesar de ocupar a primeira posição, a China pouco participa do mercado mundial pois a maior parte de sua produção é destinada ao consumo próprio, o que caracteriza a atividade como essencial para a subsistência da população. Já a Austrália e a Nova Zelândia, grandes produtores de carne e lã, destacam-se como países detentores de alta tecnologia aplicada tanto na criação dos animais como na industrialização dos produtos (FAO, 2007).

No Brasil, o rebanho ovino tem se mantido relativamente estável nos últimos anos e em 2005 o contingente estimado foi de 15,58 milhões de cabeças. A região Nordeste apresentou a maior população $(58,44 \%)$, seguida da região Sul $(28,56 \%)$, Centro-Oeste (6,01\%), Sudeste (3,89\%) e Norte (3,09\%). O Estado do Rio Grande do Sul foi o detentor do maior rebanho seguido do Estado da Bahia (INSTITUTO BRASILEIRO DE GEOGRAFIA E ESTATÍSTICA - IBGE, 2007; MAPA, 2007).

$\mathrm{Na}$ região Nordeste do Brasil a criação de ovinos é uma atividade de subsistência com pouca tecnificação, a carne produzida é de baixa qualidade e utilizada principalmente para o consumo local. Na Região Sul, onde se encontram os melhores índices de tecnificação e produtividade, a produção de carne de ovinos para comércio é bem mais desenvolvida. Em 2006 no Brasil, 10,15\% dos abates de ovinos em estabelecimentos controlados pelo Serviço de Inspeção Federal (SIF) ocorreram na região Nordeste contra 76,48\% na região Sul (MAPA, 2007).

A despeito de nos últimos anos ter sido observado no Brasil um gradativo crescimento do rebanho ovino e do aumento do abate destes animais, a ovinocultura ainda não atingiu o seu potencial quando comparada à bovinocultura de corte. Em 2005, o rebanho bovino brasileiro ultrapassava a cifra de 207 milhões de cabeças e em 2006 foram exportadas mais de 2,5 milhões de toneladas de carne, representando US\$3,99 bilhões em divisas para o país, enquanto as importações de carne bovina somaram 19,89 mil toneladas a um custo de US\$65,78 milhões. No mesmo período foram exportadas apenas 2,67 toneladas de carne ovina com a entrada de US\$21,1 mil, enquanto as importações de carne ovina somaram 7,07 mil 
toneladas a um custo de US\$14,92 milhões, demonstrando a crescente demanda do produto principalmente nas grandes capitais (ASSOCIAÇÃO BRASILEIRA DAS INDÚSTRIAS BRASILEIRAS DE CARNE - ABIEC, 2007; MINISTÉRIO DO DESENVOLVIMENTO, INDÚSTRIA E COMÉRCIO EXTERIOR, 2007).

Devido à raridade da tuberculose em ovinos muito se especulou sobre a resistência desta espécie a tal patologia. A primeira descrição foi efetuada por Sir John Mc Fadyean, em 1900, que reproduziu a doença inoculando material cáseopurulento em coelhos (MALONE et AL., 2003).

A tuberculose em ovinos é uma enfermidade insidiosa, progressiva e de caráter crônico, que apresenta evolução longa podendo se estender por muitos meses a anos (JENSEN; SWIFT, 1982). Os sintomas da infecção causada pelo Mycobacterium bovis são muito inespecíficos, de forma que podem ser muitas vezes imperceptíveis em ovinos infectados. Devido a esse comportamento, os ovinos doentes tornam-se um risco à saúde dos demais animais e dos seres humanos (HIEPE, 1972; JENSEN; SWIFT, 1982; SMITH; SHERMAN, 1994; SMITH, 2006;).

Os sintomas evidenciados são: enfraquecimento gradual, emagrecimento crônico, debilidade, apetite caprichoso, tosse discreta, dificuldade respiratória e descarga nasal persistente (AYELE et al., 2004; HIEPE, 1972; JENSEN; SWIFT, 1982; MARSH, 1965; PUGH, 2005; SMITH, 2006; SMITH; SHERMAN, 1994). Nos casos mais severos os ovinos apresentam febre, apatia, broncopneumonia grave, caquexia e em alguns casos timpanismo devido ao aumento dos linfonodos mediastínicos impedindo ou dificultando a eructação (MARSH, 1965; HIEPE, 1972; MARTIN; AITKEN, 2000; RADOSTITIS et al., 2000; PUGH, 2005; SMITH, 2006).

Os sintomas relacionados especificamente ao sistema respiratório são mais comuns, apresentando-se de forma variável, todavia os animais infectados apresentam uma tosse crônica e discreta, e uma dificuldade respiratória mais evidente quando as lesões atingem os lobos pulmonares e a pleura (HIEPE, 1972; JENSEN; SWIFT, 1982; SMITH, 2006). Nos estágios terminais da enfermidade os ovinos podem apresentar ruídos pulmonares com presença de crepitação e sibilos, dispnéia ou taquipnéia (PUGH, 2005; SMITH, 2006). As ulceras intestinais e as diarréias também podem estar associadas aos quadros de tuberculose, evidenciando a via digestiva como porta de entrada do agente (MARSH, 1965; SMITH, 2006). 
Em rebanhos acometidos pela tuberculose, é freqüente evidenciar-se pelo exame físico dos animais um menor número de ovinos acometidos do que daqueles reagentes à tuberculina e com resultados de necropsia evidenciando lesões características da enfermidade (HIEPE, 1972; RADOSTITIS et al., 2000; SMITH, 2006).

Em virtude das diversas doenças que acometem o sistema respiratório e que podem ser confundidas com a tuberculose em ovinos, deve-se realizar o diagnóstico diferencial com varias enfermidades, destacando-se: micobacterioses, pneumonia supurativa crônica; verminose pulmonar, broncopneumonias, pasteureloses, linfoadenite caseosa (Corynebacterium pseudotuberculosis), lesões faríngeanas resultantes de traumas, linfossarcoma, raiva, botulismo, actinobacilose, faringite necrótica e edema (HIEPE, 1972; RADOSTITIS et al., 2000; PUGH, 2005; SMITH, 2006).

$\mathrm{Na}$ literatura pesquisada não foram encontrados trabalhos referentes à micobacterioses em ovinos e a maioria dos relatos de tuberculose em ovinos provem de casos isolados constatados por ocasião do abate. Na Nova Zelândia, de 1986 a 1987, foram abatidos 9,9 milhões de cordeiros e 1,97 milhões de ovinos adultos sendo encontrados pelo serviço de vigilância 35 animais com lesões sugestivas de tuberculose. Destes, apenas dois apresentaram lesões histopatológicas típicas de tuberculose mas não houve isolamento de M. bovis (ALLEN, 1988).

$\mathrm{Na}$ Irlanda do Norte, em 1991, em 65.000 ovinos abatidos sob inspeção houve 22 animais provenientes de diferentes rebanhos, que apresentaram lesões suspeitas de tuberculose porém, não houve confirmação da doença nos exames histopatológicos e bacteriológicos (MALLONE et al., 2003).

A despeito dessa baixa prevalência, a doença pode assumir grandes proporções em determinadas condições. Na Irlanda do Norte, em uma propriedade em que os ovinos conviviam com bovinos tuberculosos foram observadas lesões suspeitas de tuberculose nos ovinos com as mesmas características das encontrada no bovino abatidos na mesma propriedade. A identificação genética confirmou que as micobactérias isoladas eram do complexo M. tuberculosis ( MALONE et al., 2003)

Na Nova Zelândia, Davidson, Alley e Beatson (1981) testaram 597 ovinos que pastavam com um rebanho bovino com tuberculose. Foram considerados positivos pelo teste intradérmico simples 108 animais dos quais setenta foram necropsiados e em 43 deles (61\%) foram encontradas lesões sugestivas de tuberculose. 
Cordes et al. (1981) isolaram M. bovis de 32 ovinos de um total de 43 animais abatidos com lesões suspeitas de tuberculose, provenientes de um rebanho de 15.000 animais de uma fazenda com histórico de tuberculose em bovinos e marsupiais silvestres.

Um fato a ser ressaltado é a semelhança entre as lesões provocadas pela tuberculose em ovinos com outras doenças, principalmente a Linfadenite Caseosa (LC), uma enfermidade de distribuição mundial de importância econômica e sanitária em caprinos e ovinos embora também atinja bovinos e eqüinos (CORRÊA; CORRÊA, 1992; SMITH, 2006).

A Linfadenite Caseosa (LC) é provocada pelo Corynebacterium pseudotuberculosis, bactéria Gram-positiva, pleomórfica, que forma pequenas colônias esbranquiçadas rodeadas por uma estreita zona de hemólise completa no meio de cultura, que pode não ser evidente em até 72 horas. Dois tipos de $C$. pseudotuberculosis são conhecidos: linhagens de equino/bovino e de ovino/caprino respectivamente redutoras e não redutoras de nitratos (CORRÊA E CORRÊA, 1992; SMITH, 2006).

O agente não possui vetores ou transmissores. Os animais infectados pelo $C$. pseudotuberculosis contaminam o solo, a água, as instalações e os utensílios de manejo em geral com suas fezes, descargas nasais, orais ou descargas purulentas de abcessos superficiais rompidos. O agente resiste por meses à dessecação quando abrigado da luz solar, mas é sensível aos desinfetantes comuns, à temperaturas superiores a $70^{\circ} \mathrm{C}$ e luz solar direta por cinco minutos (CORRÊA; CORRÊA, 1992; RADOSTIS et al., 2000; QUINN et al., 2005).

A prevalência da linfadenite caseosa em ovinos e caprinos aumenta consideravelmente com a idade, podendo se manifestar de forma superficial com o aparecimento de abcessos subcutâneos nos linfonodos superficiais ou de forma visceral, que se caracteriza pelo desenvolvimento de abcessos internos nos linfonodos submandibulares, mediastínicos e mesentéricos, além de órgãos como fígado e pulmão (RADOSTIS et al., 2000; QUINN et al., 2005).

O C. pseudotuberculosis é um patógeno intracelular facultativo capaz de sobreviver e de multiplicar-se em fagócitos; sua virulência está ligada aos lipídios da parede celular e à produção da exotoxina fosfolipase D (PLD) que pode aumentar a sobrevivência e a multiplicação do agente no hospedeiro. Onde quer que o agente se instale surge um material caseoso, denso, branco-amarelado contido em abcesso 
de cápsula espessa que vai aumentando lentamente podendo atingir grande diâmetro. Os abcessos mais evoluídos se parecem ao corte com "anéis de cebola", devido ao pus organizado em capas concêntricas (CORRÊA; CORRÊA, 1992; RADOSTIS et al., 2000; QUINN et al., 2005; SMITH, 2006).

Não há sinais clínicos visíveis na maioria dos casos de LC em ovinos. Ocasionalmente pode se observar dispnéia, intolerância ao exercício, infertilidade, emagrecimento progressivo, caquexia e depauperação pois os animais com múltiplos ou grandes focos podem evoluir para toxemia. Na forma superficial da doença pode ocorrer aumento e supuração dos linfonodos superficiais. A forma visceral, com envolvimento pulmonar, é mais difícil de ser detectada pela dificuldade de se auscultar as crepitações, devido à ausência de exudato nas vias aéreas e à natureza encapsulada dos abcessos pulmonares (CORRÊA; CORRÊA, 1992; RADOSTIS et al., 2000; QUINN et al., 2005; SMITH, 2006).

A dificuldade em se fazer o diagnóstico in vivo faz com que muitas vezes o problema só seja percebido no momento do abate, quando a condenação de carcaças pela doença se torna inevitável. Um teste ELISA com sanduíche de anticorpo duplo direcionado contra o C. pseudotuberculosis foi desenvolvido mas a baixa especificidade pode determinar o abate de animais não infectados (RADOSTIS et al., 2000).

No Brasil, em 2004, foi aprovado o regulamento técnico do Programa Nacional de Sanidade dos Caprinos e Ovinos (PNSCO) que tem por objetivo "controlar ou erradicar a ocorrência de doenças de caprinos e ovinos, por meio de ações sanitárias e de vigilância epidemiológica definidas pelo Departamento de Defesa Animal e executadas pelos serviços oficiais e médicos veterinários cadastrados" (MAPA, 2004). Apesar disso até o momento nenhuma medida foi tomada no sentido de pesquisar a tuberculose em caprinos e ovinos.

Após o isolamento de micobactérias, de material de necropsia de ovinos e caprinos atendidos no Hospital Veterinário da Faculdade de Medicina Veterinária e Zootecnia da Universidade de São Paulo (HOVET/ FMVZ-USP) no período de 2001 a 2005, várias linhas de pesquisa foram desencadeadas, em busca de um melhor entendimento da ocorrência desta enfermidade em pequenos ruminantes. Entretanto, as dificuldades começavam com o diagnóstico in vivo da doença.

O teste tuberculínico também é utilizado na espécie ovina para o diagnóstico da tuberculose (HIEPE, 1972; CORDES et al., 1981). Embora para os bovinos os 
testes imunoalérgicos aplicados ao diagnóstico de tuberculose sejam mundialmente difundidos e aceitos, para os pequenos ruminantes ainda não há consenso nos parâmetros a serem utilizados; alguns autores destacam a possibilidade de sua realização na pele da face interna do membro posterior, acreditando que se obtenha uma melhor resposta para a prova (CORDES et al., 1981; DAVIDSON; ALLEY; BEATSON, 1981; JENSEN; SWIFT, 1982).

Em alguns países, nas propriedades dedicadas à ovinocultura o teste de tuberculina só era realizado para determinar o valor de venda dos ovinos. A prova era efetuada no membro posterior e a medição feita com o auxilio de um compasso especial, às 72 e às 96 horas. Os ovinos que apresentassem um aumento de pele superior a $2 \mathrm{~mm}$ eram considerados positivos à prova. Recomendava-se em concomitância, quando os animais eram positivos ao teste tuberculínico que fossem submetidos à necropsia (CORDES et al., 1981; MALONE et al., 2003).

$\mathrm{Na}$ Nova Zelândia a descoberta de casos de tuberculose em ovinos ocorreu de forma ocasional, apresentando animais com a forma localizada e de evolução crônica da doença (DAVIDSON; ALLEY; BEATSON, 1981). Nesta época, os ovinos foram submetidos a testes com tuberculina sintética produzida com $0 \mathrm{M}$. tuberculosis; os testes foram feitos na pele da parte interna do membro posterior injetando-se $0,1 \mathrm{ml}$ da tuberculina sendo a leitura realizada 72 horas após injeção, com a observação do aumento de volume no local da aplicação. Devido à falta de padrões para análise da resposta tuberculínica, considerava-se qualquer tipo de inchaço como sinal de animal reativo (HIEPE, 1972; DAVIDSON; ALLEY; BEATSON, 1981; MALONE et al., 2003).

Hiepe (1972), observou que a região ano-caudal, em ovinos, é mais sensível e reativa à tuberculina do que a região cervical, pois as reações tuberculínicas foram de uma a duas vezes maior que aquelas da região cervical.

No Brasil, Silva (2004) desenvolveu experimentalmente a padronização do alergoteste da tuberculina para caprinos e, em 2006, os ovinos também tiveram seu alergoteste de tuberculina padronizado experimentalmente (SILVA et al., 2006; CYRILLO, 2006). Contudo, tais padrões ainda não foram utilizados no campo com o objetivo de verificar a situação da tuberculose em rebanhos naturalmente infectados. 
Diante da importância do tema delineou-se este trabalho buscando comparar os resultados do diagnóstico imunoalérgico tuberculínico efetuados em ovinos com os exames de necrópsia, histopatológico, cultura e identificação genética das micobactérias isoladas. 


\section{OBJETIVOS}

Tendo em vista a importância do tema, a precariedade de dados nacionais sobre tuberculose e micobacterioses em ovinos e a necessidade de aprofundamento nas técnicas de diagnóstico pertinentes, este trabalho teve por objetivos:

- isolar e tipificar microrganismos presentes em linfonodos e lesões macroscópicas sugestivas de micobacteriose e/ou tuberculose.

- Verificar a correlação entre as bactérias isoladas, o resultado do testes imunoalérgicos utilizados (TCS e TCC) na triagem e seleção dos animais e os resultados dos exames histopatológicos. 


\section{MATERIAL E MÉTODOS}

\subsection{ANIMAIS}

Foram submetidos ao Teste Cervical Simples (TCS) e ao Teste Comparativo Cervical (TCC) 353 ovinos das raças Santa Inês e Texel provenientes de duas propriedades ( $\mathrm{A}$ e B) na região de Pindamonhangaba - SP. Todos os animais eram fêmeas, com mais de seis meses de idade e sem alterações físicas visíveis no momento da seleção. Após a tuberculinização, 57 animais foram selecionados segundo o resultado ao TCC: 31 com reação a tuberculina bovina superior a aviária ( $\triangle$ PPD Bv - $\triangle$ PPD Av $\geq 0$ ) e $26 \mathrm{com}$ reação a tuberculina bovina inferior a aviária $(\triangle \mathrm{PPD} B v-\triangle \mathrm{PPD} A v<0)$. Os animais foram então submetidos ao exame clínico, abate, necropsia e colheita de material para exames bacteriológicos e histopatológicos.

\subsection{TUBERCULINAS}

Foram utilizados PPD aviário contendo $0,5 \mathrm{mg} / \mathrm{mL}$ de tubérculo-proteína (partida 001/05) e PPD bovino contendo $1 \mathrm{mg} / \mathrm{mL}$ (partida 004/04) respectivamente, produzidos pelo Instituto Biológico de São Paulo.

\subsection{MEIOS DE CULTURA}

Para o isolamento de possíveis micobactérias foram utilizados os meios de Stonebrink e Löwenstein-Jensen (CENTRO PANAMERICANO DE ZOONOSIS,1988). O meio de Stonebrink foi distribuído em tubos de vidro (18 x 180 $\mathrm{mm}$ ) com tampa de algodão hidrófobo, em volume de $7 \mathrm{~mL}$ por tubo. Para o meio de 
Löwenstein-Jensen foram empregados tubos de vidro (15 x $160 \mathrm{~mm})$ com tampa de baquelite, no volume de $5 \mathrm{~mL}$ por unidade.

Para o isolamento de outras bactérias foram utilizados $3 \mathrm{~mL}$ de caldo de infusão cérebro coração (BHI) distribuídos em tubos; $5 \mathrm{~mL}$ de ágar sangue (sangue de carneiro a $5 \%$ ) e $5 \mathrm{~mL}$ de ágar MacConkey em placas segundo as técnicas desenvolvidas por Krieg e Holt (1994) e Murray (1999).

\subsection{TÉCNICAS E PROCEDIMENTOS}

\subsubsection{Tuberculinização}

O Teste Cervical Comparativo (TCC) foi realizado em todos os animais selecionados. Após contenção e identificação do animal, os locais das inoculações foram demarcados por tricotomia com uma distância de $10 \mathrm{~cm}$ entre si (Figura 1) e a espessura da dobra da pele em cada local foi medida com cutímetro ${ }^{1}$ antes da inoculação (Figura 2). Em seguida, com seringas de insulina descartáveis, as tuberculinas aviária e bovina foram inoculadas pela via intradérmica (Figura 3) na dosagem de 0,1 mL, sendo a PPD aviária inoculada cranialmente e a PPD bovina caudalmente, sempre de um mesmo lado em todos os animais. Após 72 horas $( \pm 6$ horas) da inoculação, foi realizada nova medida da dobra da pele nos locais inoculados com as tuberculinas aviária e bovina.

\footnotetext{
${ }^{1}$ Produzido pela HAUPTNER
} 


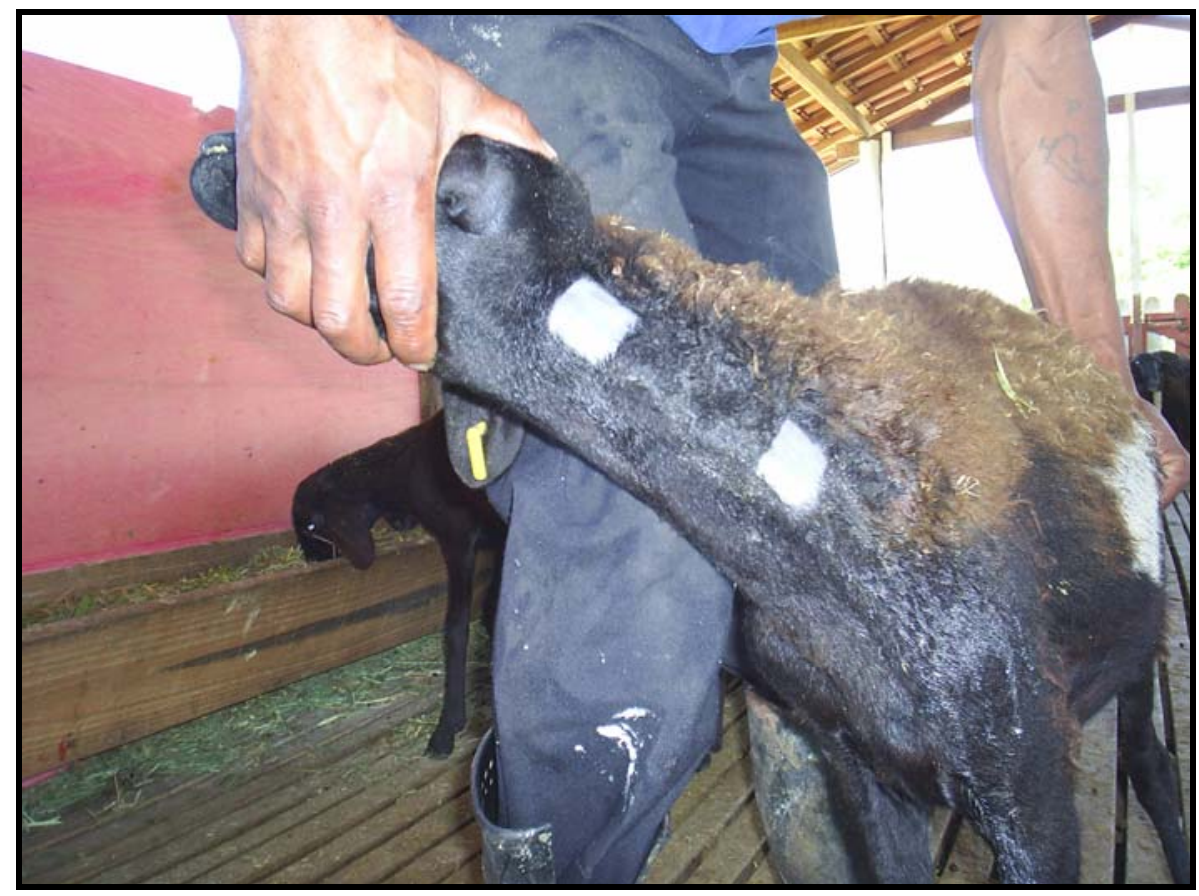

Figura 1 - Tricotomia para a realização da prova intradérmica dupla comparativa - São Paulo - 2007

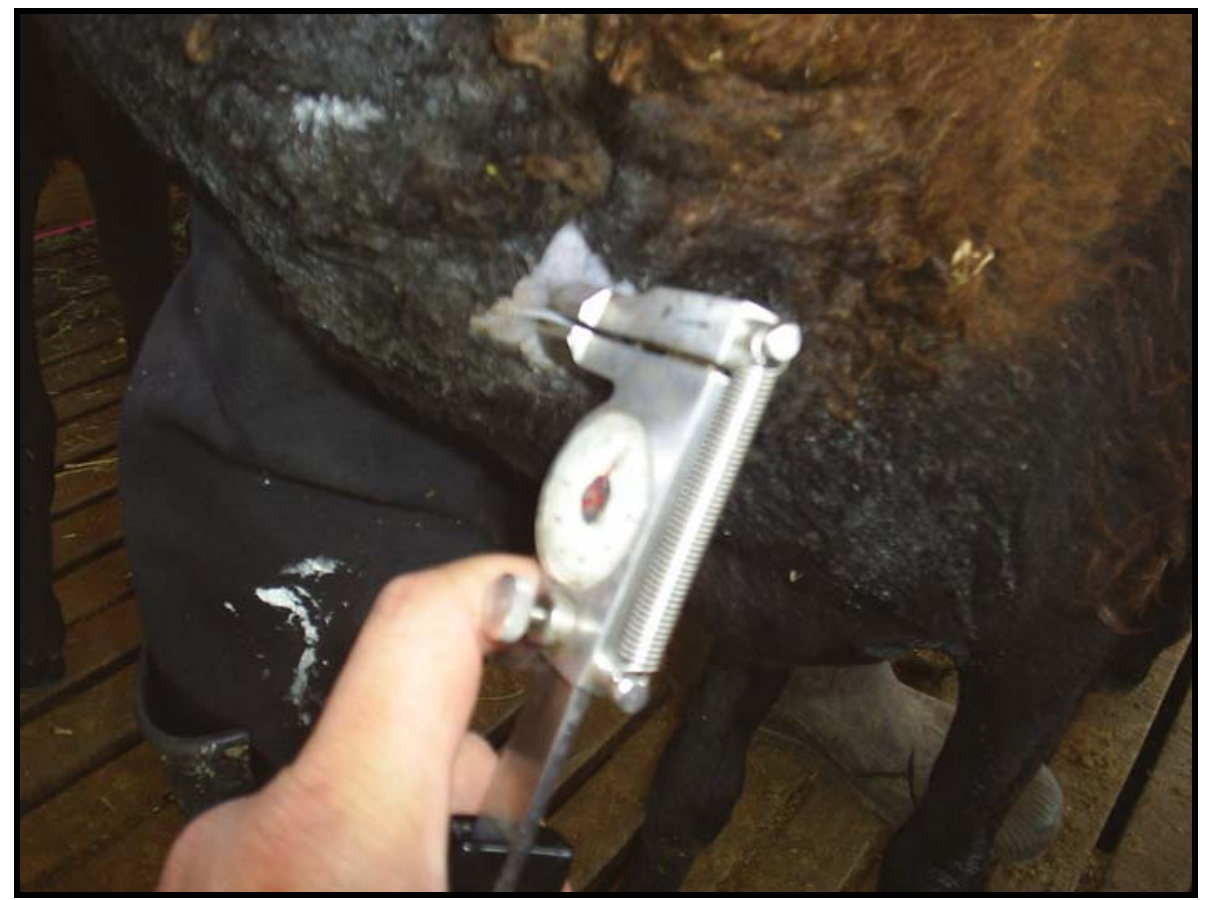

Figura 2 - Mensuração da espessura da pele com cutímetro - São Paulo - 2007 


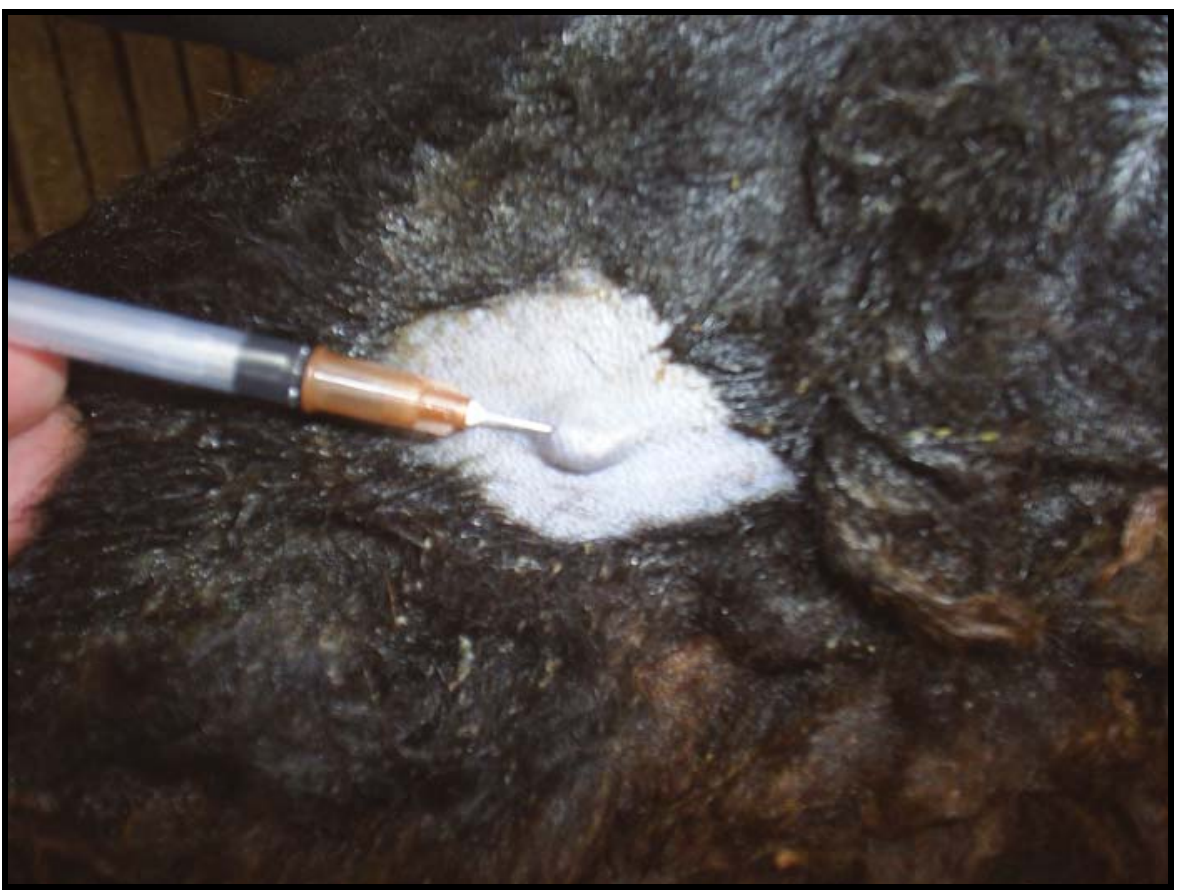

Figura 3 - Aplicação intradérmica de tuberculina. Notar a formação do "botão" no momento da aplicação - São Paulo - 2007

O resultado do TCS foi obtido calculando-se a diferença entre a espessura da pele no local da aplicação do PPD bovino imediatamente antes e 72 horas $( \pm 6$ horas) após a inoculação. Esse resultado ( $\triangle P P D B v$ ) foi interpretado segundo os parâmetros estabelecidos por Cyrillo (2006) (Quadro 1).

\begin{tabular}{|c|c|}
\hline $\begin{array}{c}\text { Diferenças das medidas }(\Delta) \text { do } \text { PPD }^{*} \\
\text { bovino }(\mathbf{m m})\end{array}$ & Interpretação \\
\hline$\Delta$ PPD $\mathrm{Bv}<1,00$ & Negativo \\
\hline $\mathbf{1 , 0 0} \leq \Delta \mathrm{PPD} \mathrm{Bv} \leq \mathbf{2 , 4 8}$ & Inconclusivo \\
\hline$\Delta \mathrm{PPD} \mathrm{Bv}>\mathbf{2 , 4 8}$ & Positivo \\
\hline
\end{tabular}

PPD: derivado proteico purificado

Quadro 1 - Interpretação do Teste Cervical Simples em ovinos segundo os parâmetros estabelecidos por Cyrillo (2006) - São Paulo - 2007

Para o TCC o resultado foi obtido calculando-se a diferença de aumento das dobras da pele provocadas pelas inoculações da tuberculina bovina ( $\triangle \mathrm{PPD} B \mathrm{Bv}$ ) e da 
tuberculina aviária ( $\triangle$ PPD Av) no momento da inoculação e 72 horas ( \pm 6 horas), subtraindo-se $\triangle$ PPD Av de $\triangle$ PPD Bv. Esse resultado ( $\triangle$ PPD Bv - $\triangle$ PPD Av) foi então interpretado segundo os parâmetros estabelecidos por Cyrillo (2006) (Quadro 2).

\begin{tabular}{|c|c|}
\hline $\begin{array}{c}\text { Diferenças das medidas }(\Delta) \text { dos } \text { PPD }^{*} \\
\text { bovinos e aviários }(\mathbf{m m})\end{array}$ & Interpretação \\
\hline$(\Delta$ PPD Bv- $\Delta$ PPD Av $) \leq \mathbf{0 , 9 9}$ & Negativo \\
\hline $\mathbf{1 , 0 0 < (} \triangle$ PPD Bv- $\Delta$ PPD Av $) \leq \mathbf{1 , 9 9}$ & Inconclusivo \\
\hline$(\Delta$ PPD Bv- $\triangle$ PPD Av $)>\mathbf{2 , 0}$ & Positivo \\
\hline
\end{tabular}

PPD: derivado proteico purificado

Quadro 2 - Interpretação do Teste Cervical Comparativo em ovinos segundo os parâmetros estabelecidos por Cyrillo (2006) - São Paulo - 2007

\subsubsection{Exame clínico dos animais}

Após a aplicação do teste cervical comparativo os animais selecionados para abate foram submetidos ao exame clínico onde foi avaliado o estado geral do animal, coloração das mucosas conjuntivais e funções vitais (temperatura corporal, freqüência cardíaca, freqüência respiratória e movimentos rumenais).

\subsubsection{Abate e necrópsia}

Os animais foram abatidos respeitando-se os princípios de abate humanitário (insensibilização por concussão) e necropsiados. Os linfonodos submandibulares, mediastínicos e mesentéricos foram retirados independentemente de apresentarem lesões visíveis. Os demais órgãos (pulmões, fígado, baço, rins e intestinos) foram examinados e, em caso de lesões sugestivas de tuberculose, estas foram fotografadas e colhidas. Para o encaminhamento, esses materiais foram acondicionados em sacos plásticos, identificados, congelados e enviados para o 
Laboratório de Zoonoses Bacterianas e Laboratório de Bacteriologia e Micologia pertencentes ao Departamento de Medicina Veterinária Preventiva e Saúde Animal (VPS) da Faculdade de Medicina Veterinária e Zootecnia da Universidade de São Paulo (FMVZ/USP), onde foram realizadas as análises.

Durante o processamento bacteriológico foram retirados fragmentos para os exames histopatológicos fixados em solução de formol a $10 \%$ e enviados para o laboratório de Patologia Animal do Departamento de Patologia Animal (VPT) da FMVZ/USP.

\subsubsection{Exames laboratoriais}

Para 0 isolamento de micobactérias o material foi descontaminado empregando-se a técnica de Petroff (CENTRO PANAMERICANO DE ZOONOSIS, 1988) e semeados nos meios de Stonenbrink e Löwenstein- Jensen. Entre três e cinco dias após a semeadura, os tubos com meio de Stonebrink tiveram a tampa de algodão hidrófobo queimada e foram fechados com rolha de cortiça para criação de ambiente de microaerofilia. Os tubos foram mantidos na posição horizontal, em estufa a $37^{\circ} \mathrm{C}$ e submetidos à leituras semanais para visualização da presença de colônias bacterianas. As colônias isoladas foram submetidas à coloração de ZiehlNeelsen (CENTRO PANAMERICANO DE ZOONOSIS, 1988) e uma vez confirmada a característica de BAAR foram repicadas e enviadas para tipificação genética. Após a oitava semana, os tubos negativos foram descartados.

Para $\mathrm{o}$ isolamento de outras bactérias os fragmentos colhidos foram mergulhados em álcool etílico $96^{\circ} \mathrm{GL}$ e flambados, procedimento repetido por três vezes. Em seguida foram triturados em graal estéril com solução fisiológica e areia estéreis, para semeadura em caldo infusão cérebro-coração $(\mathrm{BHI})$, ágar sangue de carneiro (5\%) e ágar MacConkey, com incubação a $37^{\circ} \mathrm{C}$ em ambiente de aerobiose por 24 e 48 horas. Após 24 a 48 horas as amostras semeadas em caldo BHI também foram cultivadas em ágar sangue de carneiro (5\%) e ágar Mac Conkey, por 24 e 48 horas a $37^{\circ} \mathrm{C}$, em ambiente de aerobiose. Os microrganismos isolados foram identificados de acordo com os critérios de Krieg e Holt (1994) e Murray 
(1999). Para efeito de diagnóstico diferencial, priorizou-se nesta etapa o isolamento de Corynebacterium pseudotuberculosis, agente da linfadenite caseosa.

\subsubsection{Histopatológico}

As amostras foram colocadas em refrigeração $\left(4\right.$ a $\left.8^{\circ} \mathrm{C}\right)$ durante 24 horas e em seguida foram mantidas à temperatura ambiente até serem submetidas às técnicas rotineiras de desidratação, diafanização e inclusão em parafina. Foram utilizadas as técnicas de coloração Hematoxilina-Eosina e Ziehl-Neelsen. Durante a leituras das lâminas foram considerados positivos para micobactérias os materiais com presença de granuloma e coloração de Ziehl-Neelsen positiva e negativos os materiais que não apresentaram nenhuma alteração histopatológica ou que tenham apresentado apenas necrose, calcificação, inflamação crônica ou necrose e calcificação e coloração de Ziehl-Neelsen negativa .

\subsubsection{Identificação de micobactérias}

Os isolamentos obtidos foram identificados pela Dra. Erica Chimara da Seção de Microbiologia - Setor de Micobactérias do Instituto Adolfo Lutz de São Paulo, pelo método de PRA (PCR-Restriction Enzyme Analysis).

\subsubsection{Obtenção do DNA}

Uma alçada de colônias de micobactérias foi suspensa em $500 \mu$ l água estéril, fervida por dez minutos e congelada a $-20^{\circ} \mathrm{C}$ por pelo menos 18 horas (CHIMARA et al., 2004) 


\subsubsection{PCR Restriction Enzyme Pattern Anaysis (PRA)}

Esta técnica de identificação por PCR (TELENTI et al., 1993) consiste na amplificação de um fragmento do gene $h s p 65$, seguida de digestão com duas enzimas de restrição (Haelll e BstEII). As condições utilizadas para a PCR foram: 50 $\mathrm{mM} \mathrm{KCl}, 10 \mathrm{mM}$ Tris- $\mathrm{HCl}$ ( $\mathrm{pH}$ 8.3), $1,5 \mathrm{mM} \mathrm{MgCl}_{2}, 10 \%$ glicerol, $200 \mu \mathrm{M}$ dNTPs 0,5 $\mu \mathrm{M}$ de cada iniciador (Tb11: 5'-ACCAACGATGGTGTGTCCAT e Tb 12: 5'CTTGTCGAACCGCATACCCT) e 1,25 unidades de Taq polimerase. As reações foram realizadas em tubos de polipropileno num volume final de $50 \mu \mathrm{L}$ e submetidas a um ciclo de desnaturação inicial a $95^{\circ} \mathrm{C}$ por dez minutos, seguido de 45 ciclos de amplificação com um minuto a $95^{\circ} \mathrm{C}$, um minuto a $60^{\circ} \mathrm{C}$ e um minuto a $72^{\circ} \mathrm{C}$ e um ciclo de extensão final $\mathrm{a}^{\circ} \mathrm{C} \mathrm{C}$ por sete minutos.

As reações enzimáticas foram realizadas num volume final de $20 \mu \mathrm{L}$ da seguinte maneira: $2 \mu \mathrm{L}$ de água, $2 \mu \mathrm{L}$ de tampão enzima, $1 \mu \mathrm{L}$ de enzima e $15 \mu \mathrm{L}$ do produto de PCR. No caso das digestões com BstEll a incubação foi efetuada a $60^{\circ} \mathrm{C}$ por aproximadamente quatro horas e no caso das digestões procedidas com Haelll a incubação foi realizada a $37^{\circ} \mathrm{C}$ por aproximadamente três horas.

As amostras digeridas foram aplicadas em gel de agarose $4 \%$, submetidas à eletroforese com 100 volts por aproximadamente duas horas e visualizadas em aparelho transiluminador, após serem coradas com brometo de etídio. Foram utilizados marcadores moleculares (25bp e 50bp ladder - Gibco/BRL) para o cálculo dos tamanhos das bandas obtidas.

Os padrões de restrição obtidos após digestão foram analisados conforme Devallois et al. (1997) e pelo site PRASITE (http://app.chuv.ch/prasite/index/html).

\subsubsection{Análise estatística}

A verificação da hipótese de associação entre as reações ao Teste Comparativo Cervical e a positividade para micobactérias (dada pelo isolamento e histopatológico) foi efetuada pelo teste exato de Fisher, com o nível de significância adotado de 0,05 (SIEGEL, 1981). 


\section{$4 \quad$ RESULTADOS}

Os resultados das leituras dos testes tuberculínicos por propriedade são apresentados nos apêndices A e B. Os resultados do Teste Cervical Simples segundo os parâmetros sugeridos por Cyrillo (2006) estão sintetizados na tabela 1.

Tabela 1 - Ovinos de duas propriedades da região de Pindamonhangaba - SP, Brasil submetidos ao diagnóstico intradérmico de tuberculina pelo Teste Cervical Simples (TCS) segundo a propriedade e a natureza do resultado obtido - São Paulo - 2007

\begin{tabular}{ccccc}
\hline Propriedade & Negativo & Inconclusivo & Positivo & TOTAL \\
\hline A & 33 & 144 & 73 & $\mathbf{2 5 0}$ \\
B & 54 & 41 & 8 & $\mathbf{1 0 3}$ \\
\hline TOTAL & $\mathbf{8 7}$ & $\mathbf{1 8 5}$ & $\mathbf{8 1}$ & $\mathbf{3 5 3}$ \\
\hline
\end{tabular}

Dos 353 animais, $87(24,7 \%)$ foram considerados negativos, 185 (52,4\%) inconclusivos e $81(22,9 \%)$ positivos ao TCS. Dos 87 negativos, 33 (37,93\%) eram da propriedade A e 54 (62,07\%) eram da propriedade B; dos 185 inconclusivos, 144 $(77,83 \%)$ eram da propriedade A e $41(22,16 \%)$ da propriedade B e dos 81 positivos, $73(90,12 \%)$ eram da propriedade A e $8(9,87 \%)$ da propriedade B.

Os resultados do Teste Cervical Comparativo segundo os parâmetros propostos por Cyrillo (2006) estão sintetizados na tabela 2.

Tabela 2 - Ovinos de duas propriedades da região de Pindamonhangaba - SP, Brasil submetidos ao diagnóstico intradérmico de tuberculina pelo Teste Cervical Comparativo (TCC) segundo a propriedade e a natureza do resultado obtido - São Paulo - 2007

\begin{tabular}{cccc}
\hline Propriedade & $\Delta$ PPD Bv $-\Delta$ PPD Av $\geq 0^{1}$ & $\Delta$ PPD Bv $-\Delta$ PPD Av $<0^{2}$ & TOTAL \\
\hline$A$ & 39 & 211 & 250 \\
$B$ & 6 & 97 & 103 \\
\hline TOTAL & 45 & 308 & 353
\end{tabular}

': Reação a tuberculina bovina maior que a aviária

2. Reação a tuberculina bovina menor que a aviária 
Os 353 animais $(100,0 \%)$ apresentaram reação negativa ao TCC. Destes, 45 $(12,71 \%)$ apresentaram reação a tuberculina bovina maior que a aviária ( $\triangle P P D$ Bv $\triangle \mathrm{PPD} A v \geq 0)$ e $308(87,25 \%)$ reação a tuberculina bovina menor que a aviária $(\triangle \mathrm{PPD} B v-\triangle \mathrm{PPD} \mathrm{Av}<0)$.

A distribuição dos animais selecionados para abate é apresentada na tabela 3.

Tabela 3 - Ovinos de duas propriedades da região de Pindamonhangaba - SP, Brasil submetidos ao diagnóstico de tuberculose pelo Teste Cervical Comparativo (TCC) segundo a propriedade e avaliação do resultado obtido - São Paulo - 2007

\begin{tabular}{cccc}
\hline Propriedade & $\Delta$ PPD Bv $-\Delta$ PPD Av $\geq 0^{1}$ & $\Delta$ PPD Bv $-\Delta$ PPD Av $<0^{2}$ & TOTAL \\
\hline $\boldsymbol{A}$ & 27 & 18 & 45 \\
$B$ & 4 & 8 & 12 \\
\hline TOTAL & $\mathbf{3 1}$ & $\mathbf{2 6}$ & $\mathbf{5 7}$ \\
\hline
\end{tabular}

': Reação a tuberculina bovina maior que a aviária

2: Reação a tuberculina bovina menor que a aviária

Dos 57 animais abatidos, 31 (53,45\%) apresentaram reação a tuberculina bovina maior que a aviária ( $\triangle \mathrm{PPD} B v-\triangle \mathrm{PPD} A v \geq 0)$ e $26(45,61 \%)$ reação a tuberculina bovina menor que a aviária ( $\triangle P P D B v-\triangle P P D A v<0) .45$ animais $(78,94 \%)$ eram provenientes da propriedade A e $12(21,06 \%)$ da propriedade B. Dos 31 animais com a tuberculina bovina maior que a aviária, $27(87,09 \%)$ eram da propriedade A e $4(12,01 \%)$ da propriedade B. Dos 26 animais com a tuberculina bovina menor que a aviária, $18(69,23 \%)$ eram da propriedade A e $8(30,77 \%)$ da propriedade B.

A observação clínica dos 57 animais selecionados para o abate está detalhada no Apêndice $C$, os valores observados estão dentro dos limites fisiológicos de variação estabelecidos para a espécie ovina (SMITH; SHERMAN, 1994; PUGH, 2005). A relação dos materiais colhidos dos animais abatidos está apresentada na tabela 4 . 
Tabela 4 - Ovinos de duas propriedades da região de Pindamonhangaba - SP, Brasil segundo identificação do animal, a propriedade, natureza do resultado dos testes imunoalérgicos, lesões macroscópicas encontradas e órgãos colhidos na necrópsia - São Paulo - 2007

(Continua)

\begin{tabular}{|c|c|c|c|c|c|}
\hline Animal & Propr. & TCS & $\begin{array}{c}\text { TCC } \\
(\mathrm{mm})\end{array}$ & Lesões & Material Coletado \\
\hline 20 & A & Inconclusivo & 0,1 & - & LSM, LMD \\
\hline 33 & A & Positivo & 0,1 & Fígado e Intestino & LSM, LMD, LMS, Fígado e Intestino \\
\hline 38 & $\mathrm{~B}$ & Inconclusivo & $-0,6$ & - & LSM, LMD e LMS \\
\hline 48 & A & Inconclusivo & $-0,8$ & - & LSM, LMD e LMS \\
\hline 59 & $\mathrm{~B}$ & Inconclusivo & $-0,5$ & - & LSM, LMD e LMS \\
\hline 72 & A & Inconclusivo & $-1,3$ & Fígado & LSM, LMD, LMS e Fígado \\
\hline 84 & A & Negativo & 0,2 & - & LSM, LMD e LMS \\
\hline 129 & A & Positivo & 0,2 & LSM & LSM com lesão e LMS \\
\hline 131 & A & Inconclusivo & 0,1 & - & LSM, LMD e LMS \\
\hline 168 & A & Inconclusivo & 0,2 & - & LSM, LMD e LMS \\
\hline 176 & A & Inconclusivo & 0,3 & - & LSM, LMD e LMS \\
\hline 182 & B & Negativo & 0,3 & Fígado e LMD & LSM, LMD com lesão, LMS e Fígado \\
\hline 197 & A & Inconclusivo & 0,3 & Fígado e LSM & LSM com lesão, LMD, LMS e Fígado \\
\hline 206 & A & Inconclusivo & 0,5 & - & LSM, LMD e LMS \\
\hline 279 & A & Positivo & 0,3 & - & LSM, LMD e LMS \\
\hline 294 & A & Inconclusivo & $-0,3$ & - & LSM, LMD e LMS \\
\hline 304 & A & Inconclusivo & 0,1 & Fígado & LSM, LMD e Fígado \\
\hline 342 & $A$ & Negativo & 0,3 & Pulmão, gl. Mam. & LSM, LMD, LMS, pulmão, gl. Mam. \\
\hline 352 & $\mathrm{~B}$ & Negativo & 0,3 & LMD & LSM, LMD com lesão e LMS \\
\hline 353 & $\mathrm{~B}$ & Inconclusivo & $-2,2$ & - & LSM, LMD e LMS \\
\hline 362 & $\mathrm{~B}$ & Inconclusivo & $-4,9$ & - & LSM, LMD e LMS \\
\hline 449 & A & Inconclusivo & $-0,4$ & - & LSM, LMD e LMS \\
\hline 478 & A & Positivo & 0,1 & - & LSM, LMD e LMS \\
\hline 485 & $\mathrm{~B}$ & Negativo & 0,6 & - & LSM, LMD e LMS \\
\hline 486 & A & Inconclusivo & 0,9 & - & LSM, LMD e LMS \\
\hline 516 & A & Inconclusivo & 0,9 & - & LSM, LMD e LMS \\
\hline 533 & $\mathrm{~B}$ & Inconclusivo & 0,5 & Fígado e pulmão & LSM, LMD, LMS, Fígado e pulmão \\
\hline 552 & A & Inconclusivo & 0,5 & - & LSM, LMS \\
\hline 580 & A & Negativo & 0,1 & - & LSM, LMD e LMS \\
\hline 587 & A & Negativo & $-0,1$ & & LSM, LMD e LMS \\
\hline 599 & A & Inconclusivo & 0,6 & - & LSM, LMD e LMS \\
\hline 605 & $\mathrm{~B}$ & Inconclusivo & $-0,2$ & - & LSM, LMD e LMS \\
\hline 609 & A & Inconclusivo & $-6,1$ & - & LSM, LMD e LMS \\
\hline 610 & $\mathrm{~B}$ & Inconclusivo & $-3,4$ & - & LSM, LMD e LMS \\
\hline 648 & $A$ & Negativo & $-0,7$ & - & LSM, LMD e LMS \\
\hline 690 & $A$ & Inconclusivo & 0,5 & - & LSM, LMD e LMS \\
\hline 702 & A & Negativo & 0,3 & - & LSM, LMS \\
\hline 709 & $\mathrm{~B}$ & Negativo & $-0,4$ & - & LSM, LMD e LMS \\
\hline 721 & $\mathrm{~B}$ & Negativo & $-1,6$ & - & LSM, LMD e LMS \\
\hline
\end{tabular}


(Conclusão)

\begin{tabular}{|c|c|c|c|c|c|}
\hline Animal & Propr. & TCS & $\begin{array}{c}\text { TCC } \\
(\mathrm{mm})\end{array}$ & Lesões & Material Coletado \\
\hline 727 & A & Positivo & 0,6 & - & LSM, LMD e LMS \\
\hline 737 & $A$ & Positivo & 0,4 & LSM & LSM com lesão, LMD e LMS \\
\hline 759 & A & Inconclusivo & $-0,9$ & - & LSM, LMD e LMS \\
\hline 762 & $\mathrm{~B}$ & Negativo & $-0,2$ & - & LSM, LMD e LMS \\
\hline 813 & $A$ & Inconclusivo & $-0,2$ & - & LSM, LMD e LMS \\
\hline 822 & $A$ & Inconclusivo & 0,3 & - & LSM, LMD e LMS \\
\hline 823 & $A$ & Inconclusivo & 0,1 & - & LSM, LMD e LMS \\
\hline 827 & A & Negativo & $-0,1$ & - & LSM, LMD e LMS \\
\hline 871 & $\mathrm{~B}$ & Inconclusivo & $-1,0$ & - & LSM, LMD e LMS \\
\hline 882 & A & Inconclusivo & $-0,6$ & - & LSM, LMD e LMS \\
\hline 889 & A & Inconclusivo & $-0,9$ & - & LSM, LMD e LMS \\
\hline 892 & $A$ & Inconclusivo & 0,2 & - & LSM, LMD e LMS \\
\hline 908 & A & Inconclusivo & 0,1 & - & LSM e LMS \\
\hline 921 & $A$ & Inconclusivo & 0,5 & - & LSM, LMD e LMS \\
\hline 1026 & $A$ & Negativo & $-1,0$ & - & LSM, LMD e LMS \\
\hline 1441 & $A$ & Inconclusivo & $-0,5$ & - & LSM, LMD e LMS \\
\hline 00\# & A & Inconclusivo & $-1,1$ & - & LSM, LMD e LMS \\
\hline SB1 & $A$ & Negativo & $-1,0$ & Fígado e Intestino & LSM, LMS, Fígado e Intestino \\
\hline
\end{tabular}

Propr.: Propriedade

TCS: Teste Cervical Simples

TCC: Resultado, em mm, da diferença $\triangle P P D B v-\triangle P P D A v$

-: ausência de lesão visível

LSM: linfonodos submandibulares
LMD: linfonodos mediastínicos

LMS: linfonodos mesentéricos

GI. Mam.: Glândula Mamária

Dos 57 animais abatidos 11 (19,29\%) apresentaram lesões macroscópicas sugestivas de tuberculose sendo seis $(54,54 \%)$ com lesões simultâneas em dois órgãos. Das 17 lesões encontradas sete $(41,17 \%)$ eram de fígado, três $(17,64 \%)$ de linfonodo submandibular, duas $(11,76 \%)$ de intestino, pulmão e linfonodo mediastínico e uma $(5,88 \%)$ de glândula mamária. Dos seis animais com lesão em dois órgãos, cinco $(83,33 \%)$ as tinham no fígado e outro órgão (dois no Intestino, um no linfonodo submandibular, um no mediastino e um no pulmão) e um $(16,66 \%)$ tinha lesão no pulmão e na glândula mamária. As figuras 4, 5 e 6 são lesões encontradas nos animais 33 e 129. 


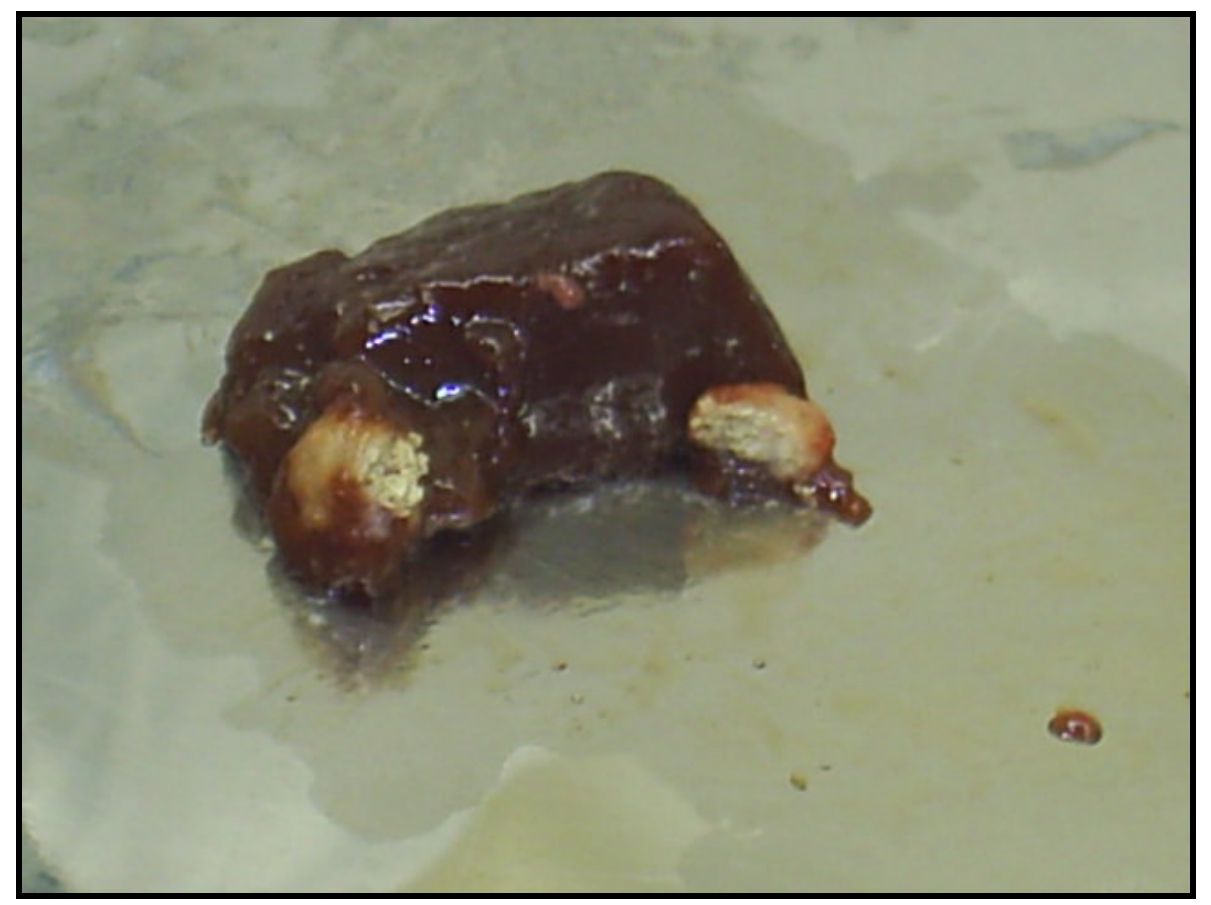

Figura 4 - Fotografia de lesão no fígado do animal 33. Notar o aspecto calcificado da lesão - São Paulo - 2007

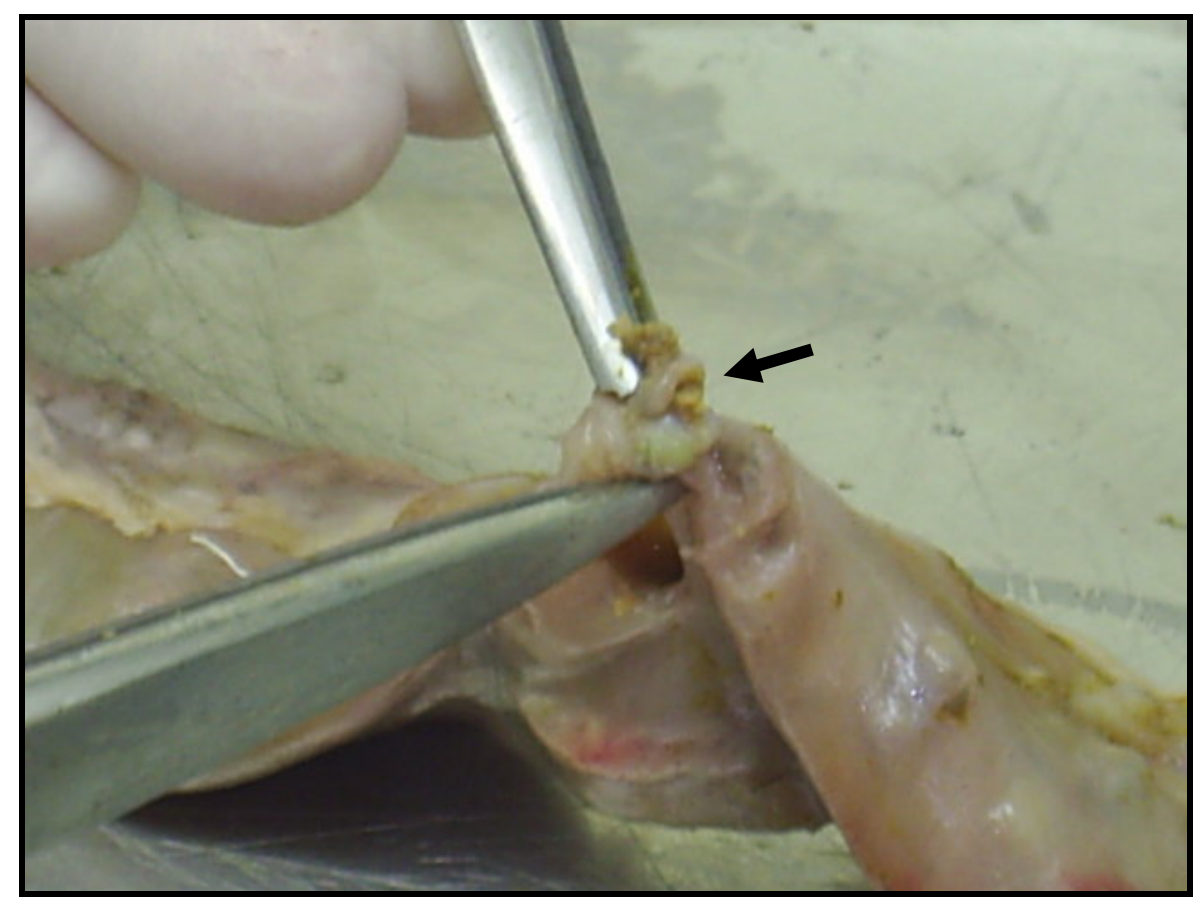

Figura 5 - Fotografia de lesão no intestino do animal 33. Notar o conteúdo caseoso da lesão (seta) São Paulo - 2007 


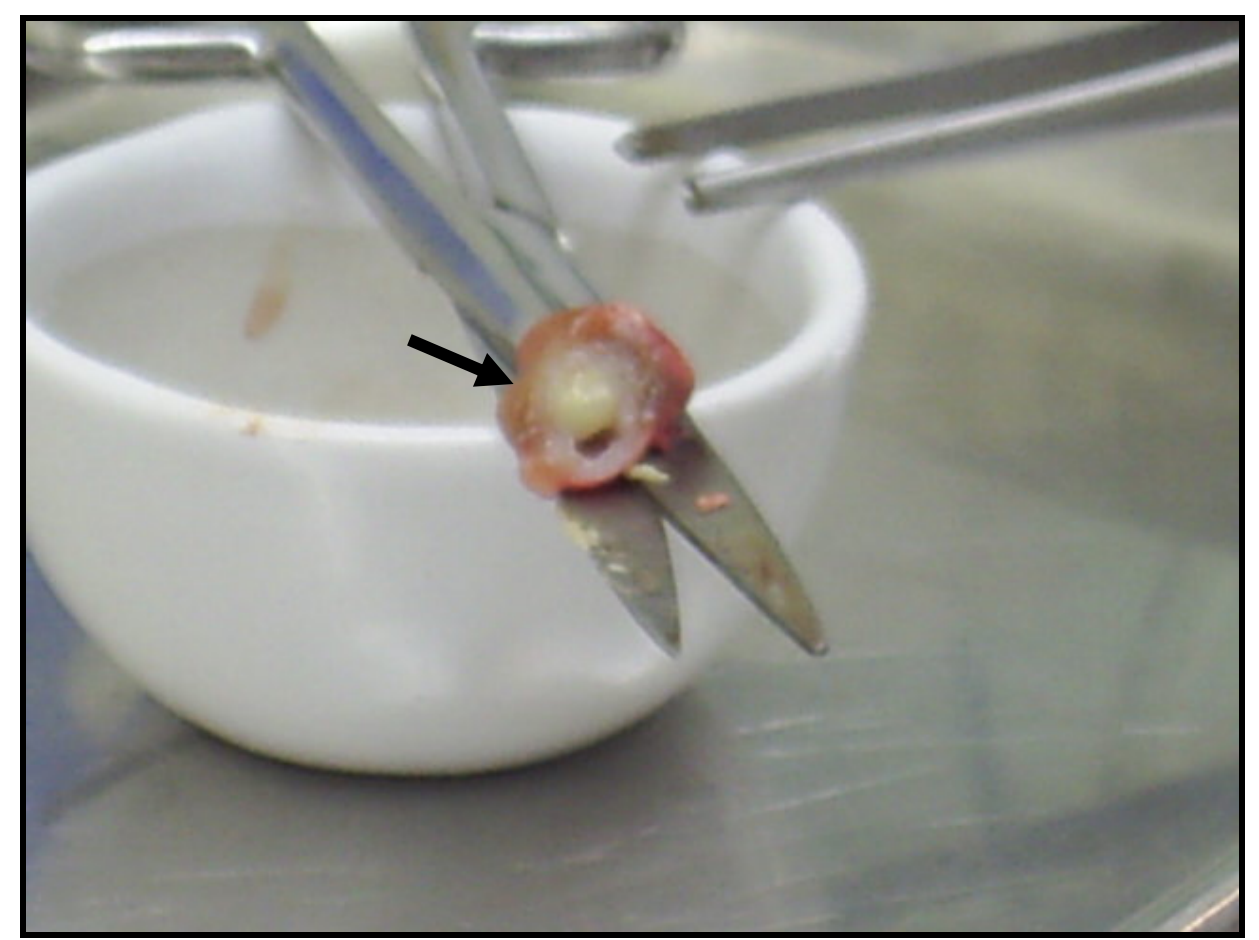

Figura 6 - Fotografia de lesão no linfonodo submandibular do animal 129. Notar o conteúdo caseoso da lesão (seta) - São Paulo - 2007

Os resultados dos exames bacteriológicos e da tipificação genética para micobactérias isoladas dos animais abatidos são apresentados na tabela 5 . 
RESULTADOS

Tabela 5 - Ovinos de duas propriedades da região de Pindamonhangaba - SP, Brasil abatidos e necropsiados com órgãos e tecidos submetidos a cultivos para isolamento de micobactérias ou outros microorganismos segundo: identificação do animal e propriedade, tipo de cultivo efetuado, órgão ou tecido examinado e a natureza do resultado obtido - São Paulo - 2007

\begin{tabular}{|c|c|c|c|c|c|c|c|c|c|c|c|c|c|c|c|c|c|c|c|c|c|c|c|}
\hline \multirow{3}{*}{ Animal } & \multirow{3}{*}{ Prop. } & \multirow{2}{*}{\multicolumn{7}{|c|}{$\begin{array}{l}\text { Bacteriológico - TB } \\
\text { Löwenstein-Jensen }\end{array}$}} & \multirow{2}{*}{\multicolumn{7}{|c|}{$\begin{array}{c}\text { Bacteriológico - TB } \\
\text { Stonebrink }\end{array}$}} & \multirow{2}{*}{\multicolumn{7}{|c|}{ Bacteriológico }} & \multirow{3}{*}{ Identificação } \\
\hline & & & & & & & & & & & & & & & & & & & & & & & \\
\hline & & SM & MD & MS & Fig. & Pul. & Int. & Outros & SM & MD & MS & Fig. & Pul. & Int. & Outros & SM & MD & MS & Fig. & Pul. & Int. & Outros & \\
\hline 20 & A & - & - & $\mathrm{N}$ & $\mathrm{N}$ & $\mathrm{N}$ & $\mathrm{N}$ & $\mathrm{N}$ & - & - & $\mathrm{N}$ & $\mathrm{N}$ & $\mathrm{N}$ & $\mathrm{N}$ & $\mathrm{N}$ & - & - & $\mathrm{N}$ & $\mathrm{N}$ & $\mathrm{N}$ & $\mathrm{N}$ & $\mathrm{N}$ & $\ldots$ \\
\hline 33 & A & - & - & - & - & $\mathrm{N}$ & - & $\mathrm{N}$ & - & - & - & - & $\mathrm{N}$ & - & $\mathrm{N}$ & - & - & - & - & $\mathrm{N}$ & - & $\mathrm{N}$ & $\ldots$ \\
\hline 38 & B & - & - & - & $\mathrm{N}$ & $\mathrm{N}$ & $\mathrm{N}$ & $\mathrm{N}$ & - & - & - & $\mathrm{N}$ & $\mathrm{N}$ & $\mathrm{N}$ & $\mathrm{N}$ & - & - & - & $\mathrm{N}$ & $\mathrm{N}$ & $\mathrm{N}$ & $\mathrm{N}$ & $\ldots$ \\
\hline 48 & A & - & - & - & $\mathrm{N}$ & $\mathrm{N}$ & N & $\mathrm{N}$ & - & - & - & $\mathrm{N}$ & N & $\mathrm{N}$ & $\mathrm{N}$ & - & - & - & $\mathrm{N}$ & $\mathrm{N}$ & $\mathrm{N}$ & $\mathrm{N}$ & $\ldots$ \\
\hline 59 & B & - & - & - & $\mathrm{N}$ & $\mathrm{N}$ & $\mathrm{N}$ & $\mathrm{N}$ & - & - & - & $\mathrm{N}$ & $\mathrm{N}$ & $\mathrm{N}$ & $\mathrm{N}$ & CT & $\mathrm{CT}$ & - & $\mathrm{N}$ & $\mathrm{N}$ & $\mathrm{N}$ & $\mathrm{N}$ & $\ldots$ \\
\hline 72 & $A$ & - & - & - & - & $\mathrm{N}$ & $\mathrm{N}$ & $\mathrm{N}$ & - & - & - & - & $\mathrm{N}$ & $\mathrm{N}$ & $\mathrm{N}$ & - & - & - & CT & $\mathrm{N}$ & $\mathrm{N}$ & $\mathrm{N}$ & $\ldots$ \\
\hline 84 & A & - & - & - & $\mathrm{N}$ & $\mathrm{N}$ & $\mathrm{N}$ & N & - & - & - & $\mathrm{N}$ & $\mathrm{N}$ & $\mathrm{N}$ & $\mathrm{N}$ & - & - & - & $\mathrm{N}$ & $\mathrm{N}$ & $\mathrm{N}$ & $\mathrm{N}$ & $\ldots$ \\
\hline 129 & $A$ & $14 d$ & $\mathrm{~N}$ & - & $\mathrm{N}$ & $\mathrm{N}$ & $\mathrm{N}$ & $\mathrm{N}$ & - & $\mathrm{N}$ & - & $\mathrm{N}$ & $\mathrm{N}$ & $\mathrm{N}$ & $\mathrm{N}$ & Cps. & $\mathrm{N}$ & - & $\mathrm{N}$ & $\mathrm{N}$ & $\mathrm{N}$ & $\mathrm{N}$ & M. flavescens 1 \\
\hline 131 & $A$ & - & $14 d$ & - & $\mathrm{N}$ & $\mathrm{N}$ & $\mathrm{N}$ & $N$ & - & - & - & $\mathrm{N}$ & $\mathrm{N}$ & $\mathrm{N}$ & $\mathrm{N}$ & - & - & - & $\mathrm{N}$ & $\mathrm{N}$ & $\mathrm{N}$ & $\mathrm{N}$ & M. flavescens 1 \\
\hline 168 & $A$ & - & - & - & $\mathrm{N}$ & $\mathrm{N}$ & $\mathrm{N}$ & N & - & - & - & $\mathrm{N}$ & $\mathrm{N}$ & $\mathrm{N}$ & $\mathrm{N}$ & - & - & - & $\mathrm{N}$ & $\mathrm{N}$ & $\mathrm{N}$ & $\mathrm{N}$ & $\ldots$ \\
\hline 176 & A & - & - & - & $\mathrm{N}$ & $\mathrm{N}$ & $\mathrm{N}$ & $\mathrm{N}$ & - & - & - & $\mathrm{N}$ & $\mathrm{N}$ & $\mathrm{N}$ & $\mathrm{N}$ & - & - & - & $\mathrm{N}$ & $\mathrm{N}$ & $\mathrm{N}$ & $\mathrm{N}$ & $\ldots$ \\
\hline 182 & B & - & - & - & - & $\mathrm{N}$ & $\mathrm{N}$ & $\mathrm{N}$ & - & - & - & - & $\mathrm{N}$ & $\mathrm{N}$ & $\mathrm{N}$ & CT & - & - & CT & $\mathrm{N}$ & $\mathrm{N}$ & $\mathrm{N}$ & $\ldots$ \\
\hline 197 & A & $14 d$ & - & $14 d$ & - & $\mathrm{N}$ & $\mathrm{N}$ & N & - & - & - & - & $\mathrm{N}$ & $\mathrm{N}$ & $\mathrm{N}$ & - & - & - & - & $\mathrm{N}$ & $\mathrm{N}$ & $\mathrm{N}$ & M. flavescens 1 \\
\hline 206 & A & - & - & - & $\mathrm{N}$ & $\mathrm{N}$ & $\mathrm{N}$ & $\mathrm{N}$ & - & - & - & $\mathrm{N}$ & $\mathrm{N}$ & $\mathrm{N}$ & $\mathrm{N}$ & - & - & - & $\mathrm{N}$ & $\mathrm{N}$ & $\mathrm{N}$ & $\mathrm{N}$ & $\ldots$ \\
\hline 279 & A & - & - & - & $\mathrm{N}$ & $\mathrm{N}$ & $\mathrm{N}$ & $\mathrm{N}$ & - & - & - & $\mathrm{N}$ & $\mathrm{N}$ & $\mathrm{N}$ & $\mathrm{N}$ & - & - & - & $\mathrm{N}$ & $\mathrm{N}$ & $\mathrm{N}$ & $\mathrm{N}$ & $\ldots$ \\
\hline 294 & $A$ & - & - & - & $\mathrm{N}$ & $\mathrm{N}$ & $\mathrm{N}$ & $\mathrm{N}$ & - & - & - & $\mathrm{N}$ & $\mathrm{N}$ & $\mathrm{N}$ & $\mathrm{N}$ & - & - & - & $\mathrm{N}$ & $\mathrm{N}$ & $\mathrm{N}$ & $\mathrm{N}$ & $\ldots$ \\
\hline 304 & $A$ & - & - & $\mathrm{N}$ & - & $\mathrm{N}$ & $\mathrm{N}$ & $\mathrm{N}$ & - & - & $\mathrm{N}$ & - & $\mathrm{N}$ & $\mathrm{N}$ & $\mathrm{N}$ & - & - & $\mathrm{N}$ & - & $\mathrm{N}$ & $\mathrm{N}$ & $\mathrm{N}$ & $\ldots$ \\
\hline 342 & A & - & - & - & $\mathrm{N}$ & - & $\mathrm{N}$ & g. mam. & - & - & - & $\mathrm{N}$ & - & $\mathrm{N}$ & g. mam. & Cps. & - & - & $\mathrm{N}$ & - & $\mathrm{N}$ & g. Mam. & $\ldots$ \\
\hline 352 & B & - & $21 d$ & - & $\mathrm{N}$ & $\mathrm{N}$ & $\mathrm{N}$ & $\mathrm{N}$ & - & - & - & $\mathrm{N}$ & $\mathrm{N}$ & $\mathrm{N}$ & $\mathrm{N}$ & - & CT & - & $\mathrm{N}$ & $\mathrm{N}$ & $\mathrm{N}$ & $\mathrm{N}$ & M. flavescens 1 \\
\hline 353 & B & - & - & - & $\mathrm{N}$ & $\mathrm{N}$ & $\mathrm{N}$ & $\mathrm{N}$ & - & - & - & $\mathrm{N}$ & $\mathrm{N}$ & $\mathrm{N}$ & $\mathrm{N}$ & - & CT & - & $\mathrm{N}$ & $\mathrm{N}$ & $\mathrm{N}$ & $\mathrm{N}$ & $\ldots$ \\
\hline 362 & B & - & - & - & $\mathrm{N}$ & $\mathrm{N}$ & $\mathrm{N}$ & $\mathrm{N}$ & - & - & - & $\mathrm{N}$ & $\mathrm{N}$ & $\mathrm{N}$ & $\mathrm{N}$ & - & - & - & $\mathrm{N}$ & $\mathrm{N}$ & $\mathrm{N}$ & $\mathrm{N}$ & $\ldots$ \\
\hline 449 & A & - & - & - & $\mathrm{N}$ & $\mathrm{N}$ & $\mathrm{N}$ & $\mathrm{N}$ & - & - & - & $\mathrm{N}$ & $\mathrm{N}$ & $\mathrm{N}$ & $\mathrm{N}$ & - & - & - & $\mathrm{N}$ & $\mathrm{N}$ & $\mathrm{N}$ & $\mathrm{N}$ & $\ldots$ \\
\hline 478 & $A$ & - & - & - & $\mathrm{N}$ & $\mathrm{N}$ & $\mathrm{N}$ & $\mathrm{N}$ & - & - & - & $\mathrm{N}$ & $\mathrm{N}$ & $\mathrm{N}$ & $\mathrm{N}$ & - & - & - & $\mathrm{N}$ & $\mathrm{N}$ & $\mathrm{N}$ & $\mathrm{N}$ & $\ldots$ \\
\hline 485 & B & - & - & - & $\mathrm{N}$ & $\mathrm{N}$ & $\mathrm{N}$ & $\mathrm{N}$ & - & - & - & $\mathrm{N}$ & $\mathrm{N}$ & $\mathrm{N}$ & $\mathrm{N}$ & - & CT & - & $\mathrm{N}$ & $\mathrm{N}$ & $\mathrm{N}$ & $\mathrm{N}$ & $\ldots$ \\
\hline
\end{tabular}




\begin{tabular}{|c|c|c|c|c|c|c|c|c|c|c|c|c|c|c|c|c|c|c|c|c|c|c|c|}
\hline \multirow{3}{*}{ Animal } & \multirow{3}{*}{ Prop. } & \multirow{2}{*}{\multicolumn{7}{|c|}{$\begin{array}{l}\text { Bacteriológico - TB } \\
\text { Löwenstein-Jensen }\end{array}$}} & \multirow{2}{*}{\multicolumn{7}{|c|}{$\begin{array}{c}\text { Bacteriológico - TB } \\
\text { Stonebrink }\end{array}$}} & \multirow{2}{*}{\multicolumn{7}{|c|}{ Bacteriológico }} & \multirow{3}{*}{ Identificação } \\
\hline & & & & & & & & & & & & & & & & & & & & & & & \\
\hline & & SM & MD & MS & Fig. & Pul. & Int. & Outros & SM & MD & MS & Fig. & Pul. & Int. & Outros & SM & MD & MS & Fig. & Pul. & Int. & Outros & \\
\hline 486 & $\bar{A}$ & $\overline{-}$ & $\overline{-}$ & $\overline{-}$ & $\bar{N}$ & $\bar{N}$ & $\bar{N}$ & $\mathrm{~N}$ & $\overline{-}$ & - & $\overline{-}$ & $\bar{N}$ & $\bar{N}$ & $\mathrm{~N}$ & $\bar{N}$ & $\overline{-}$ & $\overline{-}$ & $\overline{-}$ & $\mathrm{N}$ & $\mathrm{N}$ & $\mathrm{N}$ & $\mathrm{N}$ & $\ldots$ \\
\hline 516 & $A$ & - & - & - & $\mathrm{N}$ & $\mathrm{N}$ & $\mathrm{N}$ & $\mathrm{N}$ & - & - & - & $\mathrm{N}$ & $\mathrm{N}$ & $\mathrm{N}$ & $\mathrm{N}$ & - & - & - & $\mathrm{N}$ & $\mathrm{N}$ & $\mathrm{N}$ & $\mathrm{N}$ & $\ldots$ \\
\hline 533 & B & - & - & - & - & - & $N$ & $\mathrm{~N}$ & - & - & - & - & - & $\mathrm{N}$ & $\mathrm{N}$ & - & - & $\mathrm{CT}$ & - & $\mathrm{CT}$ & $\mathrm{N}$ & $\mathrm{N}$ & $\ldots$ \\
\hline 552 & A & - & $\mathrm{N}$ & - & $\mathrm{N}$ & $\mathrm{N}$ & $\mathrm{N}$ & $\mathrm{N}$ & - & $\mathrm{N}$ & - & $\mathrm{N}$ & $\mathrm{N}$ & $\mathrm{N}$ & $\mathrm{N}$ & Cps. & $\mathrm{N}$ & - & $\mathrm{N}$ & $\mathrm{N}$ & $\mathrm{N}$ & $\mathrm{N}$ & $\ldots$ \\
\hline 580 & A & - & - & - & $N$ & $\mathrm{~N}$ & $\mathrm{~N}$ & $\mathrm{~N}$ & - & - & - & $\mathrm{N}$ & $\mathrm{N}$ & $\mathrm{N}$ & $\mathrm{N}$ & - & - & - & $\mathrm{N}$ & $\mathrm{N}$ & $\mathrm{N}$ & $\mathrm{N}$ & $\ldots$ \\
\hline 587 & A & - & - & - & $\mathrm{N}$ & $\mathrm{N}$ & $\mathrm{N}$ & $\mathrm{N}$ & - & - & - & $\mathrm{N}$ & $\mathrm{N}$ & $\mathrm{N}$ & $N$ & - & - & - & $\mathrm{N}$ & $\mathrm{N}$ & $\mathrm{N}$ & $\mathrm{N}$ & $\ldots$ \\
\hline 599 & A & - & - & - & $\mathrm{N}$ & $\mathrm{N}$ & $\mathrm{N}$ & $\mathrm{N}$ & - & - & - & $\mathrm{N}$ & $\mathrm{N}$ & $\mathrm{N}$ & $N$ & - & - & - & $\mathrm{N}$ & $\mathrm{N}$ & $\mathrm{N}$ & $\mathrm{N}$ & $\ldots$ \\
\hline 605 & B & - & - & - & $\mathrm{N}$ & $\mathrm{N}$ & $\mathrm{N}$ & $\mathrm{N}$ & - & - & - & $\mathrm{N}$ & $\mathrm{N}$ & $\mathrm{N}$ & $\mathrm{N}$ & - & - & - & $\mathrm{N}$ & $\mathrm{N}$ & $\mathrm{N}$ & $\mathrm{N}$ & $\ldots$ \\
\hline 609 & A & - & - & - & $\mathrm{N}$ & $\mathrm{N}$ & $\mathrm{N}$ & $\mathrm{N}$ & - & - & - & $\mathrm{N}$ & $\mathrm{N}$ & $\mathrm{N}$ & $N$ & - & - & - & $\mathrm{N}$ & $\mathrm{N}$ & $\mathrm{N}$ & $\mathrm{N}$ & $\ldots$ \\
\hline 610 & B & - & - & - & $\mathrm{N}$ & $N$ & $N$ & $\mathrm{~N}$ & - & - & - & $N$ & $\mathrm{~N}$ & $N$ & $N$ & - & - & - & $N$ & $\mathrm{~N}$ & $\mathrm{~N}$ & $N$ & $\ldots$ \\
\hline 648 & A & - & $42 d$ & - & $N$ & - & $N$ & $\mathrm{~N}$ & - & $42 d$ & - & $\mathrm{N}$ & - & $\mathrm{N}$ & $\mathrm{N}$ & - & Cps. & - & $\mathrm{N}$ & - & $\mathrm{N}$ & $\mathrm{N}$ & C. M. tuberculosis \\
\hline 690 & A & - & $42 d$ & - & $\mathrm{N}$ & $\mathrm{N}$ & $\mathrm{N}$ & $\mathrm{N}$ & - & $42 d$ & - & $\mathrm{N}$ & $\mathrm{N}$ & $\mathrm{N}$ & $\mathrm{N}$ & - & - & - & $\mathrm{N}$ & $\mathrm{N}$ & $\mathrm{N}$ & $\mathrm{N}$ & M. kansasii 1 \\
\hline 702 & A & - & $N$ & - & $\mathrm{N}$ & $\mathrm{N}$ & $\mathrm{N}$ & $N$ & - & $\mathrm{N}$ & - & $\mathrm{N}$ & $\mathrm{N}$ & $\mathrm{N}$ & $\mathrm{N}$ & - & $N$ & - & $\mathrm{N}$ & $\mathrm{N}$ & $\mathrm{N}$ & $\mathrm{N}$ & $\ldots$ \\
\hline 709 & B & - & - & - & $\mathrm{N}$ & $\mathrm{N}$ & $\mathrm{N}$ & $\mathrm{N}$ & - & - & - & $\mathrm{N}$ & $\mathrm{N}$ & $\mathrm{N}$ & $\mathrm{N}$ & - & - & - & $\mathrm{N}$ & $\mathrm{N}$ & $\mathrm{N}$ & $\mathrm{N}$ & $\ldots$ \\
\hline 721 & B & - & - & - & $\mathrm{N}$ & $\mathrm{N}$ & $\mathrm{N}$ & $\mathrm{N}$ & - & - & - & $\mathrm{N}$ & $\mathrm{N}$ & $\mathrm{N}$ & $\mathrm{N}$ & - & CT & - & $\mathrm{N}$ & $\mathrm{N}$ & $\mathrm{N}$ & $\mathrm{N}$ & $\ldots$ \\
\hline 727 & A & - & - & $14 d$ & $\mathrm{~N}$ & $\mathrm{~N}$ & $\mathrm{~N}$ & $\mathrm{~N}$ & - & - & - & $\mathrm{N}$ & $\mathrm{N}$ & $\mathrm{N}$ & $\mathrm{N}$ & - & - & - & $\mathrm{N}$ & $\mathrm{N}$ & $\mathrm{N}$ & $\mathrm{N}$ & M. flavescens 1 \\
\hline 737 & A & - & - & - & $\mathrm{N}$ & $\mathrm{N}$ & $\mathrm{N}$ & $\mathrm{N}$ & - & - & - & $\mathrm{N}$ & $\mathrm{N}$ & $\mathrm{N}$ & $\mathrm{N}$ & - & - & - & $\mathrm{N}$ & $\mathrm{N}$ & $\mathrm{N}$ & $\mathrm{N}$ & $\ldots$ \\
\hline 759 & A & - & - & - & $\mathrm{N}$ & $\mathrm{N}$ & $\mathrm{N}$ & $\mathrm{N}$ & - & - & - & $\mathrm{N}$ & $\mathrm{N}$ & $\mathrm{N}$ & $\mathrm{N}$ & - & - & - & $\mathrm{N}$ & $\mathrm{N}$ & $\mathrm{N}$ & $\mathrm{N}$ & $\ldots$ \\
\hline 762 & B & - & - & - & $\mathrm{N}$ & $\mathrm{N}$ & $\mathrm{N}$ & $\mathrm{N}$ & - & - & - & $\mathrm{N}$ & $\mathrm{N}$ & $\mathrm{N}$ & $N$ & - & CT & - & $\mathrm{N}$ & $\mathrm{N}$ & $\mathrm{N}$ & $\mathrm{N}$ & $\ldots$ \\
\hline 813 & A & - & - & - & $\mathrm{N}$ & $\mathrm{N}$ & $\mathrm{N}$ & $\mathrm{N}$ & - & - & - & $\mathrm{N}$ & $\mathrm{N}$ & $\mathrm{N}$ & $\mathrm{N}$ & - & - & - & $\mathrm{N}$ & $\mathrm{N}$ & $\mathrm{N}$ & $\mathrm{N}$ & $\ldots$ \\
\hline 822 & A & - & - & - & $\mathrm{N}$ & $\mathrm{N}$ & $\mathrm{N}$ & $\mathrm{N}$ & - & - & - & $\mathrm{N}$ & $\mathrm{N}$ & $\mathrm{N}$ & $\mathrm{N}$ & - & - & CT & $\mathrm{N}$ & $\mathrm{N}$ & $\mathrm{N}$ & $\mathrm{N}$ & $\ldots$ \\
\hline 823 & A & - & - & - & $\mathrm{N}$ & $\mathrm{N}$ & $\mathrm{N}$ & $\mathrm{N}$ & - & - & - & $\mathrm{N}$ & $\mathrm{N}$ & $\mathrm{N}$ & $N$ & - & - & - & $\mathrm{N}$ & $\mathrm{N}$ & $\mathrm{N}$ & $\mathrm{N}$ & $\ldots$ \\
\hline 827 & A & - & - & - & - & $\mathrm{N}$ & $\mathrm{N}$ & $\mathrm{N}$ & - & - & - & - & $\mathrm{N}$ & $\mathrm{N}$ & $\mathrm{N}$ & - & - & - & $\mathrm{CT}$ & $\mathrm{N}$ & $\mathrm{N}$ & $\mathrm{N}$ & $\ldots$ \\
\hline 871 & B & - & - & - & $\mathrm{N}$ & $\mathrm{N}$ & $\mathrm{N}$ & $\mathrm{N}$ & - & - & - & $\mathrm{N}$ & $\mathrm{N}$ & $\mathrm{N}$ & $\mathrm{N}$ & - & $\mathrm{CT}$ & CT & $\mathrm{N}$ & $\mathrm{N}$ & $\mathrm{N}$ & $\mathrm{N}$ & $\ldots$ \\
\hline 882 & A & - & - & - & $\mathrm{N}$ & $\mathrm{N}$ & $\mathrm{N}$ & $\mathrm{N}$ & - & - & - & $\mathrm{N}$ & $\mathrm{N}$ & $\mathrm{N}$ & $\mathrm{N}$ & - & - & - & $\mathrm{N}$ & $\mathrm{N}$ & $\mathrm{N}$ & $\mathrm{N}$ & $\ldots$ \\
\hline 889 & A & - & - & - & $\mathrm{N}$ & $\mathrm{N}$ & $\mathrm{N}$ & $\mathrm{N}$ & - & - & - & $\mathrm{N}$ & $\mathrm{N}$ & $\mathrm{N}$ & $\mathrm{N}$ & - & - & - & $\mathrm{N}$ & $\mathrm{N}$ & $\mathrm{N}$ & $\mathrm{N}$ & $\ldots$ \\
\hline 892 & A & - & - & - & $\mathrm{N}$ & $\mathrm{N}$ & $\mathrm{N}$ & $\mathrm{N}$ & - & - & - & $\mathrm{N}$ & $\mathrm{N}$ & $\mathrm{N}$ & $\mathrm{N}$ & - & - & - & $\mathrm{N}$ & $\mathrm{N}$ & $\mathrm{N}$ & $\mathrm{N}$ & $\ldots$ \\
\hline
\end{tabular}




\begin{tabular}{|c|c|c|c|c|c|c|c|c|c|c|c|c|c|c|c|c|c|c|c|c|c|c|c|}
\hline \multirow{3}{*}{ Animal } & \multirow{3}{*}{ Prop. } & \multirow{2}{*}{\multicolumn{7}{|c|}{$\begin{array}{l}\text { Bacteriológico - TB } \\
\text { Löwenstein-Jensen }\end{array}$}} & \multirow{2}{*}{\multicolumn{7}{|c|}{$\begin{array}{c}\text { Bacteriológico - TB } \\
\text { Stonebrink }\end{array}$}} & \multirow{2}{*}{\multicolumn{7}{|c|}{ Bacteriológico }} & \multirow{3}{*}{ Identificação } \\
\hline & & & & & & & & & & & & & & & & & & & & & & & \\
\hline & & SM & MD & MS & Fig. & Pul. & Int. & Outros & SM & MD & MS & Fig. & Pul. & Int. & Outros & SM & MD & MS & Fig. & Pul. & Int. & Outros & \\
\hline 908 & A & - & $\mathrm{N}$ & - & $\mathrm{N}$ & $\mathrm{N}$ & $\mathrm{N}$ & $\mathrm{N}$ & - & $\mathrm{N}$ & - & $\mathrm{N}$ & $\mathrm{N}$ & $\mathrm{N}$ & $\mathrm{N}$ & - & $\mathrm{N}$ & - & $\mathrm{N}$ & $\mathrm{N}$ & $\mathrm{N}$ & $\mathrm{N}$ & $\ldots$ \\
\hline 921 & $A$ & - & - & - & $\mathrm{N}$ & $\mathrm{N}$ & $\mathrm{N}$ & $\mathrm{N}$ & - & - & - & $\mathrm{N}$ & $\mathrm{N}$ & $\mathrm{N}$ & $\mathrm{N}$ & - & - & - & $\mathrm{N}$ & $\mathrm{N}$ & $\mathrm{N}$ & $\mathrm{N}$ & $\ldots$ \\
\hline 1026 & $A$ & - & - & - & $\mathrm{N}$ & $\mathrm{N}$ & N & $\mathrm{N}$ & - & - & - & $\mathrm{N}$ & $\mathrm{N}$ & $\mathrm{N}$ & $\mathrm{N}$ & - & - & - & $\mathrm{N}$ & $\mathrm{N}$ & $\mathrm{N}$ & $\mathrm{N}$ & $\ldots$ \\
\hline 1441 & A & - & - & - & $\mathrm{N}$ & $\mathrm{N}$ & $\mathrm{N}$ & $\mathrm{N}$ & - & - & - & $\mathrm{N}$ & $\mathrm{N}$ & $\mathrm{N}$ & $\mathrm{N}$ & - & - & - & $\mathrm{N}$ & $\mathrm{N}$ & $\mathrm{N}$ & $\mathrm{N}$ & $\ldots$ \\
\hline $00 \#$ & A & - & - & - & $\mathrm{N}$ & $\mathrm{N}$ & $\mathrm{N}$ & $\mathrm{N}$ & - & - & - & $\mathrm{N}$ & $\mathrm{N}$ & $\mathrm{N}$ & $\mathrm{N}$ & - & - & - & $\mathrm{N}$ & $N$ & $\mathrm{~N}$ & $\mathrm{~N}$ & $\ldots$ \\
\hline SB1 & A & - & $\mathrm{N}$ & - & - & $\mathrm{N}$ & - & $\mathrm{N}$ & - & $\mathrm{N}$ & - & - & $\mathrm{N}$ & - & $\mathrm{N}$ & - & $\mathrm{N}$ & - & - & $\mathrm{N}$ & - & $\mathrm{N}$ & $\ldots$ \\
\hline
\end{tabular}

SM: Linfonodo submandibular

MD: Linfonodo Mediastino

MS: Linfonodo Mesentérico

Fig: Fígado
Pul.: Pulmão

Int.: Intestino

- : Cultivo negativo

N: Material não coletado
Abces.: Abcesso

CT: Contaminação

Xd: Dias de cultivo (isolamento)

C ps.: C. pseudotuberculosis g. mam.: Glândula mamária

C. M. tuberculosis: complexo M. tuberculosis 
Houve isolamento de micobactérias em sete (12,28\%) dos 57 animais abatidos. Dos 176 materiais colhidos foram isoladas micobactérias em oito $(4,54 \%)$, quatro $(50 \%)$ de linfonodos mediastínicos, dois (25\%) de submandibulares e dois (25\%) de mesentéricos. Todos os isolamentos foram obtidos em meio de Löwenstein-Jensen e dois isolamentos também ocorreram em meio de Stonebrink. Dos oito isolamentos, cinco $(62,5 \%)$ foram constatados em até duas semanas de incubação, um $(12,5 \%)$ até três semanas e dois $(25 \%)$ até a $6^{a}$ semana de incubação. Os isolamentos em meio de Stonebrink foram simultâneos (42 dias) aos obtidos em meio de Löwenstein-Jensen.

A tipificação genética de micobactérias pelo método de PRA demonstrou que de sete animais com isolamento, cinco (71,42\%) estavam infectados pelo Mycobacterium flavescens 1, um (14,28\%) pelo M. kansasii, e um (14,28\%) por micobactéria pertencente ao Complexo M. tuberculosis.

Os exames bacteriológicos para outras bactérias e/ou fungos apresentaram contaminação em 16 (9,09\%) das 176 amostras processadas. Houve isolamento de Corynebacterium pseudotuberculosis em quatro $(7,01 \%)$ dos 57 animais abatidos sendo três isolamentos (75\%) em linfonodos submandibulares e um $(25 \%)$ de linfonodo mediastínico. Houve isolamento simultâneo de micobactérias e de Corynebacterium pseudotuberculosis em dois (3,5\%) dos 57 animais abatidos, sendo um do linfonodo submandibular e outro do mediastínico.

Os resultados dos exames histopatológicos são detalhados na tabela 6.

Tabela 6 - Ovinos de duas propriedades da região de Pindamonhangaba - SP, Brasil submetidos a testes imunoalérgicos aplicados ao diagnóstico da tuberculose, abatidos e necropsiados, com lesões macroscópicas sugestivas,submetidas a cultivos para micobactérias e outros microorganismos e exame histopatológico segundo a natureza dos resultados obtidos São Paulo, 2007.

\begin{tabular}{|c|c|c|c|c|c|c|}
\hline Animal & TCS & TCC & Material & $\begin{array}{l}\text { Bacteriológico } \\
\text { (micobactérias) }\end{array}$ & $\begin{array}{c}\text { Bacteriológico } \\
\text { (outras bactérias) }\end{array}$ & Histopatológico \\
\hline \multirow{2}{*}{20} & \multirow{2}{*}{ I } & \multirow{2}{*}{0,1} & LSM & - & - & - \\
\hline & & & LMD & - & - & - \\
\hline \multirow{5}{*}{33} & \multirow{5}{*}{$P$} & \multirow{5}{*}{0,1} & LSM & - & - & - \\
\hline & & & LMD & - & - & - \\
\hline & & & LMS & - & - & - \\
\hline & & & Fígado * & - & - & Granuloma +; ZN + \\
\hline & & & Intestino * & - & - & Granuloma +; ZN + \\
\hline
\end{tabular}


(Continuação)

\begin{tabular}{|c|c|c|c|c|c|c|}
\hline Animal & TCS & TCC & Material & $\begin{array}{l}\text { Bacteriológico } \\
\text { (micobactérias) }\end{array}$ & $\begin{array}{c}\text { Bacteriológico } \\
\text { (outras bactérias) }\end{array}$ & Histopatológico \\
\hline \multirow{3}{*}{38} & \multirow{3}{*}{ I } & \multirow{3}{*}{$-0,6$} & LSM & - & - & - \\
\hline & & & LMD & - & - & - \\
\hline & & & LMS & - & - & - \\
\hline \multirow{3}{*}{48} & \multirow{3}{*}{ I } & \multirow{3}{*}{$-0,8$} & LSM & - & - & - \\
\hline & & & LMD & - & - & - \\
\hline & & & LMS & - & - & - \\
\hline \multirow{3}{*}{59} & \multirow{3}{*}{ I } & \multirow{3}{*}{$-0,5$} & LSM & - & - & - \\
\hline & & & LMD & - & - & - \\
\hline & & & LMS & - & - & - \\
\hline \multirow{4}{*}{72} & \multirow{4}{*}{ I } & \multirow{4}{*}{$-1,3$} & LSM & - & - & - \\
\hline & & & LMD & - & - & - \\
\hline & & & LMS & - & - & - \\
\hline & & & Fígado * & - & Contaminação & - \\
\hline \multirow{3}{*}{84} & \multirow{3}{*}{$\mathrm{N}$} & \multirow{3}{*}{0,2} & LSM & - & - & - \\
\hline & & & LMD & - & - & - \\
\hline & & & LMS & - & - & - \\
\hline \multirow{2}{*}{129} & \multirow{2}{*}{$P$} & \multirow{2}{*}{0,2} & $\mathrm{LSM}^{*}$ & M. flavescens 1 & C. pseudotubercul. & Granuloma +; ZN + \\
\hline & & & LMS & - & - & - \\
\hline \multirow{3}{*}{131} & \multirow{3}{*}{ I } & \multirow{3}{*}{0,1} & LSM & - & - & - \\
\hline & & & LMD & - & - & - \\
\hline & & & LMS & - & - & - \\
\hline \multirow{3}{*}{168} & \multirow{3}{*}{ I } & \multirow{3}{*}{0,2} & LSM & - & - & - \\
\hline & & & LMD & - & - & - \\
\hline & & & LMS & - & - & Granuloma +; ZN + \\
\hline \multirow{3}{*}{176} & \multirow{3}{*}{ I } & \multirow{3}{*}{0,3} & LSM & - & - & - \\
\hline & & & LMD & - & - & - \\
\hline & & & LMS & - & - & - \\
\hline \multirow{4}{*}{182} & & & LSM & - & - & - \\
\hline & $N$ & 03 & LMD* $^{*}$ & - & - & - \\
\hline & IV & 0,0 & LMS & - & - & - \\
\hline & & & Fígado* & - & - & - \\
\hline & & & LSM * & M. flavescens 1 & - & - \\
\hline 197 & 1 & 03 & LMD & - & - & - \\
\hline & & & LMS & M. flavescens 1 & - & - \\
\hline & & & Fígado * & - & - & Granuloma +; ZN + \\
\hline
\end{tabular}


RESULTADOS

(Continuação)

\begin{tabular}{|c|c|c|c|c|c|c|}
\hline Animal & TCS & TCC & Material & $\begin{array}{l}\text { Bacteriológico } \\
\text { (micobactérias) }\end{array}$ & $\begin{array}{c}\text { Bacteriológico } \\
\text { (outras bactérias) }\end{array}$ & Histopatológico \\
\hline & & & LSM & - & - & - \\
\hline \multirow[t]{3}{*}{206} & I & 0,5 & LMD & - & - & - \\
\hline & & & LMS & - & - & - \\
\hline & & & LSM & - & - & - \\
\hline \multirow[t]{3}{*}{279} & $P$ & 0,3 & LMD & - & - & - \\
\hline & & & LMS & - & - & - \\
\hline & & & LSM & - & - & - \\
\hline \multirow[t]{3}{*}{294} & I & $-0,3$ & LMD & - & - & - \\
\hline & & & LMS & - & - & - \\
\hline & & & LSM & - & - & - \\
\hline \multirow[t]{4}{*}{304} & I & 0,1 & LMD & - & - & - \\
\hline & & & Fígado * & - & - & - \\
\hline & & & $\mathrm{LSM}^{*}$ & - & C. pseudotubercul. & - \\
\hline & & & LMD & - & - & Granuloma +; ZN + \\
\hline \multirow[t]{4}{*}{342} & $\mathrm{~N}$ & 0,3 & LMS & - & - & - \\
\hline & & & Pulmão * & - & - & - \\
\hline & & & GI. Mam. * & - & - & - \\
\hline & & & LSM & - & - & - \\
\hline \multirow[t]{3}{*}{352} & $\mathrm{~N}$ & 0,3 & LMD* & M. flavescens 1 & Contaminação & Granuloma +; ZN + \\
\hline & & & LMS & - & - & - \\
\hline & & & LSM & - & - & - \\
\hline \multirow[t]{3}{*}{353} & I & $-2,2$ & LMD & - & - & - \\
\hline & & & LMS & - & - & - \\
\hline & & & LSM & - & - & - \\
\hline \multirow[t]{3}{*}{362} & I & $-4,9$ & LMD & - & - & - \\
\hline & & & LMS & - & - & - \\
\hline & & & LSM & - & - & - \\
\hline \multirow[t]{3}{*}{449} & 1 & $-0,4$ & LMD & - & - & - \\
\hline & & & LMS & - & - & - \\
\hline & & & LSM & - & - & - \\
\hline \multirow[t]{3}{*}{478} & $P$ & 0,1 & LMD & - & - & - \\
\hline & & & LMS & - & - & - \\
\hline & & & LSM & - & - & - \\
\hline \multirow[t]{2}{*}{485} & $\mathrm{~N}$ & 0,6 & LMD & - & Contaminação & - \\
\hline & & & LMS & - & - & - \\
\hline
\end{tabular}


RESULTADOS

(Continuação)

\begin{tabular}{|c|c|c|c|c|c|c|}
\hline Animal & TCS & TCC & Material & $\begin{array}{l}\text { Bacteriológico } \\
\text { (micobactérias) }\end{array}$ & $\begin{array}{c}\text { Bacteriológico } \\
\text { (outras bactérias) }\end{array}$ & Histopatológico \\
\hline \multirow{3}{*}{486} & \multirow{3}{*}{ I } & \multirow{3}{*}{0,9} & LSM & - & - & - \\
\hline & & & LMD & - & - & - \\
\hline & & & LMS & - & - & - \\
\hline \multirow{3}{*}{516} & \multirow{3}{*}{ I } & \multirow{3}{*}{0,9} & LSM & - & - & - \\
\hline & & & LMD & - & - & - \\
\hline & & & LMS & - & - & - \\
\hline \multirow{5}{*}{533} & \multirow{5}{*}{ I } & \multirow{5}{*}{0,5} & LSM & - & - & - \\
\hline & & & LMD & - & - & - \\
\hline & & & LMS & - & Contaminação & - \\
\hline & & & Fígado * & - & - & - \\
\hline & & & Pulmão * & - & Contaminação & Granuloma $+; \mathrm{ZN}+$ \\
\hline \multirow{2}{*}{552} & \multirow{2}{*}{ I } & \multirow{2}{*}{0,5} & LSM & - & C. pseudotubercul. & - \\
\hline & & & LMS & - & - & - \\
\hline \multirow{3}{*}{580} & \multirow{3}{*}{$\mathrm{N}$} & \multirow{3}{*}{0,1} & LSM & - & - & - \\
\hline & & & LMD & - & - & - \\
\hline & & & LMS & - & - & - \\
\hline \multirow{3}{*}{587} & \multirow{3}{*}{$\mathrm{N}$} & \multirow{3}{*}{$-0,1$} & LSM & - & - & - \\
\hline & & & LMD & - & - & - \\
\hline & & & LMS & - & - & - \\
\hline \multirow{3}{*}{599} & \multirow{3}{*}{ I } & \multirow{3}{*}{0,6} & LSM & - & - & - \\
\hline & & & LMD & - & - & - \\
\hline & & & LMS & - & - & - \\
\hline \multirow{3}{*}{605} & \multirow{3}{*}{ I } & \multirow{3}{*}{$-0,2$} & LSM & - & - & - \\
\hline & & & LMD & - & - & - \\
\hline & & & LMS & - & - & - \\
\hline \multirow{3}{*}{609} & \multirow{3}{*}{ I } & \multirow{3}{*}{$-6,1$} & LSM & - & - & - \\
\hline & & & LMD & - & - & - \\
\hline & & & LMS & - & - & - \\
\hline \multirow{3}{*}{610} & & & LSM & - & - & - \\
\hline & 1 & $-3,4$ & LMD & - & - & - \\
\hline & & & LMS & - & - & - \\
\hline & & & LSM & - & - & - \\
\hline 648 & $\mathrm{~N}$ & $-0,7$ & LMD & - & - & - \\
\hline & & & LMS & - & - & - \\
\hline
\end{tabular}


RESULTADOS

(Continuação)

\begin{tabular}{|c|c|c|c|c|c|c|}
\hline Animal & TCS & TCC & Material & $\begin{array}{l}\text { Bacteriológico } \\
\text { (micobactérias) }\end{array}$ & $\begin{array}{c}\text { Bacteriológico } \\
\text { (outras bactérias) }\end{array}$ & Histopatológico \\
\hline \multirow{3}{*}{690} & \multirow{3}{*}{ I } & \multirow{3}{*}{0,5} & LSM & - & - & - \\
\hline & & & LMD & M. kansasii 1 & - & - \\
\hline & & & LMS & - & - & - \\
\hline \multirow{2}{*}{702} & \multirow{2}{*}{$\mathrm{N}$} & \multirow{2}{*}{0,3} & LSM & - & - & - \\
\hline & & & LMS & - & - & - \\
\hline \multirow{3}{*}{709} & \multirow{3}{*}{$\mathrm{N}$} & \multirow{3}{*}{$-0,4$} & LSM & - & - & - \\
\hline & & & LMD & - & - & - \\
\hline & & & LMS & - & - & - \\
\hline \multirow{3}{*}{721} & \multirow{3}{*}{$\mathrm{N}$} & \multirow{3}{*}{$-1,6$} & LSM & - & - & - \\
\hline & & & LMD & - & - & - \\
\hline & & & LMS & - & - & - \\
\hline \multirow{3}{*}{727} & \multirow{3}{*}{$\mathrm{P}$} & \multirow{3}{*}{0,6} & LSM & - & - & - \\
\hline & & & LMD & - & - & - \\
\hline & & & LMS & M. flavescens 1 & - & Granuloma +; ZN + \\
\hline \multirow{3}{*}{737} & \multirow{3}{*}{$P$} & \multirow{3}{*}{0,4} & $\mathrm{LSM}^{*}$ & - & - & - \\
\hline & & & LMD & - & - & - \\
\hline & & & LMS & - & - & - \\
\hline \multirow{3}{*}{759} & \multirow{3}{*}{1} & \multirow{3}{*}{$-0,9$} & LSM & - & - & - \\
\hline & & & LMD & - & - & - \\
\hline & & & LMS & - & - & - \\
\hline \multirow{3}{*}{762} & \multirow{3}{*}{$\mathrm{N}$} & \multirow{3}{*}{$-0,2$} & LSM & - & - & - \\
\hline & & & LMD & - & - & - \\
\hline & & & LMS & - & - & - \\
\hline \multirow{3}{*}{813} & \multirow{3}{*}{ I } & \multirow{3}{*}{$-0,2$} & LSM & - & - & - \\
\hline & & & LMD & - & - & - \\
\hline & & & LMS & - & - & - \\
\hline \multirow{3}{*}{822} & & & LSM & - & - & - \\
\hline & I & 0,3 & LMD & - & - & - \\
\hline & & & LMS & - & Contaminação & - \\
\hline & & & LSM & - & - & - \\
\hline 823 & 1 & 0,1 & LMD & - & - & - \\
\hline & & & LMS & - & - & - \\
\hline & & & LSM & - & - & - \\
\hline 827 & $N$ & $-0,1$ & LMD & - & - & - \\
\hline & & & LMS & - & - & - \\
\hline
\end{tabular}


(Conclusão)

\begin{tabular}{|c|c|c|c|c|c|c|}
\hline Animal & TCS & TCC & Material & $\begin{array}{l}\text { Bacteriológico } \\
\text { (micobactérias) }\end{array}$ & $\begin{array}{c}\text { Bacteriológico } \\
\text { (outras bactérias) }\end{array}$ & Histopatológico \\
\hline \multirow{3}{*}{871} & \multirow{3}{*}{ I } & \multirow{3}{*}{$-1,0$} & LSM & - & - & - \\
\hline & & & LMD & - & - & - \\
\hline & & & LMS & - & - & - \\
\hline \multirow{3}{*}{882} & \multirow{3}{*}{ I } & \multirow{3}{*}{$-0,6$} & LSM & - & - & - \\
\hline & & & LMD & - & - & - \\
\hline & & & LMS & - & - & - \\
\hline \multirow{3}{*}{889} & \multirow{3}{*}{ I } & \multirow{3}{*}{$-0,9$} & LSM & - & - & - \\
\hline & & & LMD & - & - & - \\
\hline & & & LMS & - & - & - \\
\hline \multirow{3}{*}{892} & \multirow{3}{*}{1} & \multirow{3}{*}{0,2} & LSM & - & - & - \\
\hline & & & LMD & - & - & - \\
\hline & & & LMS & - & - & - \\
\hline \multirow{2}{*}{908} & \multirow{2}{*}{1} & \multirow{2}{*}{0,1} & LSM & - & - & - \\
\hline & & & LMS & - & - & - \\
\hline \multirow{3}{*}{921} & \multirow{3}{*}{1} & \multirow{3}{*}{0,5} & LSM & - & - & - \\
\hline & & & LMD & - & - & - \\
\hline & & & LMS & - & - & - \\
\hline \multirow{3}{*}{1026} & \multirow{3}{*}{$\mathrm{N}$} & \multirow{3}{*}{$-1,0$} & LSM & - & - & - \\
\hline & & & LMD & - & - & - \\
\hline & & & LMS & - & - & - \\
\hline \multirow{3}{*}{1441} & \multirow{3}{*}{1} & \multirow{3}{*}{$-0,5$} & LSM & - & - & - \\
\hline & & & LMD & - & - & - \\
\hline & & & LMS & - & - & - \\
\hline \multirow{3}{*}{$00 \#$} & \multirow{3}{*}{ I } & \multirow{3}{*}{$-1,1$} & LSM & - & - & - \\
\hline & & & LMD & - & - & - \\
\hline & & & LMS & - & - & - \\
\hline \multirow{4}{*}{ SB1 } & \multirow{4}{*}{$\mathrm{N}$} & \multirow{4}{*}{$-1,0$} & LSM & - & - & - \\
\hline & & & LMS & - & - & - \\
\hline & & & Fígado * & - & - & Granuloma +; ZN + \\
\hline & & & Intestino * & - & - & Granuloma +; ZN + \\
\hline
\end{tabular}

TCS: Teste Cervical Simples

TCC: Resultado, em mm, da diferença $\triangle P P D B v-\triangle P P D A v$ Neg.: Resultado Negativo ao TCS

Inc.: Resultado Inconclusivo ao TCS

Pos.: Resultado Positivo ao TCS

-:Resultado negativo para cultivo e/ou histopatológico

C. pseudotubercul.: Corynebacterium pseudotuberculosis

C. M. tuberculosis: Complexo Mycobacterium tuberculosis
*: Material com lesão

LSM: linfonodos submandibulares

LMD: linfonodos mediastínicos

LMS: linfonodos mesentéricos

GI. Mam.: Glândula Mamária

ZN: Coloração de Ziehl-Neelsen 
Dos 57 animais submetidos aos exames histopatológicos, nove (15,78\%) apresentaram pelo menos um material com granuloma sugestivo de micobacteriose (presença de granuloma e coloração de Ziehl-Neelsen positivo). Dos 176 materiais examinados, $11(6,25 \%)$ apresentaram resultado positivo sendo três $(27,27 \%)$ fígado, dois $(18,18 \%)$ linfonodo mediastínico, dois $(18,18 \% \%)$ intestino, dois (18,18\%) linfonodo mesentérico, um $(9,09 \%)$ linfonodo submandibular e um $(9,09 \%)$ pulmão. As figuras 7, 8 e 9 são lesões granulomatosas encontradas nos animais 33 e 129.

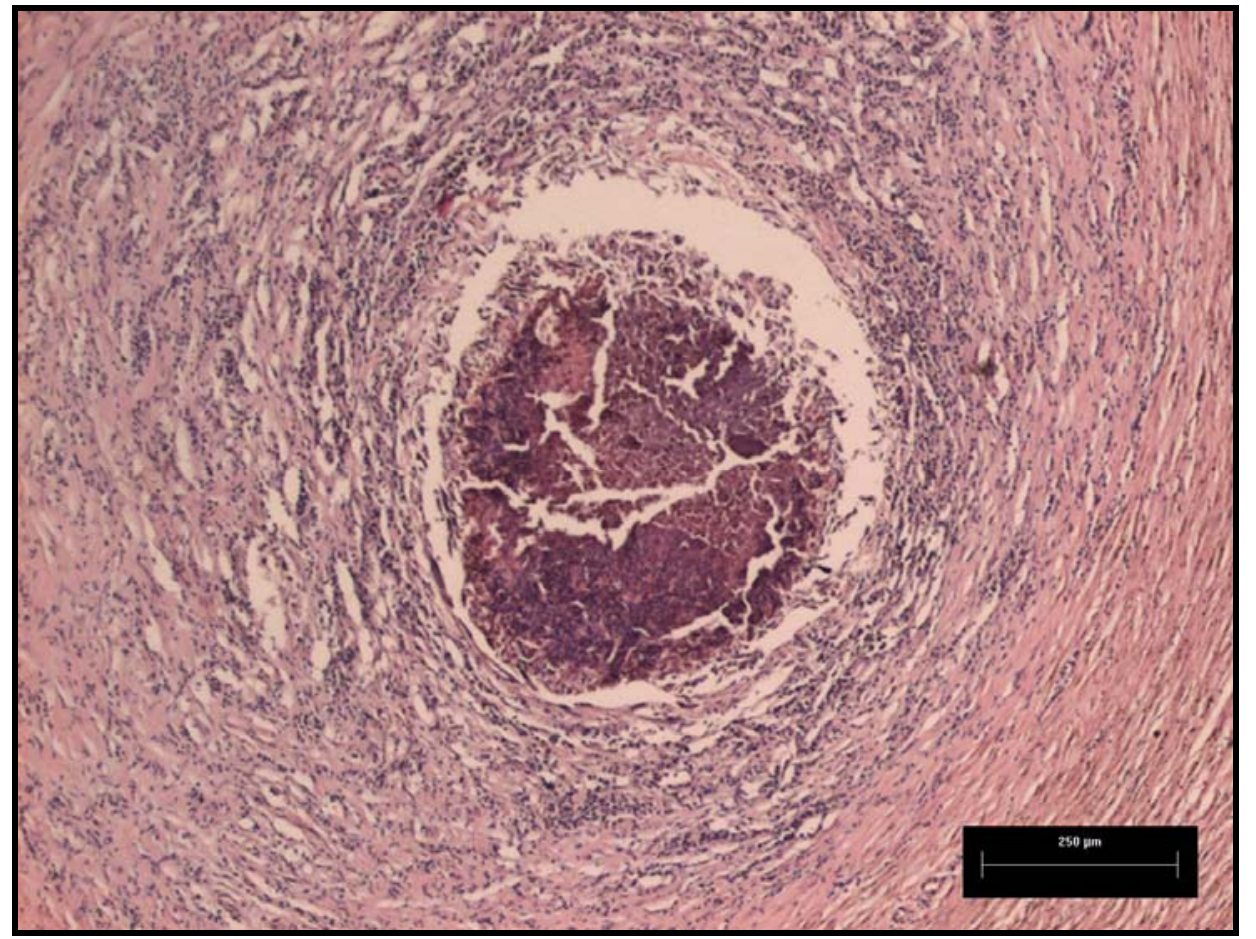

Figura 7 - Fotomicrografia de granuloma com necrose de caseificação presente na parede do intestino do animal 33 (HE - objetiva 40x) - São Paulo - 2007 


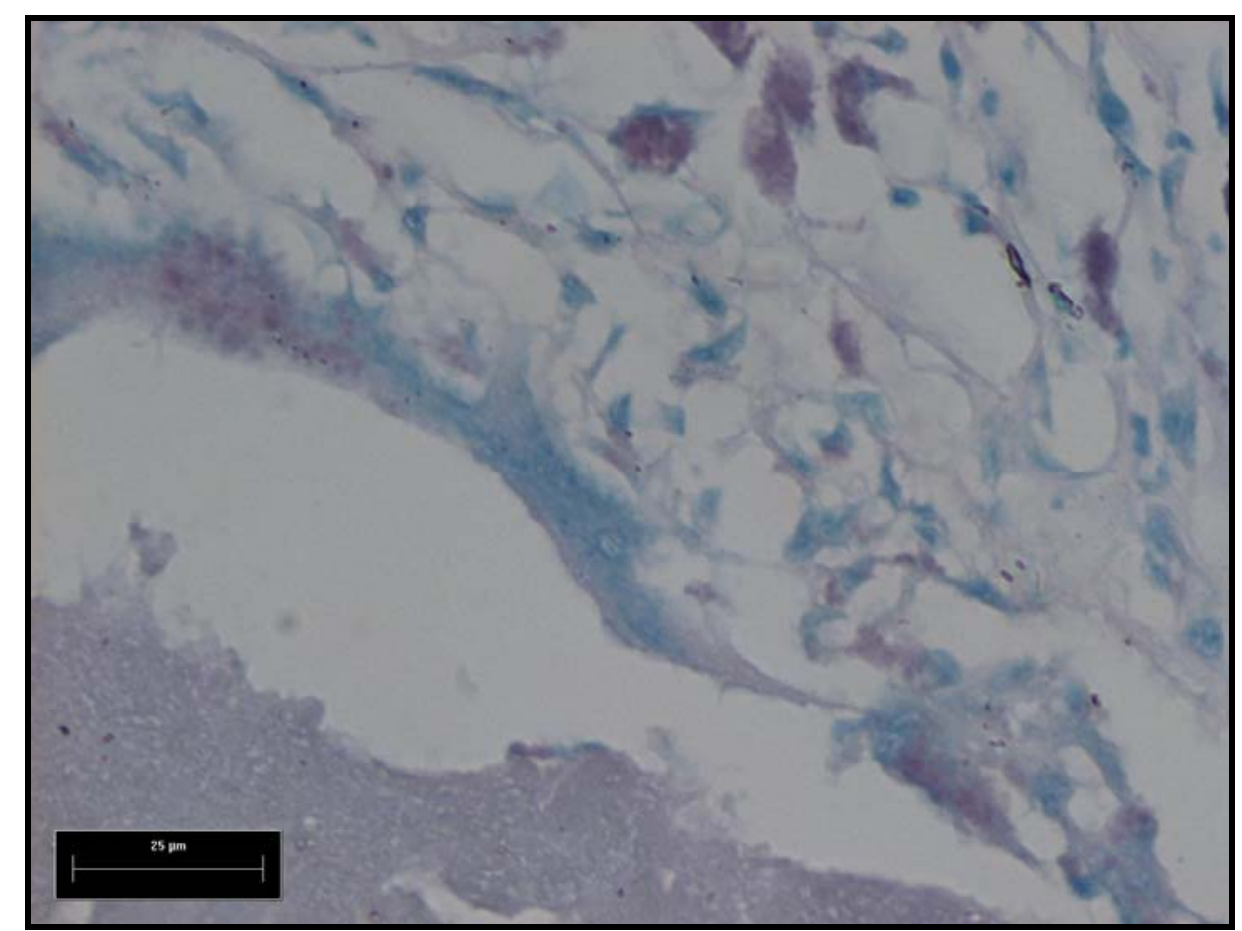

Figura 8 - Fotomicrografia de lesão na parede do intestino do animal $33 \mathrm{com}$ presença de bacilo álcool-ácido resistente (ZN - objetiva 40x) - São Paulo - 2007

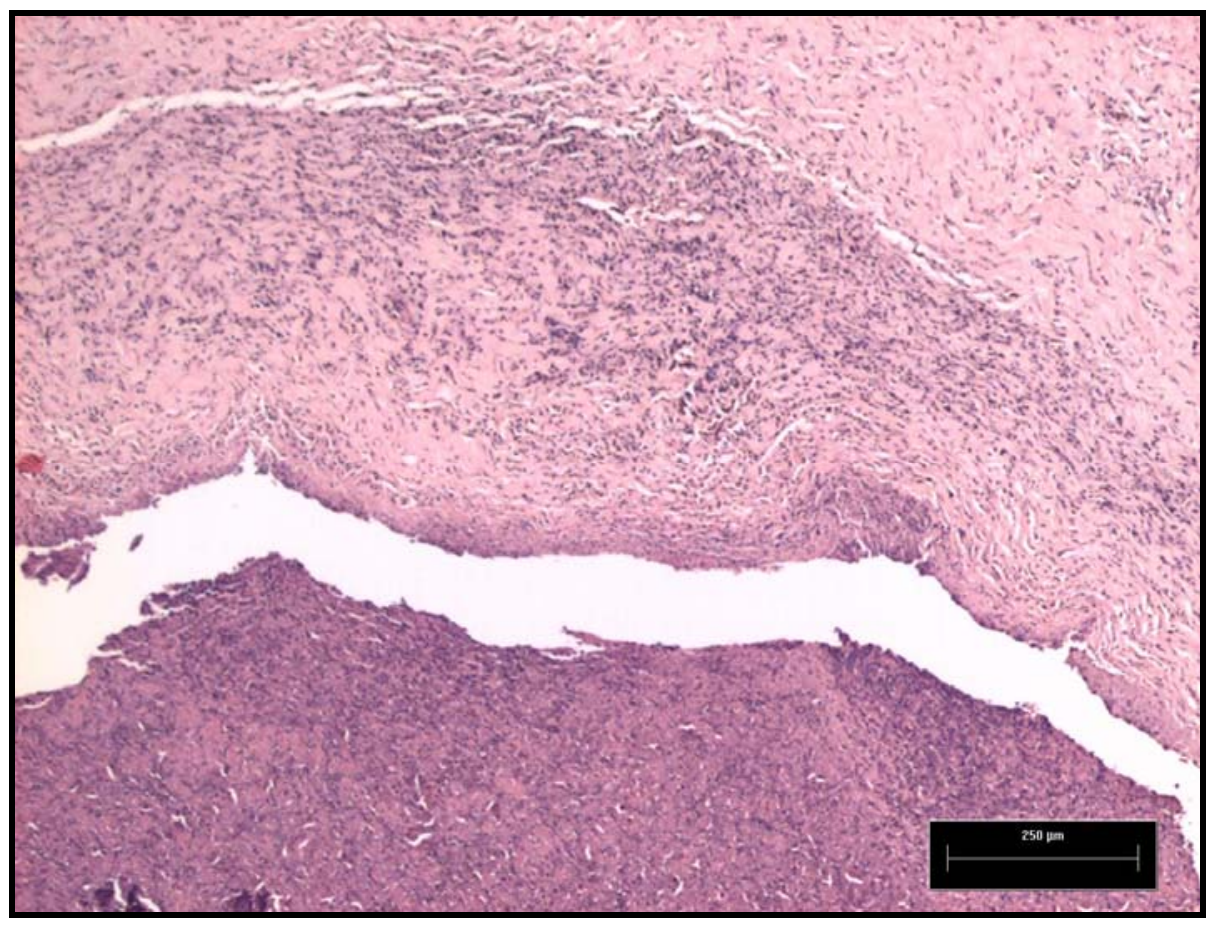

Figura 9 - Fotomicrografia de granuloma com necrose de caseificação do linfonodo submandibular do animal 129 (HE - objetiva 40x) - São Paulo - 2007 
Dos nove animais com granuloma ao exame histopatológico, cinco $(55,56 \%)$ foram negativos e quatro $(44,44 \%)$ positivos para o cultivo de micobactérias, houve isolamento de micobactérias em um animal cujo resultado ao exame histopatológico foi negativo. Dos 11 materiais positivos no exame histopatológico, oito $(72,72 \%)$ foram negativos e três $(27,23 \%)$ foram positivos para o cultivo de micobactérias. Houve isolamento de micobactérias em três materiais negativos ao exame histopatológico.

Dos isolamentos de outros microorganismos que não micobactérias, dos dez materiais foram positivos no exame histopatológico, em nove $(90 \%)$ não houve isolamento de outras bactérias e em um (10\%) houve o isolamento de Corynebacterium pseudotuberculosis. Outros dois materiais com isolamento de $C$. pseudotuberculosis não foram positivos no exame histopatológico.

A compilação dos resultados segundo a reação tuberculínica bovina obtidos no TCC, por animal e por exame, é apresentado nas tabelas 7 e 8 . 
Tabela 7 - Ovinos de duas propriedades da região de Pindamonhangaba - SP, Brasil submetidos a testes imunoalérgicos aplicados ao diagnóstico da tuberculose, abatidos, necropsiados, com lesões macroscópicas sugestivas de micobactérias, submetidas a cultivo para micobactérias e outros microorganismos, exame histopatológico e tipificação genética dos microorganismos isolados, segundo a natureza dos resultados obtidos - São Paulo - 2007

\begin{tabular}{|c|c|c|c|c|c|c|c|}
\hline An. & TCS & $\mathrm{TCC}(\mathrm{mm})$ & $\begin{array}{c}\text { Necrópsia } \\
\text { (lesões) }\end{array}$ & Micobactérias & $\begin{array}{c}\text { Outras } \\
\text { bactérias }\end{array}$ & Histopat. & $\begin{array}{c}\text { Tipificação } \\
\text { genética }\end{array}$ \\
\hline 587 & Neg. & $-0,1$ & - & - & - & - & $\ldots$ \\
\hline 827 & Neg. & $-0,1$ & - & - & - & - & $\ldots$ \\
\hline 605 & Inc. & $-0,2$ & - & - & - & - & $\ldots$ \\
\hline 762 & Neg. & $-0,2$ & - & - & - & - & $\ldots$ \\
\hline 813 & Inc. & $-0,2$ & - & - & - & - & $\ldots$ \\
\hline 294 & Inc. & $-0,3$ & - & - & -- & - & $\ldots$ \\
\hline 449 & Inc. & $-0,4$ & - & - & - & - & $\ldots$ \\
\hline 709 & Neg. & $-0,4$ & - & - & - & - & $\ldots$ \\
\hline 59 & Inc. & $-0,5$ & - & - & - & - & $\ldots$ \\
\hline 1441 & Inc. & $-0,5$ & - & - & - & - & $\ldots$ \\
\hline 38 & Inc. & $-0,6$ & - & - & - & - & $\ldots$ \\
\hline 882 & Inc. & $-0,6$ & - & - & - & - & $\ldots$ \\
\hline 648 & Neg. & $-0,7$ & - & $\mathrm{P}$ & $P$ & - & C. M. tuberculosis \\
\hline 48 & Inc. & $-0,8$ & - & - & - & - & $\ldots$ \\
\hline 759 & Inc. & $-0,9$ & - & - & - & - & $\ldots$ \\
\hline 889 & Inc. & $-0,9$ & - & - & - & - & $\ldots$ \\
\hline 871 & Inc. & $-1,0$ & - & - & - & - & $\ldots$ \\
\hline 1026 & Neg. & $-1,0$ & - & - & - & - & $\ldots$ \\
\hline SB1 & Neg. & $-1,0$ & $\mathrm{P}$ & - & - & $P$ & $\ldots$ \\
\hline 00\# & Inc. & $-1,1$ & - & - & - & - & $\ldots$ \\
\hline 72 & Inc. & $-1,3$ & $P$ & - & - & - & $\ldots$ \\
\hline 721 & Neg. & $-1,6$ & - & - & - & - & $\ldots$ \\
\hline 353 & Inc. & $-2,2$ & - & - & - & - & $\ldots$ \\
\hline 610 & Inc. & $-3,4$ & - & - & - & - & $\ldots$ \\
\hline 362 & Inc. & $-4,9$ & - & - & - & - & $\ldots$ \\
\hline 609 & Inc. & $-6,1$ & - & - & - & - & $\ldots$ \\
\hline
\end{tabular}

An.: Animal

TCS: Teste Cervical Simples

Neg.: Resultado negativo ao TCS

Inc.: Resultado inconclusivo ao TCS

TCC: Resultado, em mm, da diferença $\triangle$ PPD Bv - $\triangle$ PPD Av

- : Resultado Negativo aos exames de necropsia, bacteriológico e histopatológico

P: Resultado Positivo aos exames de necropsia, bacteriológico e histopatológico

Outras bactérias: Resultado do exame bacteriológico para cultivo de Corynebacterium pseudotuberculosis.

Histopat.: Resultado do exame histopatológico.

C. M. tuberculosis: complexo Mycobacterium tuberculosis 
Tabela 8 - Ovinos de duas propriedades da região de Pindamonhangaba - SP, Brasil submetidos a testes imunoalérgicos aplicados ao diagnóstico da tuberculose, abatidos e necropsiados, com lesões macroscópicas sugestivas,submetidas a cultivos para micobactérias e outros microorganismos e exame histopatológico segundo a natureza dos resultados obtidos São Paulo - 2007

\begin{tabular}{cccccccc}
\hline An. & TCS & $\begin{array}{c}\text { TCC } \\
(\mathbf{m m})\end{array}$ & $\begin{array}{c}\text { Necrópsia } \\
\text { (lesões) }\end{array}$ & Micobactérias & $\begin{array}{c}\text { Outras } \\
\text { bactérias }\end{array}$ & Histopat. & $\begin{array}{c}\text { Tipificação } \\
\text { genética }\end{array}$ \\
\hline $\mathbf{4 8 6}$ & Inc. & 0,9 & - & - & - & - & $\ldots$ \\
$\mathbf{5 1 6}$ & Inc. & 0,9 & - & - & - & - & $\ldots$ \\
$\mathbf{4 8 5}$ & Neg. & 0,6 & - & - & - & - & $\ldots$ \\
$\mathbf{5 9 9}$ & Inc. & 0,6 & - & - & - & - & $\ldots$ \\
$\mathbf{7 2 7}$ & Pos. & 0,6 & - & $\mathrm{P}$ & - & $\mathrm{P}$ & M. flavescens \\
$\mathbf{2 0 6}$ & Inc. & 0,5 & - & - & - & - & $\ldots$ \\
$\mathbf{5 3 3}$ & Inc. & 0,5 & $\mathrm{P}$ & - & - & $\mathrm{P}$ & $\ldots$ \\
$\mathbf{5 5 2}$ & Inc. & 0,5 & - & - & $\mathrm{P}$ & - & $\ldots$ \\
$\mathbf{6 9 0}$ & Inc. & 0,5 & - & $\mathrm{P}$ & - & - & M. kansasii \\
$\mathbf{9 2 1}$ & Inc. & 0,5 & - & - & - & - & $\ldots$ \\
$\mathbf{7 3 7}$ & Pos. & 0,4 & $\mathrm{P}$ & - & - & - & $\ldots$ \\
$\mathbf{1 7 6}$ & Inc. & 0,3 & - & - & - & - & $\ldots$ \\
$\mathbf{1 8 2}$ & Neg. & 0,3 & $\mathrm{P}$ & - & - & - & $\ldots$ \\
$\mathbf{1 9 7}$ & Inc. & 0,3 & $\mathrm{P}$ & $\mathrm{P}$ & - & $\mathrm{P}$ & M. flavescens \\
$\mathbf{2 7 9}$ & Pos. & 0,3 & - & - & - & - & $\ldots$ \\
$\mathbf{3 4 2}$ & Neg. & 0,3 & $\mathrm{P}$ & - & $\mathrm{P}$ & $\mathrm{P}$ & $\ldots$ \\
$\mathbf{3 5 2}$ & Neg. & 0,3 & $\mathrm{P}$ & $\mathrm{P}$ & - & $\mathrm{P}$ & M. flavescens \\
$\mathbf{7 0 2}$ & Neg. & 0,3 & - & - & - & - & $\ldots$ \\
$\mathbf{8 2 2}$ & Inc. & 0,3 & - & - & - & - & $\ldots$ \\
$\mathbf{8 4}$ & Neg. & 0,2 & - & - & - & - & $\ldots$ \\
$\mathbf{1 2 9}$ & Pos. & 0,2 & $\mathrm{P}$ & $\mathrm{P}$ & $\mathrm{P}$ & $\mathrm{P}$ & $\ldots$ \\
$\mathbf{1 6 8}$ & Inc. & 0,2 & - & - & - & $\mathrm{P}$ & $\ldots$ \\
$\mathbf{8 9 2}$ & Inc. & 0,2 & - & - & - & - & $\ldots$ \\
$\mathbf{2 0}$ & Inc. & 0,1 & - & - & - & - & $\ldots$ \\
$\mathbf{3 3}$ & Pos. & 0,1 & $\mathrm{P}$ & - & - & $\mathrm{P}$ & $\ldots$ \\
$\mathbf{1 3 1}$ & Inc. & 0,1 & - & $\mathrm{P}$ & - & - & M. flavescens \\
$\mathbf{3 0 4}$ & Inc. & 0,1 & $\mathrm{P}$ & - & - & - & $\ldots$ \\
$\mathbf{4 7 8}$ & Pos. & 0,1 & - & - & - & - & $\ldots$ \\
$\mathbf{5 8 0}$ & Neg. & 0,1 & - & - & - & - & $\ldots$ \\
$\mathbf{8 2 3}$ & Inc. & 0,1 & - & - & - & - & $\ldots$ \\
$\mathbf{9 0 8}$ & Inc. & 0,1 & - & - & - & - & $\ldots$ \\
\hline & & & & & & & $\ldots$ \\
& & - & - & - & $\ldots$ \\
\end{tabular}

An.: Animal

TCS: Teste Cervical Simples

Neg.: Resultado negativo ao TCS

Inc.: Resultado inconclusivo ao TCS

TCC: Resultado, em mm, da diferença $\triangle P P D B v-\triangle P P D$ Av

- : Resultado Negativo aos exames de necropsia, bacteriológico e histopatológico

P: Resultado Positivo aos exames de necropsia, bacteriológico e histopatológico

Outras bactérias: Resultado do exame bacteriológico para cultivo de Corynebacterium pseudotuberculosis.

Histopat.: Resultado do exame histopatológico.

C. M. tuberculosis: complexo Mycobacterium tuberculosis 
Dos 26 animais com reação a tuberculina bovina maior que a aviária, oito $(30,77 \%)$ foram negativos e $18(69,23 \%)$ inconclusivos ao TCS. Um animal $(3,84 \%)$ apresentou lesão visível à necropsia e em outro houve isolamento simultâneo de micobactéria (Complexo M. tuberculosis) e C. pseudotuberculosis. Em um terceiro animal o resultado do exame histopatológico foi positivo.

Dos 31 animais com reação a tuberculina bovina maior que a aviária, sete $(22,58 \%)$ foram negativos, $18(58,06 \%)$ inconclusivos e seis $(19,35 \%)$ foram positivos ao TCS. Nove animais $(29,03 \%)$ apresentaram lesões visíveis à necropsia. Em seis animais $(19,35 \%)$ houve isolamento de micobactérias, sendo cinco $(83,33 \%)$ de $M$. flavescens e um $(16,67 \%)$ de M. kansasii. O C. pseudotuberculosis foi isolado em três $(9,67 \%)$ animais sendo de um deles também isolado $M$. flavescens. Oito animais $(25,80 \%)$ foram positivos para o exame de histopatológico.

A análise estatística pelo teste de Fischer demonstrou a existência de associação entre as reações ao Teste Comparativo Cervical e a positividade para micobactérias, dada pelo isolamento e histopatológico, quando a diferença de relação a reação de tuberculina bovina ( $\triangle P P D B v-\triangle P P D A v)$ for igual ou superior a 0,2 mm, com nível de significância de 0,05 . 
Utilizando-se os padrões recomendados por Cyrillo (2006) para a interpretação do teste imunoalérgico de tuberculina aplicado ao diagnóstico de tuberculose em ovinos, dos 353 animais testados $24,7 \%$ foram classificados como negativos, $52,4 \%$ inconclusivos e $22,9 \%$ positivos ao TCS (Tabela 1 ). Todos os animais testados foram considerados negativos ao TCC (Tabela 2), sendo 12,75\% com reação a tuberculina bovina superior a aviária ( $\triangle P P D B v-\triangle P P D A v \geq 0)$ e $87,25 \%$ com reação a tuberculina bovina inferior a aviária $(\triangle P P D B v-\triangle P P D A v<$ $0)$.

Embora para os bovinos os testes imunoalérgicos aplicados ao diagnóstico de tuberculose sejam mundialmente difundidos e aceitos, para os pequenos ruminantes ainda não há consenso nos parâmetros a serem utilizados. Alguns pesquisadores têm se utilizado dos mesmos parâmetros estabelecidos para bovinos (CORDES et al., 1981) ou mesmo valores arbitrados para a sua interpretação (MALONE et al., 2003).

Cyrillo (2006), em ovinos experimentalmente sensibilizados com cultivos inativados de M. bovis e M. avium, acrescidos de adjuvantes oleoso, demonstrou que as reações tuberculínicas obtidas com uso de PPD bovino e aviário eram específicas permitindo a distinção entre reações mecânicas, heterólogas e homólogas.

Os resultados da prova ao TCC serviram de parâmetros para a escolha dos 57 animais abatidos (Tabela 3): 31 (54,38\%) apresentaram reação a tuberculina bovina superior a aviária ( $\triangle P P D B v-\triangle P P D A v \geq 0)$ e $26(45,62 \%)$ reação a tuberculina bovina inferior a aviária $(\triangle \mathrm{PPD} B v-\triangle \mathrm{PPD} A v<0)$. Os parâmetros clínicos dos animais selecionados estavam dentro dos limites fisiológicos de variação estabelecidos para a espécie ovina (Apêndice $C$ ).

A tuberculose e as micobacterioses nos rebanhos de animais de produção são doenças de evolução lenta, assim muitas vezes não há exteriorização de sinais clínicos (principalmente em animais de criação de ciclo mais rápido) ou há apenas sinais inespecíficos como dispnéia, tosse, mastite, infertilidade, caquexia e depauperação; freqüentemente a sua presença só é percebida no momento do 
abate, aonde é praticamente impossível a caracterização do tipo de microorganismo envolvido (FERREIRA NETO et al., 1989; BALIAN et al., 1997; ABRAHÃO, 1998; MAPA, 2006).

Dos 57 animais abatidos, 11 (19,29\%) apresentaram lesões macroscópicas no exame post mortem e seis deles $(54,54 \%)$ apresentaram lesões em dois órgãos. Das 17 lesões observadas sete $(41,11 \%)$ ocorreram no fígado, três $(17,64 \%)$ no linfonodo submandibular, duas (11,76\%) nos intestinos, pulmão e linfonodos mediastínicos e uma (5,88\%) na glândula mamária (Tabela 4).

A presença de lesões sugestivas de tuberculose (inflamação crônica granulomatosa) em $19,29 \%$ dos animais necropsiados é um número bastante expressivo. Allen (1988) na Nova Zelândia observou 0,0003\% de animais com lesões suspeitas de tuberculose de 11,87 milhões de ovinos abatidos. Malone et al. (2003) referiram que, em 1991 na Irlanda do Norte, de 65 mil ovinos abatidos houve 0,033\% de carcaças com presença de lesões tuberculóides.

Houve isolamento de micobactérias em sete (12,28\%) dos 57 animais abatidos (Tab. 5), sendo cinco isolamentos (71,44\%) de M. flavescens, um (14,28\%) de $M$. kansasii e um (14,28\%) de micobactéria pertencente ao complexo $M$. tuberculosis. Não há citações de isolamento de $M$. flavescens e de $M$. kansasii em ovinos.

O M. flavescens é uma micobactéria do Grupo II de Runyon (escotocromogênica) de colônias amarelas, que pode apresentar crescimento rápido e não possui importância epidemiológica significativa (KONEMAN et al, 1993).

O M. kansasii é uma micobactéria do Grupo I de Runyon (fotocromogênica) que em humanos se caracteriza por provocar nódulos subcutâneos ou abcessos em pacientes com problemas de resistência. Também é reconhecido pela capacidade de sobreviver em fontes de água, inclusive em sistemas de captação e tratamento urbano (FALKINHAM III, 1993; KONEMAN et al., 1993; PEDLEY et al., 2004). O isolamento em fígado e linfonodos sugere que a ingestão desses agentes normalmente encontrados no solo, poeira e água se deu pelo pastejar rente ao solo que é característica da espécie, diferentemente das infecções por $M$. bovis que geralmente se dão por via aerógena, provocando lesões nos pulmões e linfonodos mediastínicos. 
A micobactéria isolada pertencente ao complexo $M$. tuberculosis apresentou crescimento lento e colônias esbranquiçadas. Apesar de ter se desenvolvido tanto em meio de Stonebrink quanto em meio de Löwenstein-Jensen, provavelmente se trata de isolamento de $M$. bovis. Apesar da sua preferência por meios com piruvato (ABRAHÃO, 1998), algumas estirpes não demonstram preferências por esses meios crescendo também nos meios glicerinados: portanto, o crescimento diferencial nos dois meios não deve ser utilizado como único diferencial (CORNER; NICOLAPOPOULOS, 1988). Na Espanha, Seva et al. (2002) isolaram M. bovis em cabras produtoras de leite em meio de Löwenstein-Jensen. De fato Corner e Nicolapopoulos (1988) relataram que os principais fatores envolvidos no sucesso do isolamento do $M$. bovis a partir de espécimes clínicos são: meio de cultura utilizado, processo de descontaminação e condições de incubação.

A baixa prevalência da tuberculose em rebanhos ovinos comerciais foi verificada por Allen (1988) na Nova Zelândia. Entretanto Davidson, Alley e Beatson (1981) verificaram, também na Nova Zelândia, que de 597 ovinos que pastavam com bovinos tuberculosos, 108 animais foram positivos ao teste de tuberculina intradérmico simples, dos quais setenta foram necropsiados e em 43 deles $(61 \%)$ foram encontradas lesões sugestivas de tuberculose.

Sharp (2000) afirmou que a tuberculose era rara em ovinos pois as oportunidades de contaminação são restritas e não por serem resistentes à doença como o sugerido por Edelman et. al. em 1925 (EDELMAN; MOHLER; EICHHORN ${ }^{1}$, 1925 apud CARMICHAEL, 1938, p. 1139).

Hulet et al. (1975) apontou o manejo extensivo dos ovinos (pastando durante o dia e recolhidos à noite) como um dos fatores responsáveis pela baixa disseminação da doença. Em bovinos ocorre situação semelhante, pois a tuberculose é menos freqüente em rebanhos de corte do que nos leiteiros, onde o sistema de criação é mais intensivo (MAPA, 2006). No presente estudo os animais eram mantidos a campo durante o dia sendo recolhidos aos galpões para alimentação e para passarem a noite.

Embora o Ministério da Agricultura, Pecuária e Abastecimento tenha publicado em 20/12/2004 a Instrução Normativa SDA 87 que aprova o Regulamento Técnico do Programa Nacional de Sanidade dos Caprinos e Ovinos (PNSCO), a

\footnotetext{
${ }^{1}$ Edelman, Mohler and Eichhorn. Meat hygiene. $5^{\text {th }}$ ed. 296. London: J.\& H. Churchill, Ltd., 1925.
} 
tuberculose ainda não foi considerada como doença a ser combatida pois sua incidência nessas espécies animais é admitida como rara. Entretanto, na Espanha já existe o Programa de Erradicação da Tuberculose na região da Murcia, voltado para - combate à doença em rebanhos de cabras leiteiras especialmente da raça Murciano-Granadina, inclusive com indenização aos proprietários de animais positivos abatidos (SEVA et al., 2002). No Brasil, a confirmação de tuberculose em um caprino atendido pelo HOVET da FMVZ-USP em 2001 desencadeou pesquisas que tem contribuído para a avaliação de ocorrência desta doença em pequenos ruminantes de rebanhos do Sudeste do país (CYRILLO, 2006; SILVA et al., 2006).

$O$ isolamento de Corynebacterium pseudotuberculosis em quatro $(7,01 \%)$ dos 57 animais abatidos dos quais dois $(50 \%)$ também houve isolamento de micobactérias (Tab. 6) reforça a necessidade do diagnóstico diferencial da micobacteriose com a linfadenite caseosa (LC), doença infecto-contagiosa crônica de grande importância para os ovinos e caprinos (COSTA, 2002; BAIRD; SYNGE; DERCKSEN, 2004) considerada como a maior causa de prejuízos econômicos para a ovinocultura por todo o mundo incluindo a América do Norte e a Austrália (BROWN; OLANDER, 1987).

Devido a grande semelhança dos sintomas e das lesões a LC pode ser confundida com a tuberculose (LANGENEGGER; LANGENEGGER, 1989; LANGENEGGER; LANGENEGGER; SCHERER, 1991; PATON et al., 2002), ocorrendo o desenvolvimento de abcessos internos nos linfonodos submandibulares, mediastínicos e mesentéricos, além de órgãos como fígado e pulmão (RADOSTIS et al., 2000; QUINN et al., 2005).

Na região oeste da Austrália, Paton (1993) calculou que a prevalência da LC entre os rebanhos era de $45 \%$ gerando prejuízos econômicos de 10 a 15 milhões de dólares australianos com as perdas na produção de lã e 10 milhões de dólares autralianos com a, toalete dos abcessos nas carcaças, principalmente nos abatedouros destinados a exportação.

No Brasil não foram encontrados dados recentes sobre a incidência e prevalência de LC. Em publicações dos anos 70 , já se estimava que a maioria dos rebanhos ovinos e caprinos estavam infectados e que a prevalência clínica chegava a $30 \%$ dos animais (SILVA, 1972; COSTA et al., 1973). 
rebanhos ovinos e caprinos estavam infectados e que a prevalência clínica chegava a 30\% dos animais (SILVA, 1972; COSTA et al., 1973).

A dificuldade para o estabelecimento do diagnóstico in vivo da LC faz com que muitas vezes o problema só seja percebido no momento do abate, quando a condenação de carcaças pela doença se torna inevitável. Um teste ELISA do tipo sanduíche de anticorpo duplo direcionado contra o C. pseudotuberculosis foi desenvolvido mas a baixa especificidade pode determinar o abate de animais não infectados (RADOSTIS et al., 2000).

A proximidade taxonômica dos gêneros Corynebacterium e Mycobacterium, a alta prevalência em ovinos e os resultados obtidos neste trabalho - $75 \%$ dos isolamentos de C. pseudotuberculosis ocorreram no grupo com reação a tuberculina bovina superior a aviária - sugerem a realização de estudos sistemáticos para melhor aferir a relação entre essas duas patologias. Essa problemática é bastante conhecida em outras espécies de interesse zootécnico devido às grandes perdas econômicas geradas pelo descarte de carcaças com lesões sugestivas de tuberculose: calcula-se que a linfadenite granulomatosa dos suínos (provocada principalmente por agentes do complexo Micobacterium avium) tenha provocado em 1999, apenas no Estado de Santa Catarina, prejuízos de 5,8 a 8,0 milhões de reais (PINHEIRO, 2001).

A associação entre as reações ao Teste Comparativo Cervical e a positividade para micobactérias (dada pelo isolamento e pelo histopatológico) foi estatisticamente significante quando a reação a tuberculina bovina foi superior a aviária com diferença igual ou superior a 0,2 $\mathrm{mm}$.

Cyrillo (2006) ao padronizar o alergoteste em ovinos utilizou animais previamente selecionados e negativos ao TCC (segundo padrão para bovinos) que foram mantidos durante todo experimento sob condições controladas. Convém ressaltar também que houve inoculação experimental de sensibilizantes elaborados com estirpes padrão ( $M$. bovis - AN5 e M. avium- D4), contudo os resultados obtidos em condições experimentais necessitam de validação a campo em animais naturalmente infectados.

A presença de micobactérias ambientais e de C. pseudotuberculosis neste experimento (Tabela 6) provavelmente interferiram nos resultados dos exames tuberculínicos. No TCC $90 \%$ dos animais positivos ocorreram no grupo com reação a 
tuberculina bovina superior a aviária: o único caso de isolamento que não pertence a este grupo foi de um animal infectado por micobactéria do complexo $M$. tuberculosis (provavelmente $M$. bovis), que não apresentou reação a tuberculina bovina superior a aviária (animal 648) provavelmente por ainda estar no início da infecção (MAPA, 2006).

Em relação ao teste cervical simples, os $22,9 \%$ de positividade provavelmente foram provocados por reações cruzadas com as micobactérias ambientais e o C. pseudotuberculosis. Caso se optasse exclusivamente pelo teste cervical simples, 81 animais teriam sido considerados como positivos enquanto para o TCC todos foram negativos.

O teste cervical comparativo é recomendado para a eliminação de reações inespecíficas e possível confirmação de positividade em animais com reação inconclusiva ou positiva ao PPD bovino no teste cervical simples (TCS), normalmente utilizado como teste de triagem (MAPA, 2004).

Haagsma (1995) refere que o TCC é usado para diferenciar os animais infectados por $M$. bovis daqueles expostos a outras micobactérias ou gêneros afins. A proximidade antigênica entre o PPD aviário e as micobactérias não pertencentes ao Complexo M. tuberculosis (MOTT) (BELISLE; BRENNAN, 2000) permite a identificação de reações inespecíficas, tanto provocadas pelas MOTT quanto por agentes dos gêneros Nocardia e Corynebacterium (CORRÊA; CORRÊA, 1992).

A análise estatística pelo teste de Fischer demonstrou haver associação entre as reações ao Teste Comparativo Cervical e a positividade para micobactérias, dada pelo isolamento e histopatológico, quando a reação a tuberculina bovina ( $\triangle P P D B v$ - $\triangle$ PPD Av) for igual ou superior a $0,2 \mathrm{~mm}$ da reação a tuberculina aviária, com nível de significância de 0,05.

No Brasil, o Ministério da Agricultura, Pecuária e Abastecimento (MAPA), recomenda pelo PNCEBT no controle da tuberculose dos bovinos e bubalinos que 0 diagnóstico seja efetuado pelo teste de tuberculina e que os animais positivos a sejam abatidos (MAPA, 2004). Nos ovinos, como não há legislação específica, a medida de controle adotada passa a ser a identificação de carcaças que apresentem lesões sugestivas de tuberculose, linfadenite e outras micobacterioses que possam determinar a condenação das mesmas. 
Deve-se ressaltar que, no presente estudo, o material dos 57 animais abatidos foi submetido a exames histopatológicos e teve como resultado $15,78 \%$ (nove animais) de positividade determinada pela presença de granuloma e coloração de Ziehl-Neelsen positiva (BAAR). Em seis animais (19,35\%) houve isolamento de micobactérias, sendo cinco $(83,33 \%)$ de $M$. flavescens e um $(16,67 \%)$ de $M$. kansasii. Foram isolados $C$. pseudotuberculosis em três $(9,67 \%)$ animais sendo que em um deles também foi isolado $M$. flavescens. Oito animais $(25,80 \%)$ foram considerados positivos para tuberculose pelo exame histopatológico. Se fosse feito o descarte da carcaça pela presença de lesões sugestivas, ocorreria a condenação de animais falso-positivos para a tuberculose.

Outro fator a ser considerado é a localização das lesões. Dos 176 materiais examinados, $11(6,25 \%)$ apresentaram lesões macroscópicas sugestivas de tuberculose, sendo três $(27,27 \%)$ no fígado, dois $(18,18 \%)$ em linfonodo mediastínico, dois $(18,18 \% \%)$ no intestino, dois $(18,18 \%)$ em linfonodo mesentérico, um $(9,09 \%)$ em linfonodo submandibular e um $(9,09 \%)$ em pulmão. De fato o predomínio de lesões no trato digestivo sugere que a porta de entrada tenha sido a ingestão de alimentos ou água contaminada.

A inspeção de carcaças ovinas em frigoríficos pode revelar a presença de granulomas tuberculosos, sendo o sistema respiratório o mais acometido, observando-se $82,6 \%$ de lesões nos pulmões (FRANCIS, 1958; KUMMENEJE; FODSTAD, 1976; ROBINSON, 1983); entretanto, podem ser acometidos diversos linfonodos, em particular os brônquicos, mediastínicos e mesentéricos, além de órgãos como o fígado, baço e os rins (BARTON; ACLAND, 1973; CHAUHAN et al.,1974; PUGH, 2005)

A utilização de informações geradas nos abatedouros de animais é de grande valia no acompanhamento do problema da tuberculose em espécies de interesse zootécnico (NATIONAL RESEARCH COUNCIL, 1994) Para os ovinos sugere-se que haja, sobretudo se associado aos testes tuberculínicos, um apoio laboratorial na identificação dos agentes nos materiais colhidos nos abatedouros. 


\section{CONCLUSÕES}

Nas condições do referido trabalho, os resultados obtidos permitem as seguintes conclusões:

1. Houve o isolamento de Mycobacterium kansasi, M. flavescens 1, micobactéria do complexo $M$. tuberculosis e Corynebacterium pseudotuberculosis das lesões sugestivas de tuberculose;

2. Nos exames macroscópico e histopatológico as lesões provocadas por $M$. flavescens 1, M. kansasi e C. pseudotuberculosis não foram diferenciáveis das provocadas pela micobactéria do complexo M. tuberculosis;

3. Houve isolamento concomitante de $M$. flavescens 1 e micobactéria do complexo M. tuberculosis com C. pseudotuberculosis; e

4. Os resultados obtidos nos testes imunoalérgicos utilizados (TCS e TCC) não serviram para a diferenciação de infecção por Mycobacterium kansasi, $M$. flavescens 1 e complexo M. tuberculosis de C. pseudotuberculosis. 


\section{REFERÊNCIAS ${ }^{1}$}

ABIEC - ASSOCIAÇÃO BRASILEIRA DAS INDÚSTRIAS EXPORTADORAS DE CARNE. Estatísticas. Disponível em: <http://www.abiec.com.br/estatisticas.asp>. Acesso em: 28 Fev. 2007.

ABRAHÃO, R. M. C. M. Tuberculose humana causada pelo Mycobacterium bovis: considerações gerais e a importância dos reservatórios animais. 1998. f.125; 90 -137. Dissertação (Mestrado em Saúde Pública) - Faculdade de Saúde Pública, Universidade de São Paulo, São Paulo, 1998.

ALLEN, G. M. Tuberculosis in sheep - a very rare disease. Surveillance. v. 15, p. 8 $-9,1988$.

ANERIK, A. I. Estudio experimental sobre el diagnóstico de la tuberculosis bovina mediante pruebas de cultivo e inoculación animal. Ciencia Veterinaria, Maracaibo, v. 4, p. 137-200, 1974.

AYELE, W. Y.; NEILL, S. D.; ZINSSTAG, J.; WEISS, M. G.; PAVLINK, L. Bovine tuberculosis: an old disease but a new threat to Africa. Institute Journal Tuberculosis Lung Disease, v. 8, n. 8, p. 924-937, 2004.

BAIRD, G.; SYNGE, B.; DERCKSEN, D. Survey of caseous lymphadenitis seroprevance in British terminal sire sheep breeds. The Veterinary Record, v. 154, n. 17, p. 505-506, 2004.

BALIAN, S. C.; RIBEIRO, P.; VASCONCELOS, S. A.; PINHEIRO, S. R.; FERREIRA NETO, J. S.; GUERRA, J. L.; XAVIER, J.G.; MORAIS, Z. M.; TELLES, M. A. S. Linfadenites tuberculóides em suínos abatidos no Estado de São Paulo, Brasil: aspectos macroscópicos, histopatológicos e pesquisa de micobactérias. Revista Brasileira de Saúde Pública da Faculdade de Saúde Pública da Universidade de São Paulo (SP), v. 31, n. 4, p. 391-397, 1997.

BARTON, M. D.; ACLAND, H. M. Mycobacterium avium serotype 2 infection in a sheep. Australian Veterinary Journal, v. 49, n. 4, p. 212-213, 1973.

$\mathrm{BELCHIOR,} \mathrm{A.} \mathrm{P.} \mathrm{C.} \mathrm{Prevalência,} \mathrm{distribuição} \mathrm{regional} \mathrm{e} \mathrm{fatores} \mathrm{de} \mathrm{risco} \mathrm{da}$ tuberculose bovina em Minas Gerais. 2000. 98 f. Dissertação (Mestrado) - Escola de Medicina Veterinária, Universidade Federal de Minas Gerais, Belo Horizonte, 2000.

BELISLE, J. T.; BRENNAN, P. J.; Mycobacteria In: Encyclopedia of microbiology. 2. ed., , London: Academic Press, 2000. p. 312-327

BIER, O. Micobactérias. In:

Bacteriologia e imunologia. $19^{\text {a. }}$ ed. São Paulo: Edições Melhoramentos, 1961. p. 500-525.

\footnotetext{
${ }^{1}$ Conforme as Diretrizes para apresentação de dissertações e teses na Faculdade de Medicina Veterinária e Zootecnia da Universidade de São Paulo. 4. ed. rev. atual. e ampl. São Paulo: FMVZUSP, 2003. $84 \mathrm{p}$.
} 
BROSCH, R.; GORDON, S. V.; MARMIESSE, M.; BRODIN, P.; BUCHRIESER, C.; EIGLMEIER, K.; GARNIER, T.; GUTIERREZ, C.; HEWINSON, G.; KREMER, K.; PARSONS, L. M.; PYM, A. S.; SAMPER, S.; VAN SOLINGEN, D.; COLE, A. A new evolutionary scenario for the Mycobacterium tuberculosis complex. Proccedings of National Academy of Sciences of the United States of America, v. 99, n.6, p. 3684-3689, 2002.

BROWN, C. C.; OLANDER, H. J. Caseous lymphadenitis of goats and sheep: A review. Veterinary Bulletin. n. 57, p. 1-11, 1987.

CENTRO PANAMERICANO DE ZOONOSIS. Bacteriologia de la tuberculosis humana y animal. Buenos Aires; Organización Panamericana de la Salud, 1988. 63 p. (Serie de Monografias Científicas y Técnicas; 11 rev. 1).

CHALMERS, J. W. T.; JAMIELSON, A. F.; RAFFERTY, P. An outbreak of bovine tuberculosis in two herds in south west Scotland: veterinary and human public health response. Journal of Public Health Medicine, v. 18, p. 54-58, 1996.

CHAUHAN, H. V. S.; DWIVEDI, D. P.; CHAUHAN, S. S.; KALRA, D. S. Tuberculosis in animal in India - a review. Indian Journal Tuberculosis, v. 21, n. 1, p. 22-35, 1974.

CHIMARA, E.; GIAMPAGLIA, C. M. S.; MARTINS, M. C.; TELLES, M. A. S.; UEKI, S. Y. M.; FERRAZOLI, L. Molecular caracterization of Mycobacterium kansasii Isolates in the State of São Paulo between 1995-1998. Memórias Instituto Oswaldo Cruz, v. 99, n. 7, p. 739-743, 2004.

COLLINS, C. H.; GRANGE, J. M .; YATES, M. D. Organization and pratice in tuberculosis bacteriology. Great Britain: Butterworth, 1985. p. 1-6.

COLLINS, M. T. Encyclopedia of dairy sciences. 1. ed. Washington: Academic Press, 2002.

CORDES, D. O.; BULLIANS, J. A.; LAKE, D. E.; CARTER, M. E. Observation on tuberculosis caused by Mycobacterium bovis in sheep. New Zeland Veterinary Journal. v. 29, p. 60 - 62, 1981.

CORNER, L. A. Post mortem diagnosis of mycobacterium bovis infection in cattle. Veterinary Microbiology, v. 40, p. 53-63, 1994.

CORNER, L. A.; NICOLAPOULOS, C. Comparison of media used for the primary isolation of Mycobacterium bovis by veterinary and medical diagnostic laboratories. Australian veterinary Journal, v. 65, n.7, p. 202-204, July, 1988.

CORREA, W. M.; CORREA, C. M. Enfermidades infecciosas dos mamíferos domésticos. São Paulo: Varela, 1992. 823 p. 
COSIVI, O.; GRANJE, J. M.; DABORN, C. J.; RAVIGLIONE, M. C.; FUGIKURA, T.; COUSINS, D.; ROBINSON, R. A.; HUCHZERMEYER, H. F. A. K.; KANTOR, I.; MESLIN, F. X. Zoonotic tuberculosis due to Mycobacterium bovis in developing countries. Emerging Infectious Diseases, v. 4, n. 1, p. 1998.

COSTA, L. F. M. Corynebacterium pseudotuberculosis, o agente etiológico da linfadenite caseosa em caprinos. Revista Ciência Biológica, v. 1, n. 1, p. 105-115, 2002.

COSTA, M. D. M.; CÂMARA, J. Q.; ROCHA, J. V. N.; MARTINEZ, T. C. N. Linfadenite caseosa dos caprinos no Estado da Bahia - Distribuição geográfica da doença. Boletim do Instituto Biológico da Bahia, v. 12, n. 1, p. 1-7, 1973.

CYRILLO, F. C. Padronização do alergoteste da tuberculina em ovinos (Ovis áries). 2006. 92 f. Dissertação (Mestrado em Clínica Médica) - Faculdade de Medicina Veterinária e Zootecnia, Universidade de São Paulo, São Paulo, 2006.

DAVIDSON, R. M.; ALLEY, M. R.; BEATSON, N. S. Tuberculosis in a flock sheep. New Zeland Veterinary Journal. v. 29, p. 1-2, 1981.

DEVALLOIS, A.; GOH, K. S.; RASTOGI, N. Rapid identification of mycobacteria to species level by PCR-restriction fragment length polymorphism analysis of the hsp65 gene and proposition of an algorithm to differentiate 34 mycobacterial species. Journal of Clinical Microbiology, v. 35, p. 2969-2973, 1997.

EUZÉBY, J. P. List of Prokaryotic Names with Standing in nomenclature - Genus Mycobacterium. Disponível em: <http://www.bacterio.cict.fr/m/mycobacterium.html . Acesso em: 6 mar. 2007.

FALKINHAM III, J. O. Epidemiology of infection by Nontuberculous Mycobacteria. Clinical Microbiology Reviews, v. 9, n. 2, p. 177-215, 1996.

FAO - FOOD AND AGRICULTURE ORGANIZATION (FAO Satistic Series, v. 47, n. 117, 1993).

FAO - FOOD AND AGRICULTURE ORGANIZATION Global Livestock Production and Health Atlas - GLIPHA. Disponível em: <http://www.fao.org/ag/aga/glipha/index.jsp>. Acesso em 3 Mar. 2007.

FERREIRA NETO, J. S.; CÔRTES, J. A.; SINHORINI, I. L.; VASCONCELOS, S. A.; ITO, F. H.; SILVA, E. A. M. A lesão tuberculóide como critério de diagnóstico da infecção micobacteriana em suínos abatidos em matadouro. Revista da Faculdade de Medicina Veterinária e Zootecnia da Universidade de São Paulo, São Paulo, v. 26, n. 1, p. 22-23, 1989.

FRANCIS, J. Tuberculosis in animals ad man: a study in comparative phatology. London: Cassell, 1958. 357 p.

GRANGE, J. M. Humam and bovine tuberculosis - New threats from na old disease. British Veterinary Journal, v. 152, n. 3, p. 3-5, 1996. 
HAAGSMA, J. Bovine tuberculosis. Office International des Épizooties (Manual Amendment, 2), 11 p.,1995.

HIEPE, H. T. Enfermidades de la oveja. Zaragoza: Acribia, 1972. 391 p.

HULET, C. V.; ALEXANDER, G.; HAFEZ, E. S. E. The behavior of sheep. In: The Behaviour of Domestic Animals. London: Balliére Tindall, 1975 , p. 246-294

IBGE - INSTITUTO BRASILEIRO DE GEOGRAFIA E ESTATÍSTICA. Banco de dados agragados - SIDRA. Disponível em: <http://www.sidra.ibge.gov.br/>. Acesso em: 4 mar. 2007.

JENSEN, R.; SWIFT, B. L. Diseases of respiratory system: In disease of sheep. 2. ed. Philadelphia: Lea \& Febiger, 1982. 330 p.

KANTOR, I. N. Situación de la tuberculosis bovina en América Latina y el Caribe. OPASIOMS. Nota técnica n. 8, 23 p., 1988.

KONEMAN, E. W.; ALLEN, S. D.; DOWELL JR., V. R.; SOMMERS, H. M. Micobactérias. In: Diagnóstico microbiológico: texto e atlas colorido. 2. ed. São Paulo: Medicina Panamericana Editora do Brasil. 1993. p. 489-535.

KRIEG, N. R.; HOLT, J. C., ed. Bergey's manual of determinative bacteriology. 9. ed. Baltimore: Willians \& Wilkins, 1994.

KUMMENEJE, K.; FODSTAD, F. H. A case of avian tuberculosis in sheep. Acta Veterinary Scandinavia, v. 17, n. 3, p. 286-292, 1976.

KURY, M. G. Dicionário de mitologia grega e romana. 7. ed. Editora Jorge Zahar, 2003. 406 p.

LANGENEGGER, C. H.; LANGENEGGER, J. Monitoramento sorológico e alérgico da infecção por Corynebacterium pseudotuberculosis. Pesquisa Veterinária Brasileira, v. 7, n. 2. p. 27-32, 1987.

LANGENEGGER, C. H.; LANGENEGGER, J.; SCHERER, P. O. Prevalência e diagnóstico comparativoda linfadenite caseosa em caprinos do Estado do Rio de Janeiro. Pesquisa Veterinária Brasileira, v. 11, n. 1/ 2, p. 31-34, 1991.

LILENBAUM, W. Atualização em tuberculose bovina. Revista Brasileira de medicina Veterinária, v. 22, n. 4, p. 145-151, 2000.

LIMA, M. M. Comparação entre diferentes políticas anti-tuberculose por meio de simulação epidemiológica em Ribeirão Preto/São Paulo 1980 a 1995.1995. p. 2-5. Tese (Mestrado em Saúde Pública) - Faculdade de Saúde Pública, Universidade de São Paulo, São Paulo, 1995.

LONDON SCHOOL OF HYGIENE \& TROPICAL MEDICINE "Third Annual Public Health Forum, Tuberculosis: back to the future". Great Britain: John Wiley \& Sons LTd. 1994. p. 14-18. 
MALONE, F. E.; WILSON, E. C.; PLLOCK, J. M.; SKUCE, R. A. Investigation into an outbreak of tuberculosis in a flock of sheep in contact with tuberculous cattle. Journal of Veterinary Medicine v. 50, n. 10 p. 500-504, 2003.

MAPA - MINISTÉRIO DA AGRICULTURA, PECUÁRIA E ABASTECIMENTO. Instrução Normativa SDA 53 de 12 de Julho de 2004. Regulamento técnico do Programa Nacional de Sanidade dos Caprinos e Ovinos - PNSCO. Disponível em: <http://www.agricultura.gov.br>. Acesso em: 28 fev. 2007.

MAPA - MINISTÉRIO DA AGRICULTURA, PECUÁRIA E ABASTECIMENTO. Manual técnico do Programa Nacional de Controle e Erradicação da Brucelose e da Tuberculose Animal (PNCEBT), Brasília: 2006.

MAPA - MINISTÉRIO DA AGRICULTURA, PECUÁRIA E ABASTECIMENTO. Estatísticas/Pecuária [2006?] Disponível em: $<$ http://www.agricultura.gov.br/pls/portal/docs/PAGE/MAPA/ESTATISTICAS/PECUA RIA/3.5.XLS >. Acesso em: 4. mar. 2007.

MAPA - MINISTÉRIO DA AGRICULTURA, PECUÁRIA E ABASTECIMENTO. Sistema de Informações Gerenciais do Serviço de Inspeção Federal - SIGSIF. [2007?] Disponível em: $<$ http://extranet.agricultura.gov.br/sigsif cons/lap abate estaduais cons $>$. Acesso em: 4 mar. 2007.

MARSH, H. Newsom's sheep diseases. 3. ed. Baltimore: The Williams \& Wilkins Company, 1965, $456 \mathrm{p}$.

MARTIN, W. B.; AITKEN, I. D. Tuberculosis in sheep: In Diseases of sheep. 3. ed. Editora Blackwell Science, p. 147-148, 2000.

MINISTÉRIO DO DESENVOLVIMENTO, INDÚSTRIA E COMÉRCIO EXTERIOR. Sistema de Análise das Informações de Comércio Exterior via Internet Aliceweb. Disponível em: <http://aliceweb.desenvolvimento.gov.br/default.asp $>$. Acesso em: 28 fev. 2007.

MURRAY, P. R.; BARON, E. J.; PFALLER, M. A.; TENOVER, F. C.; YOLKEN, R. H. Manual of clinical microbiology. 7. ed. Washington: American Society for Microbiology. 1999.

NATIONAL RESEARCH COUNCIL. Livestock disease eradication: Evaluation of the cooperative state-federal bovine tuberculosis eradication program. Washington: National Academy Press,1994, 97 p.

OHARA, P. M. Microbiologia e histopatologia de linfonodos de bovines com lesões macroscópicas sugestivas de tuberculose. Colheitas efetuadas de Maio/2002 à Janeiro/2004, São Paulo, Brasil. 2003. 103 f. Dissertação (Mestrado em Medicina Veterinária) - Faculdade de Medicina Veterinária e Zootecnia, Universidade de São Paulo, São Paulo, 2006. 
ORGANIZACIÓN PANAMERICANA DE LA SALUD. Situación de la tuberculosis bovina en las americas. Washington D. C.:OPS, 1995 (RIMSA 9 Informativo 26).

PACKER, R. A. Veterinarians challenge Dr. Robert Koch regarding bovine tuberculosis and public health. Journal of American Veterinary Medicine Association, v. 196, p. 574-575, 1990.

PATON, M. W.; MERCY, A. R.; WILKINSON, F. C.; GARDNER, J. J.; SUTHERLAND, S. S.; ELLIS, T. M. The effects of caseous lymphadenitis on wool production and body weight in young sheep. Australian Veterinary Journal, v. 65, p. 117-119, 1988.

PEDLEY, S.; BARTRAM, J.; REES, G.; DUFOUR, A.; COTRUVO, J. A. Pathogenic mycobacteria in water: a guide to public health consequences, monitoring and management. Emerging issues in water and infectious diseases, IWA publishing 237 p. 2004.

PINHEIRO, S. R. Avaliação da atividade micobactericida de desinfetantes químicos sobre estirpes de Mycobacterium avium, isoladas de suínos abatidos no estado de Santa Catarina, no ano de 1999. 2001. f. 14-33. 42. Tese (livre Docência) - Departamento de Medicina veterinária Preventiva e Saúde Animal da Universidade de São Paulo, São Paulo, 2001.

PRITCHARD, D. G. Acentury of bovine tuberculosis 1888-1988. journal of Comparative Pathology, v. 99, p. 357-99,1988.

PUGH, D. G. Clínica de ovinos e caprinos. São Paulo: Roca, 2005. 513 p.

QUINN, P. J.; MARKEY, B. K.; CARTER, M. E.; DONNELY, W. J. C.; LEONARD, F. C.; MAGUIRE, D. Microbiologia veterinária e doenças infecciosas. 1. ed. Artmed editora p. 2005.

RADOSTIS, O. M.; GAY, C. C.; BLOOD, D. C.; HINCHCLIFF, K. W. Veterinary Medicine. A textbook of the diseases of cattle, sheep, pigs, goats and horses. 9. ed., Londres: W. B. Saunders Company Ltd. 2000. 1737 p.

ROBINSON, R. A. Synposium on sheep and goat medicine. The Veterinary Clinics of Nort America - Large Animal Practice, v. 5, n. 3. p. 500-502, 1983.

ROCHA, H. C. Produção do cordeiro de corte em sistema de consorciação. Passo Fundo, Universidade de Passo Fundo, 2003. 64 p.

SANTOS, L. A. R. Co-infecção tuberculose/HIV no Estado de São Paulo: contribuição ao processo de vigilância epidemiológica da tuberculose. 1995. f. 2-5. Tese (Mestrado em Saúde Pública) - Faculdade de Saúde Pública da Universidade de São Paulo, São Paulo, 1995. 
SEVA, J.; MENCHÉN, V.; NAVARRO, J. A.; PALLARÉS, F. J.; VILLAR, D.; VÁSQUEZ, F.; BERNABÉ, A. Caprine tuberculosis eradication program: an immunohistochemical study. Small ruminant research, n. 46, p. 107-114, 2002.

SHARP, J. M. Tuberculosis in sheep. In: MARTIN, W. B.; AITKEN, I. D. Diseases of sheep. Oxford: Blackwell Science, p. 147. 2000.

SIEGEL, S. Estatística não-paramétrica (para as ciências do comportamento). São Paulo: McGraw-Hill, 1981. 350 p.

SILVA, F. M. Caroço dos caprinos (linfadenite caseosa) no Estado de Pernanbuco. Recife: Universidade Federal Rural de Pernanbuco, 1972.

SILVA, P. E. G. Padronização do alergoteste da tuberculina em caprinos (Capra hircus). 2004. 73 f. Dissertação (Mestrado em Clínica Médica) - Faculdade de Medicina Veterinária e Zootecnia , Universidade de São Paulo, São Paulo, 2004.

SILVA, P. E. G.; PINHEIRO, S. R.; LEAL, M. L. R.; BERTAGNON, H. G.; MOTA, P. M. P. C.; SINHORINI, I. L.; VASCONCELLOS, S. A.; BENESI, F. J. Teste de tuberculinização em caprinos (Capra hircus) experimentalmente identificados. Ciência Rural Santa Maria, v. 36, n. 3, p. 880-886, 2006.

SMITH, B. P. Medicina Interna de grandes animais. São Paulo: Editora Manole, 3. edição, 2006.

SMITH, M. C.; SHERMAN, D. M. Goat Medicine. 1. ed. Philadelphia: Lea e Febiger, 1994. $620 \mathrm{p}$.

TELENTI, A.; MARCHESI, F.; BALZ, M.; BALLY, F.; BÖTTGER, E. C.; BODMER, T. Rapid identification of mycobacteria to the species level by polymerase chain reaction and restriction enzyme analysis. Journal of Clinic Microbiology, v. 31, p. 175-178, 1993.

VASCONCELOS, S. A. Epidemiologia da tuberculose. Comunicação científica da Faculdade de Medicina Veterinária e Zootecnia da Universidade de São Paulo, v. 3, n. 1/2, p. 81-89, 1979.

WIKIPEDIA. Wikipédia, a enciclopédia livre. Disponível em: < http://pt.wikipedia.org/wiki/Ovino>. Acesso em: 3 mar. 2007.

WHO - WORLD HEALTH ORGANIZATION. Fact Sheet $\mathbf{N}^{\circ}$ 104. Disponível em: <http://www.who.int/mediacentre/factsheets/fs104/en/>. Acesso em: 19 jul. 2006.

WHO - WORLD HEALTH ORGANIZATION. Report of the WHO meeting on zoonotic tuberculosis (Mycobacterium bovis) with the participation of FAO. Genéve: FAO, 1993.

WHO - WORLD HEALTH ORGANIZATION. Zoonotic tuberculosis (Mycobacterium bovis): memorandum from a WHO meeting with the participation of FAO. Bulletin World Health Organization, v. 72, p. 851-857, 1994. 
WOLINSKY, E. Nontuberculous mycobacteria and associated diseases. American Review of Respiratory Disease, v. 119, p. 107-159, 1979.

ZINK, A. R.; NERLICH, A. G. Molecular strain identification of the Mycobacterium tuberculosis complex in archival tissue samples. Journal of Clinic Pathology, v. 57 p. 1185-1192, 2004. 
Apêndice A - Resultados do teste tuberculínico dos ovinos da propriedade A, segundo o animal, o momento da leitura e o tipo de tuberculina - São Paulo - 2007.

\begin{tabular}{|c|c|c|c|c|c|c|c|}
\hline \multirow{2}{*}{ Animal } & \multicolumn{2}{|c|}{0 hora } & \multicolumn{2}{|c|}{$72 \pm 6$ horas } & \multirow{2}{*}{$\Delta A v$} & \multirow{2}{*}{$\Delta B v$} & \multirow{2}{*}{$\Delta \mathrm{Bv}-\Delta \mathrm{Av}$} \\
\hline & PPD Av. & PPD Bov. & PPD Av. & PPD Bov & & & \\
\hline 9 & 3,2 & 3,5 & 7,9 & 5,7 & 4,7 & 2,2 & $-2,5$ \\
\hline 16 & 3,0 & 2,9 & 6,7 & 4,8 & 3,7 & 1,9 & $-1,8$ \\
\hline 17 & 2,1 & 1,9 & 5,9 & 4,5 & 3,8 & 2,6 & $-1,2$ \\
\hline 18 & 3,4 & 3,3 & 7,9 & 5,9 & 4,5 & 2,6 & $-1,9$ \\
\hline 20 & 2,5 & 2,5 & 3,8 & 3,9 & 1,3 & 1,4 & 0,1 \\
\hline 22 & 3,0 & 3,1 & 9,4 & 6,2 & 6,4 & 3,1 & $-3,3$ \\
\hline 29 & 3,1 & 3,1 & 6,7 & 4,4 & 3,6 & 1,3 & $-2,3$ \\
\hline 33 & 2,2 & 1,9 & 4,9 & 4,7 & 2,7 & 2,8 & 0,1 \\
\hline 39 & 2,3 & 2,4 & 4,9 & 3,2 & 2,6 & 0,8 & $-1,8$ \\
\hline 40 & 2,5 & 2,5 & 6,4 & 5,0 & 3,9 & 2,5 & $-1,4$ \\
\hline 41 & 2,5 & 2,3 & 5,6 & 4,8 & 3,1 & 2,5 & $-0,6$ \\
\hline 41 & 2,7 & 2,5 & 5,5 & 4,5 & 2,8 & 2,0 & $-0,8$ \\
\hline 48 & 2,5 & 2,3 & 5,4 & 4,4 & 2,9 & 2,1 & $-0,8$ \\
\hline 49 & 2,8 & 2,5 & 7,6 & 4,5 & 4,8 & 2,0 & $-2,8$ \\
\hline 54 & 3,6 & 3,4 & 7,0 & 6,4 & 3,4 & 3,0 & $-0,4$ \\
\hline 55 & 2,6 & 2,5 & 7,0 & 3,5 & 4,4 & 1,0 & $-3,4$ \\
\hline 58 & 3,7 & 3,5 & 7,3 & 4,8 & 3,6 & 1,3 & $-2,3$ \\
\hline 60 & 3,2 & 2,5 & 9,2 & 4,5 & 6,0 & 2,0 & $-4,0$ \\
\hline 65 & 2,6 & 2,5 & 5,6 & 3,4 & 3,0 & 0,9 & $-2,1$ \\
\hline 67 & 2,8 & 2,0 & 6,7 & 4,0 & 3,9 & 2,0 & $-1,9$ \\
\hline 71 & 3,8 & 3,0 & 8,6 & 4,8 & 4,8 & 1,8 & $-3,0$ \\
\hline 72 & 2,1 & 2,3 & 4,9 & 3,8 & 2,8 & 1,5 & $-1,3$ \\
\hline 73 & 3,7 & 2,4 & 7,0 & 4,9 & 3,3 & 2,5 & $-0,8$ \\
\hline 84 & 2,0 & 2,1 & 2,3 & 2,6 & 0,3 & 0,5 & 0,2 \\
\hline 90 & 2,9 & 2,9 & 6,4 & 5,2 & 3,5 & 2,3 & $-1,2$ \\
\hline 92 & 3,2 & 3,0 & 6,2 & 4,1 & 3,0 & 1,1 & $-1,9$ \\
\hline 94 & 4,5 & 3,8 & 8,3 & 6,6 & 3,8 & 2,8 & $-1,0$ \\
\hline 97 & 3,2 & 3,4 & 7,4 & 6,3 & 4,2 & 2,9 & $-1,3$ \\
\hline 100 & 2,7 & 2,5 & 7,0 & 5,6 & 4,3 & 3,1 & $-1,2$ \\
\hline 103 & 3,0 & 2,7 & 7,3 & 5,3 & 4,3 & 2,6 & $-1,7$ \\
\hline 113 & 2,6 & 2,3 & 5,6 & 4,1 & 3,0 & 1,8 & $-1,2$ \\
\hline 114 & 2,9 & 3,0 & 6,4 & 5,4 & 3,5 & 2,4 & $-1,1$ \\
\hline 117 & 1,6 & 1,5 & 4,5 & 3,9 & 2,9 & 2,4 & $-0,5$ \\
\hline 122 & 3,9 & 4,0 & 7,5 & 6,2 & 3,6 & 2,2 & $-1,4$ \\
\hline 126 & 2,7 & 1,7 & 2,7 & 2,6 & 0,0 & 0,9 & 0,9 \\
\hline 127 & 2,9 & 2,7 & 8,1 & 4,9 & 5,2 & 2,2 & $-3,0$ \\
\hline 129 & 3,1 & 2,7 & 6,4 & 6,2 & 3,3 & 3,5 & 0,2 \\
\hline 131 & 3,7 & 2,6 & 6,0 & 5,0 & 2,3 & 2,4 & 0,1 \\
\hline 136 & 3,3 & 3,0 & 4,2 & 3,8 & 0,9 & 0,8 & $-0,1$ \\
\hline 145 & 3,0 & 2,7 & 6,7 & 4,7 & 3,7 & 2,0 & $-1,7$ \\
\hline 146 & 3,8 & 3,0 & 6,8 & 5,5 & 3,0 & 2,5 & $-0,5$ \\
\hline 147 & 2,8 & 2,6 & 7,5 & 4,7 & 4,7 & 2,1 & $-2,6$ \\
\hline 153 & 1,9 & 1,7 & 4,6 & 3,9 & 2,7 & 2,2 & $-0,5$ \\
\hline 155 & 2,5 & 2,6 & 4,4 & 4,3 & 1,9 & 1,7 & $-0,2$ \\
\hline 165 & 2,5 & 2,5 & 5,7 & 4,8 & 3,2 & 2,3 & $-0,9$ \\
\hline 168 & 2,4 & 2,3 & 3,9 & 4,0 & 1,5 & 1,7 & 0,2 \\
\hline 173 & 2,2 & 2,3 & 5,3 & 4,9 & 3,1 & 2,6 & $-0,5$ \\
\hline 175 & 3,2 & 2,9 & 5,9 & 3,9 & 2,7 & 1,0 & $-1,7$ \\
\hline 176 & 2,5 & 2,0 & 4,0 & 3,8 & 1,5 & 1,8 & 0,3 \\
\hline
\end{tabular}


APÊNDICE A

(Continuação)

\begin{tabular}{|c|c|c|c|c|c|c|c|}
\hline \multirow{2}{*}{ Animal } & \multicolumn{2}{|c|}{ O hora } & \multicolumn{2}{|c|}{$72 \pm 6$ horas } & \multirow{2}{*}{$\Delta A \mathbf{v}$} & \multirow{2}{*}{$\Delta \mathrm{Bv}$} & \multirow{2}{*}{$\Delta B v-\Delta A v$} \\
\hline & PPD Av. & PPD Bov. & PPD Av. & PPD Bov & & & \\
\hline 177 & 2,4 & 2,1 & 5,2 & 3,5 & 2,8 & 1,4 & $-1,4$ \\
\hline 182 & 4,6 & 4,8 & 4,8 & 5,3 & 0,2 & 0,5 & 0,3 \\
\hline 186 & 2,9 & 3,0 & 4,7 & 4,2 & 1,8 & 1,2 & $-0,6$ \\
\hline 193 & 2,9 & 2,7 & 7,2 & 6,4 & 4,3 & 3,7 & $-0,6$ \\
\hline 197 & 3,4 & 2,7 & 5,0 & 4,6 & 1,6 & 1,9 & 0,3 \\
\hline 206 & 2,2 & 2,0 & 3,7 & 4,0 & 1,5 & 2,0 & 0,5 \\
\hline 211 & 2,8 & 2,7 & 8,4 & 5,5 & 5,6 & 2,8 & $-2,8$ \\
\hline 221 & 2,5 & 2,2 & 5,4 & 4,0 & 2,9 & 1,8 & $-1,1$ \\
\hline 223 & 3,9 & 3,6 & 8,5 & 6,3 & 4,6 & 2,7 & $-1,9$ \\
\hline 226 & 3,4 & 3,2 & 6,7 & 5,2 & 3,3 & 2,0 & $-1,3$ \\
\hline 228 & 2,6 & 2,9 & 5,5 & 4,0 & 2,9 & 1,1 & $-1,8$ \\
\hline 230 & 2,6 & 2,1 & 3,7 & 2,9 & 1,1 & 0,8 & $-0,3$ \\
\hline 232 & 3,2 & 2,7 & 6,1 & 5,5 & 2,9 & 2,8 & $-0,1$ \\
\hline 235 & 2,9 & 2,5 & 7,2 & 5,0 & 4,3 & 2,5 & $-1,8$ \\
\hline 239 & 2,8 & 2,3 & 5,9 & 4,5 & 3,1 & 2,2 & $-0,9$ \\
\hline 239 & 3,6 & 3,2 & 7,7 & 6,0 & 4,1 & 2,8 & $-1,3$ \\
\hline 240 & 3,0 & 2,7 & 7,0 & 5,0 & 4,0 & 2,3 & $-1,7$ \\
\hline 253 & 3,3 & 2,8 & 7,3 & 5,3 & 4,0 & 2,5 & $-1,5$ \\
\hline 258 & 3,0 & 2,6 & 6,5 & 3,2 & 3,5 & 0,6 & $-2,9$ \\
\hline 262 & 3,1 & 3,2 & 9,8 & 5,9 & 6,7 & 2,7 & $-4,0$ \\
\hline 263 & 2,8 & 2,7 & 6,2 & 6,0 & 3,4 & 3,3 & $-0,1$ \\
\hline 265 & 1,9 & 1,6 & 3,9 & 4,1 & 2,0 & 2,5 & 0,5 \\
\hline 269 & 3,0 & 2,5 & 6,7 & 5,2 & 3,7 & 2,7 & $-1,0$ \\
\hline 270 & 2,3 & 2,2 & 4,6 & 4,6 & 2,3 & 2,4 & 0,1 \\
\hline 272 & 3,2 & 3,2 & 7,5 & 5,5 & 4,3 & 2,3 & $-2,0$ \\
\hline 275 & 4,2 & 3,5 & 5,6 & 3,4 & 1,4 & $-0,1$ & $-1,5$ \\
\hline 279 & 2,3 & 2,0 & 4,5 & 4,5 & 2,2 & 2,5 & 0,3 \\
\hline 282 & 3,5 & 2,9 & 3,5 & 2,9 & 0,0 & 0,0 & 0,0 \\
\hline 286 & 2,5 & 2,3 & 6,5 & 4,5 & 4,0 & 2,2 & $-1,8$ \\
\hline 294 & 2,2 & 1,8 & 4,2 & 3,5 & 2,0 & 1,7 & $-0,3$ \\
\hline 295 & 2,9 & 2,7 & 4,5 & 3,9 & 1,6 & 1,2 & $-0,4$ \\
\hline 296 & 3,9 & 3,7 & 7,2 & 6,5 & 3,3 & 2,8 & $-0,5$ \\
\hline 301 & 2,7 & 2,5 & 5,8 & 4,5 & 3,1 & 2,0 & $-1,1$ \\
\hline 302 & 3,1 & 2,6 & 6,3 & 5,0 & 3,2 & 2,4 & $-0,8$ \\
\hline 304 & 2,7 & 2,2 & 3,9 & 3,5 & 1,2 & 1,3 & 0,1 \\
\hline 311 & 1,6 & 1,7 & 4,7 & 3,6 & 3,1 & 1,9 & $-1,2$ \\
\hline 313 & 3,6 & 3,0 & 8,1 & 5,7 & 4,5 & 2,7 & $-1,8$ \\
\hline 319 & 3,0 & 3,1 & 6,5 & 5,0 & 3,5 & 1,9 & $-1,6$ \\
\hline 323 & 1,6 & 1,5 & 3,0 & 2,6 & 1,4 & 1,1 & $-0,3$ \\
\hline 324 & 3,6 & 3,5 & 8,8 & 5,7 & 5,2 & 2,2 & $-3,0$ \\
\hline 327 & 2,9 & 2,3 & 4,5 & 2,8 & 1,6 & 0,5 & $-1,1$ \\
\hline 330 & 2,6 & 2,6 & 7,2 & 6,3 & 4,6 & 3,7 & $-0,9$ \\
\hline 342 & 2,2 & 1,9 & 2,6 & 2,6 & 0,4 & 0,7 & 0,3 \\
\hline 346 & 2,9 & 3,0 & 5,9 & 5,0 & 3,0 & 2,0 & $-1,0$ \\
\hline 349 & 2,0 & 2,1 & 5,1 & 4,8 & 3,1 & 2,7 & $-0,4$ \\
\hline 362 & 5,1 & 5,3 & 11,9 & 7,2 & 6,8 & 1,9 & $-4,9$ \\
\hline 365 & 2,9 & 2,5 & 7,6 & 4,8 & 4,7 & 2,3 & $-2,4$ \\
\hline 366 & 2,9 & 3,0 & 7,0 & 5,7 & 4,1 & 2,7 & $-1,4$ \\
\hline 369 & 2,3 & 2,3 & 3,8 & 3,7 & 1,5 & 1,4 & $-0,1$ \\
\hline 374 & 3,2 & 2,7 & 5,9 & 5,0 & 2,7 & 2,3 & $-0,4$ \\
\hline
\end{tabular}


APÊNDICE A

(Continuação)

\begin{tabular}{|c|c|c|c|c|c|c|c|}
\hline \multirow{2}{*}{ Animal } & \multicolumn{2}{|c|}{ O hora } & \multicolumn{2}{|c|}{$72 \pm 6$ horas } & \multirow{2}{*}{$\Delta A \mathbf{v}$} & \multirow{2}{*}{$\Delta \mathrm{Bv}$} & \multirow{2}{*}{$\Delta B v-\Delta A v$} \\
\hline & PPD Av. & PPD Bov. & PPD Av. & PPD Bov & & & \\
\hline 375 & 3,6 & 3,5 & 10,6 & 4,9 & 7,0 & 1,4 & $-5,6$ \\
\hline 376 & 3,6 & 3,7 & 13,9 & 6,6 & 10,3 & 2,9 & $-7,4$ \\
\hline 383 & 2,9 & 2,5 & 6,1 & 4,0 & 3,2 & 1,5 & $-1,7$ \\
\hline 389 & 2,2 & 2,0 & 4,0 & 2,8 & 1,8 & 0,8 & $-1,0$ \\
\hline 390 & 2,9 & 3,0 & 5,1 & 4,6 & 2,2 & 1,6 & $-0,6$ \\
\hline 412 & 2,8 & 2,7 & 10,3 & 6,6 & 7,5 & 3,9 & $-3,6$ \\
\hline 418 & 2,8 & 2,9 & 6,3 & 4,4 & 3,5 & 1,5 & $-2,0$ \\
\hline 420 & 3,2 & 2,7 & 6,4 & 3,3 & 3,2 & 0,6 & $-2,6$ \\
\hline 423 & 3,2 & 3,1 & 11,2 & 6,2 & 8,0 & 3,1 & $-4,9$ \\
\hline 426 & 3,5 & 3,2 & 8,2 & 5,3 & 4,7 & 2,1 & $-2,6$ \\
\hline 435 & 3,4 & 3,0 & 8,0 & 4,8 & 4,6 & 1,8 & $-2,8$ \\
\hline 440 & 3,9 & 3,4 & 8,6 & 5,6 & 4,7 & 2,2 & $-2,5$ \\
\hline 448 & 3,6 & 3,0 & 7,7 & 4,7 & 4,1 & 1,7 & $-2,4$ \\
\hline 449 & 1,6 & 1,8 & 3,2 & 3,0 & 1,6 & 1,2 & $-0,4$ \\
\hline 453 & 2,6 & 2,4 & 9,2 & 4,3 & 6,6 & 1,9 & $-4,7$ \\
\hline 464 & 3,4 & 2,9 & 6,3 & 4,8 & 2,9 & 1,9 & $-1,0$ \\
\hline 465 & 3,5 & 2,8 & 6,7 & 5,2 & 3,2 & 2,4 & $-0,8$ \\
\hline 466 & 3,5 & 3,3 & 5,5 & 5,2 & 2,0 & 1,9 & $-0,1$ \\
\hline 467 & 3,5 & 3,1 & 6,4 & 5,2 & 2,9 & 2,1 & $-0,8$ \\
\hline 477 & 4,0 & 3,2 & 7,9 & 5,7 & 3,9 & 2,5 & $-1,4$ \\
\hline 478 & 2,2 & 1,8 & 4,8 & 4,5 & 2,6 & 2,7 & 0,1 \\
\hline 480 & 3,4 & 3,0 & 6,0 & 5,3 & 2,6 & 2,3 & $-0,3$ \\
\hline 486 & 2,5 & 2,2 & 3,0 & 3,6 & 0,5 & 1,4 & 0,9 \\
\hline 488 & 2,5 & 2,0 & 6,0 & 3,6 & 3,5 & 1,6 & $-1,9$ \\
\hline 512 & 3,3 & 3,2 & 6,5 & 5,6 & 3,2 & 2,4 & $-0,8$ \\
\hline 516 & 2,7 & 2,2 & 3,8 & 4,2 & 1,1 & 2,0 & 0,9 \\
\hline 525 & 3,0 & 3,1 & 11,2 & 5,0 & 8,2 & 1,9 & $-6,3$ \\
\hline 530 & 2,9 & 2,4 & 5,5 & 4,3 & 2,6 & 1,9 & $-0,7$ \\
\hline 535 & 2,9 & 2,8 & 5,2 & 4,5 & 2,3 & 1,7 & $-0,6$ \\
\hline 539 & 3,2 & 2,6 & 6,5 & 5,7 & 3,3 & 3,1 & $-0,2$ \\
\hline 544 & 2,9 & 2,8 & 8,7 & 4,3 & 5,8 & 1,5 & $-4,3$ \\
\hline 545 & 2,8 & 2,4 & 5,7 & 4,9 & 2,9 & 2,5 & $-0,4$ \\
\hline 552 & 2,4 & 2,2 & 3,5 & 3,8 & 1,1 & 1,6 & 0,5 \\
\hline 554 & 4,0 & 3,9 & 5,5 & 3,8 & 1,5 & $-0,1$ & $-1,6$ \\
\hline 561 & 2,2 & 1,9 & 4,8 & 3,1 & 2,6 & 1,2 & $-1,4$ \\
\hline 563 & 2,7 & 3,0 & 7,5 & 5,7 & 4,8 & 2,7 & $-2,1$ \\
\hline 575 & 2,9 & 2,6 & 7,8 & 4,4 & 4,9 & 1,8 & $-3,1$ \\
\hline 576 & 3,2 & 2,8 & 6,7 & 4,2 & 3,5 & 1,4 & $-2,1$ \\
\hline 580 & 2,1 & 2,3 & 2,5 & 2,8 & 0,4 & 0,5 & 0,1 \\
\hline 583 & 3,2 & 3,0 & 7,7 & 4,8 & 4,5 & 1,8 & $-2,7$ \\
\hline 584 & 3,3 & 3,0 & 6,2 & 3,8 & 2,9 & 0,8 & $-2,1$ \\
\hline 585 & 2,8 & 3,0 & 5,6 & 5,6 & 2,8 & 2,6 & $-0,2$ \\
\hline 587 & 2,6 & 2,3 & 3,4 & 3,0 & 0,8 & 0,7 & $-0,1$ \\
\hline 597 & 3,2 & 2,7 & 6,2 & 5,2 & 3,0 & 2,5 & $-0,5$ \\
\hline 599 & 1,9 & 1,8 & 3,2 & 3,7 & 1,3 & 1,9 & 0,6 \\
\hline 600 & 1,7 & 1,4 & 2,6 & 2,3 & 0,9 & 0,9 & 0,0 \\
\hline 608 & 3,5 & 3,0 & 6,2 & 4,3 & 2,7 & 1,3 & $-1,4$ \\
\hline 609 & 1,6 & 1,7 & 9,0 & 3,0 & 7,4 & 1,3 & $-6,1$ \\
\hline 617 & 3,3 & 2,8 & 6,0 & 5,0 & 2,7 & 2,2 & $-0,5$ \\
\hline 624 & 2,8 & 2,2 & 4,3 & 3,0 & 1,5 & 0,8 & $-0,7$ \\
\hline
\end{tabular}


APÊNDICE A

(Continuação)

\begin{tabular}{|c|c|c|c|c|c|c|c|}
\hline \multirow{2}{*}{ Animal } & \multicolumn{2}{|c|}{ O hora } & \multicolumn{2}{|c|}{$72 \pm 6$ horas } & \multirow{2}{*}{$\Delta A \mathbf{v}$} & \multirow{2}{*}{$\Delta \mathrm{Bv}$} & \multirow{2}{*}{$\Delta B v-\Delta A v$} \\
\hline & PPD Av. & PPD Bov. & PPD Av. & PPD Bov & & & \\
\hline 625 & 2,5 & 2,5 & 5,2 & 4,2 & 2,7 & 1,7 & $-1,0$ \\
\hline 627 & 2,5 & 2,4 & 6,5 & 4,4 & 4,0 & 2,0 & $-2,0$ \\
\hline 628 & 3,3 & 2,7 & 5,2 & 4,2 & 1,9 & 1,5 & $-0,4$ \\
\hline 635 & 3,4 & 2,7 & 6,7 & 4,4 & 3,3 & 1,7 & $-1,6$ \\
\hline 639 & 3,1 & 2,9 & 6,7 & 4,1 & 3,6 & 1,2 & $-2,4$ \\
\hline 648 & 2,2 & 2,1 & 3,5 & 2,7 & 1,3 & 0,6 & $-0,7$ \\
\hline 661 & 2,6 & 2,5 & 6,3 & 4,3 & 3,7 & 1,8 & $-1,9$ \\
\hline 664 & 3,9 & 3,7 & 7,4 & 5,7 & 3,5 & 2,0 & $-1,5$ \\
\hline 672 & 2,7 & 2,8 & 5,1 & 3,9 & 2,4 & 1,1 & $-1,3$ \\
\hline 682 & 3,6 & 2,6 & 6,7 & 4,5 & 3,1 & 1,9 & $-1,2$ \\
\hline 684 & 3,1 & 3,0 & 6,2 & 5,9 & 3,1 & 2,9 & $-0,2$ \\
\hline 686 & 3,0 & 3,0 & 8,3 & 6,5 & 5,3 & 3,5 & $-1,8$ \\
\hline 687 & 2,9 & 2,3 & 7,2 & 5,1 & 4,3 & 2,8 & $-1,5$ \\
\hline 690 & 2,3 & 1,7 & 4,1 & 4,0 & 1,8 & 2,3 & 0,5 \\
\hline 694 & 2,3 & 1,8 & 2,5 & 3,0 & 0,2 & 1,2 & 1,0 \\
\hline 695 & 3,5 & 3,1 & 6,7 & 6,2 & 3,2 & 3,1 & $-0,1$ \\
\hline 702 & 2,1 & 1,8 & 2,7 & 2,7 & 0,6 & 0,9 & 0,3 \\
\hline 706 & 3,2 & 3,0 & 7,2 & 4,9 & 4,0 & 1,9 & $-2,1$ \\
\hline 714 & 1,8 & 1,7 & 4,2 & 4,9 & 2,4 & 3,2 & 0,8 \\
\hline 722 & 2,3 & 2,0 & 5,5 & 5,1 & 3,2 & 3,1 & $-0,1$ \\
\hline 723 & 2,6 & 2,5 & 7,0 & 5,3 & 4,4 & 2,8 & $-1,6$ \\
\hline 727 & 2,2 & 2,0 & 4,6 & 5,0 & 2,4 & 3,0 & 0,6 \\
\hline 734 & 2,7 & 2,7 & 6,1 & 5,1 & 3,4 & 2,4 & $-1,0$ \\
\hline 737 & 2,0 & 1,8 & 4,7 & 4,9 & 2,7 & 3,1 & 0,4 \\
\hline 738 & 3,2 & 2,9 & 8,5 & 4,0 & 5,3 & 1,1 & $-4,2$ \\
\hline 739 & 3,2 & 2,9 & 8,9 & 5,2 & 5,7 & 2,3 & $-3,4$ \\
\hline 740 & 3,2 & 3,3 & 7,4 & 6,2 & 4,2 & 2,9 & $-1,3$ \\
\hline 747 & 1,8 & 1,8 & 3,9 & 3,5 & 2,1 & 1,7 & $-0,4$ \\
\hline 750 & 2,6 & 2,2 & 8,2 & 5,4 & 5,6 & 3,2 & $-2,4$ \\
\hline 753 & 2,9 & 2,6 & 3,4 & 3,4 & 0,5 & 0,8 & 0,3 \\
\hline 754 & 1,9 & 2,0 & 4,2 & 4,1 & 2,3 & 2,1 & $-0,2$ \\
\hline 759 & 3,0 & 2,8 & 5,1 & 4,0 & 2,1 & 1,2 & $-0,9$ \\
\hline 765 & 2,5 & 2,2 & 7,7 & 4,5 & 5,2 & 2,3 & $-2,9$ \\
\hline 770 & 3,0 & 2,8 & 7,3 & 3,9 & 4,3 & 1,1 & $-3,2$ \\
\hline 774 & 2,7 & 2,4 & 6,4 & 4,7 & 3,7 & 2,3 & $-1,4$ \\
\hline 776 & 2,3 & 2,2 & 5,5 & 3,7 & 3,2 & 1,5 & $-1,7$ \\
\hline 780 & 2,3 & 1,9 & 7,9 & 3,5 & 5,6 & 1,6 & $-4,0$ \\
\hline 806 & 3,4 & 3,0 & 5,9 & 4,1 & 2,5 & 1,1 & $-1,4$ \\
\hline 809 & 2,5 & 2,5 & 5,7 & 5,3 & 3,2 & 2,8 & $-0,4$ \\
\hline 813 & 2,4 & 2,7 & 4,0 & 4,1 & 1,6 & 1,4 & $-0,2$ \\
\hline 814 & 3,1 & 2,9 & 5,6 & 4,6 & 2,5 & 1,7 & $-0,8$ \\
\hline 819 & 2,5 & 2,1 & 6,4 & 5,1 & 3,9 & 3,0 & $-0,9$ \\
\hline 822 & 2,8 & 2,3 & 4,2 & 4,0 & 1,4 & 1,7 & 0,3 \\
\hline 823 & 2,5 & 2,4 & 4,0 & 4,0 & 1,5 & 1,6 & 0,1 \\
\hline 824 & 1,1 & 1,2 & 3,4 & 3,4 & 2,3 & 2,2 & $-0,1$ \\
\hline 826 & 2,9 & 2,5 & 6,2 & 5,6 & 3,3 & 3,1 & $-0,2$ \\
\hline 827 & 1,7 & 1,6 & 2,6 & 2,4 & 0,9 & 0,8 & $-0,1$ \\
\hline 828 & 2,3 & 2,4 & 6,0 & 4,0 & 3,7 & 1,6 & $-2,1$ \\
\hline 837 & 1,3 & 1,1 & 7,6 & 2,4 & 6,3 & 1,3 & $-5,0$ \\
\hline 841 & 2,3 & 2,3 & 7,0 & 4,3 & 4,7 & 2,0 & $-2,7$ \\
\hline
\end{tabular}


APÊNDICE A

(Continuação)

\begin{tabular}{|c|c|c|c|c|c|c|c|}
\hline \multirow{2}{*}{ Animal } & \multicolumn{2}{|c|}{ O hora } & \multicolumn{2}{|c|}{$72 \pm 6$ horas } & \multirow{2}{*}{$\Delta A \mathbf{v}$} & \multirow{2}{*}{$\Delta \mathrm{Bv}$} & \multirow{2}{*}{$\Delta B v-\Delta A v$} \\
\hline & PPD Av. & PPD Bov. & PPD Av. & PPD Bov & & & \\
\hline 852 & 2,3 & 2,2 & 5,2 & 4,1 & 2,9 & 1,9 & $-1,0$ \\
\hline 856 & 2,6 & 2,4 & 8,1 & 5,9 & 5,5 & 3,5 & $-2,0$ \\
\hline 858 & 2,5 & 2,5 & 5,7 & 4,9 & 3,2 & 2,4 & $-0,8$ \\
\hline 859 & 3,0 & 2,8 & 7,0 & 4,9 & 4,0 & 2,1 & $-1,9$ \\
\hline 869 & 2,9 & 2,5 & 8,9 & 5,8 & 6,0 & 3,3 & $-2,7$ \\
\hline 871 & 3,1 & 3,0 & 6,0 & 4,9 & 2,9 & 1,9 & $-1,0$ \\
\hline 879 & 3,1 & 3,2 & 11,1 & 6,6 & 8,0 & 3,4 & $-4,6$ \\
\hline 880 & 2,6 & 2,4 & 7,6 & 4,9 & 5,0 & 2,5 & $-2,5$ \\
\hline 882 & 2,6 & 2,6 & 4,8 & 4,2 & 2,2 & 1,6 & $-0,6$ \\
\hline 883 & 2,6 & 2,8 & 6,0 & 5,1 & 3,4 & 2,3 & $-1,1$ \\
\hline 888 & 3,0 & 3,0 & 5,0 & 4,6 & 2,0 & 1,6 & $-0,4$ \\
\hline 889 & 2,6 & 2,0 & 5,0 & 3,5 & 2,4 & 1,5 & $-0,9$ \\
\hline 892 & 2,7 & 2,5 & 4,5 & 4,5 & 1,8 & 2,0 & 0,2 \\
\hline 896 & 3,0 & 2,8 & 4,8 & 3,6 & 1,8 & 0,8 & $-1,0$ \\
\hline 902 & 3,0 & 2,8 & 5,7 & 3,5 & 2,7 & 0,7 & $-2,0$ \\
\hline 908 & 2,4 & 2,1 & 3,5 & 3,3 & 1,1 & 1,2 & 0,1 \\
\hline 915 & 2,8 & 3,1 & 11,2 & 6,6 & 8,4 & 3,5 & $-4,9$ \\
\hline 921 & 2,4 & 2,5 & 3,2 & 3,8 & 0,8 & 1,3 & 0,5 \\
\hline 933 & 2,6 & 2,6 & 8,5 & 6,0 & 5,9 & 3,4 & $-2,5$ \\
\hline 934 & 2,8 & 3,1 & 8,2 & 6,5 & 5,4 & 3,4 & $-2,0$ \\
\hline 940 & 2,4 & 2,0 & 7,5 & 5,4 & 5,1 & 3,4 & $-1,7$ \\
\hline 950 & 2,0 & 1,9 & 4,9 & 4,0 & 2,9 & 2,1 & $-0,8$ \\
\hline 951 & 3,1 & 2,6 & 8,3 & 5,0 & 5,2 & 2,4 & $-2,8$ \\
\hline 952 & 2,5 & 2,3 & 4,7 & 4,6 & 2,2 & 2,3 & 0,1 \\
\hline 953 & 2,0 & 1,8 & 5,6 & 4,6 & 3,6 & 2,8 & $-0,8$ \\
\hline 959 & 2,8 & 3,1 & 5,9 & 4,0 & 3,1 & 0,9 & $-2,2$ \\
\hline 966 & 3,9 & 3,0 & 7,6 & 4,4 & 3,7 & 1,4 & $-2,3$ \\
\hline 985 & 2,5 & 2,4 & 6,0 & 4,8 & 3,5 & 2,4 & $-1,1$ \\
\hline 988 & 2,9 & 2,5 & 4,4 & 3,6 & 1,5 & 1,1 & $-0,4$ \\
\hline 991 & 3,5 & 3,1 & 8,5 & 6,5 & 5,0 & 3,4 & $-1,6$ \\
\hline 997 & 2,4 & 2,2 & 7,2 & 5,3 & 4,8 & 3,1 & $-1,7$ \\
\hline 998 & 2,9 & 2,4 & 6,1 & 4,6 & 3,2 & 2,2 & $-1,0$ \\
\hline 1.022 & 1,9 & 1,5 & 3,6 & 3,6 & 1,7 & 2,1 & 0,4 \\
\hline 1.026 & 1,7 & 1,7 & 3,5 & 2,5 & 1,8 & 0,8 & $-1,0$ \\
\hline 1.027 & 1,6 & 1,6 & 3,2 & 2,6 & 1,6 & 1,0 & $-0,6$ \\
\hline 1.029 & 3,2 & 2,0 & 3,5 & 4,2 & 0,3 & 2,2 & 1,9 \\
\hline 1.030 & 2,0 & 2,0 & 5,0 & 4,6 & 3,0 & 2,6 & $-0,4$ \\
\hline 1.031 & 3,5 & 3,0 & 11,5 & 5,8 & 8,0 & 2,8 & $-5,2$ \\
\hline 1.038 & 2,8 & 2,5 & 6,5 & 4,5 & 3,7 & 2,0 & $-1,7$ \\
\hline 1.044 & 3,5 & 3,0 & 8,5 & 5,6 & 5,0 & 2,6 & $-2,4$ \\
\hline 1.048 & 2,7 & 2,5 & 7,0 & 4,7 & 4,3 & 2,2 & $-2,1$ \\
\hline 1.049 & 2,2 & 2,3 & 7,0 & 3,7 & 4,8 & 1,4 & $-3,4$ \\
\hline 1.050 & 3,3 & 3,0 & 8,6 & 5,8 & 5,3 & 2,8 & $-2,5$ \\
\hline 1.055 & 3,1 & 2,9 & 7,5 & 5,8 & 4,4 & 2,9 & $-1,5$ \\
\hline 1.071 & 2,7 & 2,4 & 4,7 & 3,6 & 2,0 & 1,2 & $-0,8$ \\
\hline 1.075 & 1,9 & 1,7 & 3,0 & 2,5 & 1,1 & 0,8 & $-0,3$ \\
\hline 1.088 & 2,1 & 1,9 & 6,9 & 4,8 & 4,8 & 2,9 & $-1,9$ \\
\hline 1.095 & 3,0 & 2,6 & 5,8 & 4,9 & 2,8 & 2,3 & $-0,5$ \\
\hline 1.441 & 2,0 & 1,9 & 4,4 & 3,8 & 2,4 & 1,9 & $-0,5$ \\
\hline $00 \#$ & 3,2 & 2,9 & 5,9 & 4,5 & 2,7 & 1,6 & $-1,1$ \\
\hline
\end{tabular}


(Continuação)

\begin{tabular}{|c|c|c|c|c|c|c|c|}
\hline \multirow{2}{*}{ Animal } & \multicolumn{2}{|c|}{0 hora } & \multicolumn{2}{|c|}{$72 \pm 6$ horas } & \multirow{2}{*}{$\Delta A v$} & \multirow{2}{*}{$\Delta \mathrm{Bv}$} & \multirow{2}{*}{$\Delta \mathrm{Bv}-\Delta \mathrm{Av}$} \\
\hline & PPD Av. & PPD Bov. & PPD Av. & PPD Bov & & & \\
\hline SB1 & 2,8 & 2,4 & 4,2 & 2,8 & 1,4 & 0,4 & $-1,0$ \\
\hline
\end{tabular}

PPD Av: Tuberculina aviária

PPD Bov.: Tuberculina bovina

$\triangle A v$ : Diferença final da espessura da pele em $\mathrm{mm}$ (entre $72 \pm 6$ horas e 0 hora) no local de aplicação do PPD aviário.

$\triangle$ Bv: Diferença final da espessura da pele em $\mathrm{mm}$ (entre $72 \pm 6$ horas e 0 hora) no local de aplicação do PPD bovino.

$\triangle P P D B v-\triangle P P D$ Av: Diferença (em $\mathrm{mm}$ ) entre as variações da espessura da pele do local da aplicação do PPD bovino e do PPD aviário. 
Apêndice B - Resultados do teste tuberculínico dos ovinos da propriedade $B$, segundo o animal, o momento da leitura e o tipo de tuberculina - São Paulo - 2007.

\begin{tabular}{|c|c|c|c|c|c|c|c|}
\hline \multirow{2}{*}{ Animal } & \multicolumn{2}{|c|}{0 hora } & \multicolumn{2}{|c|}{$72 \pm 6$ horas } & \multirow{2}{*}{$\Delta A v$} & \multirow{2}{*}{$\Delta \mathrm{Bv}$} & \multirow{2}{*}{$\Delta \mathrm{Bv}-\Delta \mathrm{Al}$} \\
\hline & PPD Av. & PPD Bov. & PPD Av. & PPD Bov & & & \\
\hline 7 & 4,7 & 4,2 & 9,6 & 5,5 & 4,9 & 1,3 & $-3,6$ \\
\hline 10 & 5,0 & 5,4 & 9,5 & 7,6 & 4,5 & 2,2 & $-2,3$ \\
\hline 12 & 4,2 & 4,8 & 5,2 & 4,7 & 1,0 & $-0,1$ & $-1,1$ \\
\hline 23 & 4,0 & 4,3 & 5,0 & 4,3 & 1,0 & 0,0 & $-1,0$ \\
\hline 25 & 4,9 & 5,5 & 8,5 & 7,2 & 3,6 & 1,7 & $-1,9$ \\
\hline 26 & 4,5 & 5,1 & 6,6 & 6,2 & 2,1 & 1,1 & $-1,0$ \\
\hline 32 & 4,5 & 5,0 & 5,5 & 5,2 & 1,0 & 0,2 & $-0,8$ \\
\hline 37 & 4,5 & 4,6 & 10,2 & 5,9 & 5,7 & 1,3 & $-4,4$ \\
\hline 38 & 3,8 & 3,9 & 5,6 & 5,1 & 1,8 & 1,2 & $-0,6$ \\
\hline 59 & 4,3 & 4,4 & 5,9 & 5,5 & 1,6 & 1,1 & $-0,5$ \\
\hline 62 & 3,5 & 3,5 & 10,2 & 5,0 & 6,7 & 1,5 & $-5,2$ \\
\hline 63 & 4,7 & 4,2 & 10,7 & 6,8 & 6,0 & 2,6 & $-3,4$ \\
\hline 67 & 4,0 & 3,7 & 5,4 & 4,6 & 1,4 & 0,9 & $-0,5$ \\
\hline 80 & 4,5 & 4,2 & 12,0 & 4,9 & 7,5 & 0,7 & $-6,8$ \\
\hline 85 & 3,7 & 4,0 & 5,9 & 5,0 & 2,2 & 1,0 & $-1,2$ \\
\hline 88 & 5,0 & 4,8 & 12,7 & 7,8 & 7,7 & 3,0 & $-4,7$ \\
\hline 92 & 4,1 & 4,8 & 11,9 & 6,0 & 7,8 & 1,2 & $-6,6$ \\
\hline 112 & 4,6 & 4,1 & 5,8 & 5,0 & 1,2 & 0,9 & $-0,3$ \\
\hline 116 & 4,0 & 5,0 & 7,0 & 5,0 & 3,0 & 0,0 & $-3,0$ \\
\hline 153 & 4,1 & 4,7 & 6,6 & 5,1 & 2,5 & 0,4 & $-2,1$ \\
\hline 170 & 3,5 & 3,9 & 5,1 & 4,7 & 1,6 & 0,8 & $-0,8$ \\
\hline 182 & 4,6 & 4,8 & 4,8 & 5,3 & 0,2 & 0,5 & 0,3 \\
\hline 186 & 3,7 & 3,8 & 5,0 & 4,3 & 1,3 & 0,5 & $-0,8$ \\
\hline 200 & 4,5 & 4,0 & 7,6 & 5,5 & 3,1 & 1,5 & $-1,6$ \\
\hline 201 & 3,8 & 4,1 & 8,6 & 5,1 & 4,8 & 1,0 & $-3,8$ \\
\hline 267 & 4,8 & 4,8 & 11,3 & 6,0 & 6,5 & 1,2 & $-5,3$ \\
\hline 270 & 3,2 & 3,3 & 7,4 & 7,3 & 4,2 & 4,0 & $-0,2$ \\
\hline 295 & 4,2 & 4,3 & 6,0 & 5,1 & 1,8 & 0,8 & $-1,0$ \\
\hline 301 & 3,2 & 2,8 & 9,0 & 5,9 & 5,8 & 3,1 & $-2,7$ \\
\hline 315 & 4,2 & 4,2 & 12,8 & 8,7 & 8,6 & 4,5 & $-4,1$ \\
\hline 327 & 5,5 & 6,5 & 6,9 & 5,5 & 1,4 & $-1,0$ & $-2,4$ \\
\hline 328 & 3,9 & 4,5 & 6,0 & 4,9 & 2,1 & 0,4 & $-1,7$ \\
\hline 330 & 3,4 & 3,5 & 7,2 & 6,4 & 3,8 & 2,9 & $-0,9$ \\
\hline 333 & 5,1 & 5,4 & 7,6 & 5,4 & 2,5 & 0,0 & $-2,5$ \\
\hline 336 & 6,3 & 6,0 & 8,0 & 5,4 & 1,7 & $-0,6$ & $-2,3$ \\
\hline 343 & 5,1 & 4,9 & 4,9 & 4,7 & $-0,2$ & $-0,2$ & 0,0 \\
\hline 351 & 4,5 & 4,3 & 6,6 & 5,7 & 2,1 & 1,4 & $-0,7$ \\
\hline 352 & 3,8 & 4,0 & 4,4 & 4,9 & 0,6 & 0,9 & 0,3 \\
\hline 353 & 4,2 & 5,0 & 7,6 & 6,2 & 3,4 & 1,2 & $-2,2$ \\
\hline 362 & 5,1 & 5,3 & 11,9 & 7,2 & 6,8 & 1,9 & $-4,9$ \\
\hline 363 & 5,0 & 4,5 & 6,4 & 5,4 & 1,4 & 0,9 & $-0,5$ \\
\hline 365 & 4,4 & 4,0 & 6,1 & 4,4 & 1,7 & 0,4 & $-1,3$ \\
\hline 366 & 4,8 & 5,7 & 6,3 & 5,0 & 1,5 & $-0,7$ & $-2,2$ \\
\hline 366 & 4,5 & 4,6 & 8,0 & 5,5 & 3,5 & 0,9 & $-2,6$ \\
\hline 369 & 4,8 & 4,9 & 5,9 & 4,4 & 1,1 & $-0,5$ & $-1,6$ \\
\hline 370 & 4,4 & 4,3 & 9,7 & 5,5 & 5,3 & 1,2 & $-4,1$ \\
\hline 378 & 3,8 & 3,8 & 12,5 & 6,1 & 8,7 & 2,3 & $-6,4$ \\
\hline 386 & 4,2 & 4,6 & 7,1 & 4,3 & 2,9 & $-0,3$ & $-3,2$ \\
\hline
\end{tabular}


(Continuação)

\begin{tabular}{|c|c|c|c|c|c|c|c|}
\hline \multirow{2}{*}{ Animal } & \multicolumn{2}{|c|}{ O hora } & \multicolumn{2}{|c|}{$72 \pm 6$ horas } & \multirow{2}{*}{$\Delta A v$} & \multirow{2}{*}{$\Delta B v$} & \multirow{2}{*}{$\Delta B v-\Delta A$} \\
\hline & PPD Av. & PPD Bov. & PPD Av. & PPD Bov & & & \\
\hline 389 & 4,7 & 4,4 & 9,9 & 6,5 & 5,2 & 2,1 & $-3,1$ \\
\hline 391 & 4,1 & 4,2 & 5,6 & 5,1 & 1,5 & 0,9 & $-0,6$ \\
\hline 393 & 4,7 & 4,9 & 5,9 & 5,5 & 1,2 & 0,6 & $-0,6$ \\
\hline 395 & 3,8 & 4,2 & 10,2 & 5,0 & 6,4 & 0,8 & $-5,6$ \\
\hline 398 & 3,8 & 3,9 & 7,0 & 5,0 & 3,2 & 1,1 & $-2,1$ \\
\hline 399 & 4,8 & 5,5 & 7,4 & 7,3 & 2,6 & 1,8 & $-0,8$ \\
\hline 408 & 5,8 & 5,0 & 9,0 & 5,9 & 3,2 & 0,9 & $-2,3$ \\
\hline 411 & 5,8 & 5,1 & 12,8 & 8,7 & 7,0 & 3,6 & $-3,4$ \\
\hline 417 & 4,5 & 4,5 & 6,3 & 5,3 & 1,8 & 0,8 & $-1,0$ \\
\hline 418 & 4,9 & 4,3 & 6,9 & 5,5 & 2,0 & 1,2 & $-0,8$ \\
\hline 419 & 4,5 & 4,8 & 6,0 & 4,9 & 1,5 & 0,1 & $-1,4$ \\
\hline 420 & 4,5 & 5,0 & 7,2 & 6,4 & 2,7 & 1,4 & $-1,3$ \\
\hline 426 & 4,6 & 4,4 & 6,6 & 5,7 & 2,0 & 1,3 & $-0,7$ \\
\hline 479 & 4,6 & 5,0 & 11,9 & 7,2 & 7,3 & 2,2 & $-5,1$ \\
\hline 485 & 5,4 & 5,6 & 5,1 & 5,9 & $-0,3$ & 0,3 & 0,6 \\
\hline 500 & 4,4 & 4,1 & 6,1 & 4,4 & 1,7 & 0,3 & $-1,4$ \\
\hline 525 & 3,0 & 2,9 & 6,9 & 5,2 & 3,9 & 2,3 & $-1,6$ \\
\hline 526 & 4,2 & 3,9 & 5,9 & 4,4 & 1,7 & 0,5 & $-1,2$ \\
\hline 530 & 4,3 & 4,4 & 12,5 & 6,1 & 8,2 & 1,7 & $-6,5$ \\
\hline 533 & 4,5 & 5,8 & 5,5 & 7,3 & 1,0 & 1,5 & 0,5 \\
\hline 538 & 4,9 & 4,7 & 9,9 & 6,5 & 5,0 & 1,8 & $-3,2$ \\
\hline 561 & 4,8 & 4,9 & 6,2 & 5,7 & 1,4 & 0,8 & $-0,6$ \\
\hline 572 & 3,9 & 4,2 & 6,3 & 5,3 & 2,4 & 1,1 & $-1,3$ \\
\hline 577 & 4,9 & 5,0 & 6,9 & 5,2 & 2,0 & 0,2 & $-1,8$ \\
\hline 578 & 4,7 & 4,7 & 18,3 & 5,7 & 13,6 & 1,0 & $-12,6$ \\
\hline 583 & 4,2 & 4,7 & 4,7 & 5,0 & 0,5 & 0,3 & $-0,2$ \\
\hline 590 & 4,4 & 4,0 & 5,2 & 4,7 & 0,8 & 0,7 & $-0,1$ \\
\hline 598 & 4,5 & 4,0 & 5,7 & 4,8 & 1,2 & 0,8 & $-0,4$ \\
\hline 603 & 2,3 & 2,7 & 12,2 & 7,6 & 9,9 & 4,9 & $-5,0$ \\
\hline 605 & 3,8 & 3,6 & 5,9 & 5,5 & 2,1 & 1,9 & $-0,2$ \\
\hline 610 & 4,0 & 4,1 & 8,7 & 5,4 & 4,7 & 1,3 & $-3,4$ \\
\hline 630 & 4,4 & 4,2 & 5,7 & 4,8 & 1,3 & 0,6 & $-0,7$ \\
\hline 646 & 5,0 & 5,7 & 12,2 & 7,6 & 7,2 & 1,9 & $-5,3$ \\
\hline 708 & 5,3 & 5,3 & 5,5 & 5,5 & 0,2 & 0,2 & 0,0 \\
\hline 709 & 4,7 & 4,5 & 6,0 & 5,4 & 1,3 & 0,9 & $-0,4$ \\
\hline 712 & 5,1 & 4,3 & 6,2 & 4,5 & 1,1 & 0,2 & $-0,9$ \\
\hline 721 & 5,1 & 5,1 & 6,1 & 4,5 & 1,0 & $-0,6$ & $-1,6$ \\
\hline 734 & 3,3 & 2,9 & 5,5 & 4,9 & 2,2 & 2,0 & $-0,2$ \\
\hline 747 & 4,0 & 4,0 & 8,7 & 5,4 & 4,7 & 1,4 & $-3,3$ \\
\hline 755 & 3,9 & 3,5 & 9,5 & 5,9 & 5,6 & 2,4 & $-3,2$ \\
\hline 762 & 3,5 & 2,8 & 4,5 & 3,6 & 1,0 & 0,8 & $-0,2$ \\
\hline 768 & 3,4 & 3,6 & 6,0 & 5,4 & 2,6 & 1,8 & $-0,8$ \\
\hline 769 & 3,7 & 3,5 & 6,2 & 4,5 & 2,5 & 1,0 & $-1,5$ \\
\hline 777 & 3,9 & 4,2 & 6,1 & 4,5 & 2,2 & 0,3 & $-1,9$ \\
\hline 790 & 4,2 & 3,9 & 5,4 & 4,5 & 1,2 & 0,6 & $-0,6$ \\
\hline 791 & 4,6 & 3,8 & 8,4 & 5,2 & 3,8 & 1,4 & $-2,4$ \\
\hline 796 & 3,7 & 3,3 & 6,5 & 5,3 & 2,8 & 2,0 & $-0,8$ \\
\hline 840 & 3,5 & 3,1 & 5,3 & 4,5 & 1,8 & 1,4 & $-0,4$ \\
\hline 871 & 3,1 & 3,0 & 6,0 & 4,9 & 2,9 & 1,9 & $-1,0$ \\
\hline
\end{tabular}


(Continuação)

\begin{tabular}{|c|c|c|c|c|c|c|c|}
\hline \multirow{2}{*}{ Animal } & \multicolumn{2}{|c|}{ O hora } & \multicolumn{2}{c|}{$\mathbf{7 2} \pm \mathbf{6}$ horas } & \multirow{2}{*}{$\boldsymbol{\Delta} \mathbf{A v}$} & \multirow{2}{*}{$\boldsymbol{\Delta} \mathbf{v}$} & \multirow{2}{*}{$\boldsymbol{\Delta} \mathbf{B v}-\boldsymbol{\Delta} \mathbf{A v}$} \\
\cline { 2 - 5 } & PPD Av. & PPD Bov. & PPD Av. & PPD Bov & & & \\
\hline 897 & 4,2 & 4,7 & 5,1 & 5,0 & 0,9 & 0,3 & $-0,6$ \\
\hline 933 & 3,7 & 3,5 & 5,3 & 4,9 & 1,6 & 1,4 & $-0,2$ \\
\hline 938 & 4,9 & 4,9 & 9,5 & 5,9 & 4,6 & 1,0 & $-3,6$ \\
\hline 37 C & 3,8 & 4,2 & 4,3 & 4,4 & 0,5 & 0,2 & $-0,3$ \\
\hline 85 A & 4,2 & 3,8 & 5,4 & 4,5 & 1,2 & 0,7 & $-0,5$ \\
\hline SB & 4,3 & 4,3 & 7,3 & 6,5 & 3,0 & 2,2 & $-0,8$ \\
\hline
\end{tabular}

PPD Av: Tuberculina aviária PPD Bov.: Tuberculina bovina

$\triangle A v$ : Diferença final da espessura da pele em $\mathrm{mm}$ (entre $72 \pm 6$ horas e 0 hora) no local de aplicação do PPD aviário.

$\triangle$ Bv: Diferença final da espessura da pele em $\mathrm{mm}$ (entre $72 \pm 6$ horas e 0 hora) no local de aplicação do PPD bovino.

$\triangle \mathrm{PPD} \mathrm{Bv}-\triangle \mathrm{PPD} \mathrm{Av}$ : Diferença (em $\mathrm{mm}$ ) entre as variações da espessura da pele do local da aplicação do PPD bovino e do PPD aviário. 
Apêndice C - Resultados dos exames clínicos dos animais abatidos das propriedades A e B - São Paulo - 2007.

\begin{tabular}{|c|c|c|c|c|c|c|}
\hline Animal & Propried. & Temperatura $^{1}$ & Freq. Resp. ${ }^{2}$ & Freq. Card. ${ }^{3}$ & Mov. Rum. ${ }^{4}$ & Mucosas \\
\hline 20 & $A$ & 39,4 & 24 & 120 & 2 & Normais \\
\hline 33 & $A$ & 39,5 & 40 & 112 & 4 & Normais \\
\hline 38 & B & 39,6 & 38 & 128 & 4 & Normais \\
\hline 48 & $A$ & 39,0 & 40 & 82 & 2 & Normais \\
\hline 59 & B & 39,8 & 60 & 108 & 2 & Normais \\
\hline 72 & $A$ & 39,4 & 50 & 100 & 2 & Normais \\
\hline 84 & A & 39,4 & 36 & 128 & 2 & Normais \\
\hline 129 & $A$ & 39,7 & 60 & 120 & 3 & Normais \\
\hline 131 & $A$ & 38,5 & 36 & 100 & 3 & Normais \\
\hline 168 & $A$ & 40,1 & 58 & 132 & 3 & Normais \\
\hline 176 & $A$ & 38,7 & 20 & 72 & 3 & Normais \\
\hline 182 & B & 39,5 & 28 & 108 & 3 & Normais \\
\hline 197 & $A$ & 39,6 & 32 & 116 & 2 & Normais \\
\hline 206 & $A$ & 39,6 & 38 & 120 & 4 & Normais \\
\hline 279 & A & 39,9 & 56 & 116 & 3 & Normais \\
\hline 294 & A & 39,5 & 32 & 124 & 3 & Normais \\
\hline 304 & $A$ & 40,0 & 42 & 88 & 2 & Normais \\
\hline 342 & $A$ & 39,4 & 44 & 108 & 3 & Normais \\
\hline 352 & B & 39,4 & 36 & 108 & 3 & Normais \\
\hline 353 & $B$ & 39,3 & 48 & 132 & 3 & Normais \\
\hline 362 & B & 39,4 & 54 & 98 & 2 & Normais \\
\hline 449 & A & 38,7 & 24 & 80 & 3 & Normais \\
\hline 478 & $A$ & 39,5 & 32 & 108 & 3 & Normais \\
\hline 485 & $B$ & 39,0 & 40 & 88 & 2 & Normais \\
\hline 486 & $A$ & 38,8 & 40 & 80 & 3 & Normais \\
\hline 516 & $A$ & 39,5 & 44 & 108 & 4 & Normais \\
\hline 533 & B & 39,4 & 80 & 100 & 3 & Normais \\
\hline 552 & $A$ & 40,0 & 48 & 130 & 3 & Normais \\
\hline 580 & $A$ & 39,5 & 40 & 108 & 3 & Normais \\
\hline 587 & $A$ & 39,0 & 52 & 84 & 2 & Normais \\
\hline
\end{tabular}


(Continuação)

\begin{tabular}{|c|c|c|c|c|c|c|}
\hline Animal & Fazenda & Temperatura $^{1}$ & Freq. Resp. ${ }^{2}$ & Freq. Card. ${ }^{3}$ & Mov. Rum. ${ }^{4}$ & Mucosas \\
\hline 599 & $A$ & 39,3 & 54 & 112 & 3 & Normais \\
\hline 605 & B & 39,9 & 56 & 120 & 3 & Normais \\
\hline 609 & A & 38,5 & 40 & 112 & 3 & Normais \\
\hline 610 & B & 39,4 & 46 & 128 & 2 & Normais \\
\hline 648 & A & 39,7 & 72 & 128 & 3 & Normais \\
\hline 690 & A & 39,8 & 60 & 100 & 2 & Normais \\
\hline 702 & A & 39,4 & 80 & 112 & 3 & Normais \\
\hline 709 & B & 40,3 & 36 & 126 & 2 & Normais \\
\hline 721 & B & 40,0 & 48 & 120 & 3 & Normais \\
\hline 727 & A & 38,8 & 50 & 100 & 3 & Normais \\
\hline 737 & A & 40,1 & 58 & 100 & 3 & Normais \\
\hline 759 & A & 39,6 & 38 & 116 & 4 & Normais \\
\hline 762 & B & 38,7 & 42 & 76 & 3 & Normais \\
\hline 813 & A & 38,5 & 40 & 100 & 2 & Normais \\
\hline 822 & A & 39,5 & 28 & 100 & 3 & Normais \\
\hline 823 & A & 39,3 & 52 & 132 & 4 & Normais \\
\hline 827 & A & 38,8 & 42 & 92 & 3 & Normais \\
\hline 871 & B & 39,5 & 42 & 120 & 3 & Normais \\
\hline 882 & A & 39,4 & 28 & 100 & 2 & Normais \\
\hline 889 & A & 39,4 & 36 & 90 & 2 & Normais \\
\hline 892 & A & 39,5 & 38 & 124 & 3 & Normais \\
\hline 908 & A & 40,0 & 44 & 88 & 2 & Normais \\
\hline 921 & A & 40,3 & 36 & 130 & 2 & Normais \\
\hline 1026 & A & 39,0 & 40 & 96 & 2 & Normais \\
\hline 1441 & A & 39,4 & 24 & 112 & 2 & Normais \\
\hline 00\# & A & 39,7 & 76 & 116 & 3 & Normais \\
\hline SB1 & A & 39,6 & 32 & 108 & 2 & Normais \\
\hline
\end{tabular}

Propried.: Propriedade

1: Temperatura corporal em graus Celsius

2: Freqüência respiratória em movimentos/ minuto

3: Frequência cardíaca em movimentos/ minuto

4: Movimentos rumenais em movimentos/ 5 minutos 